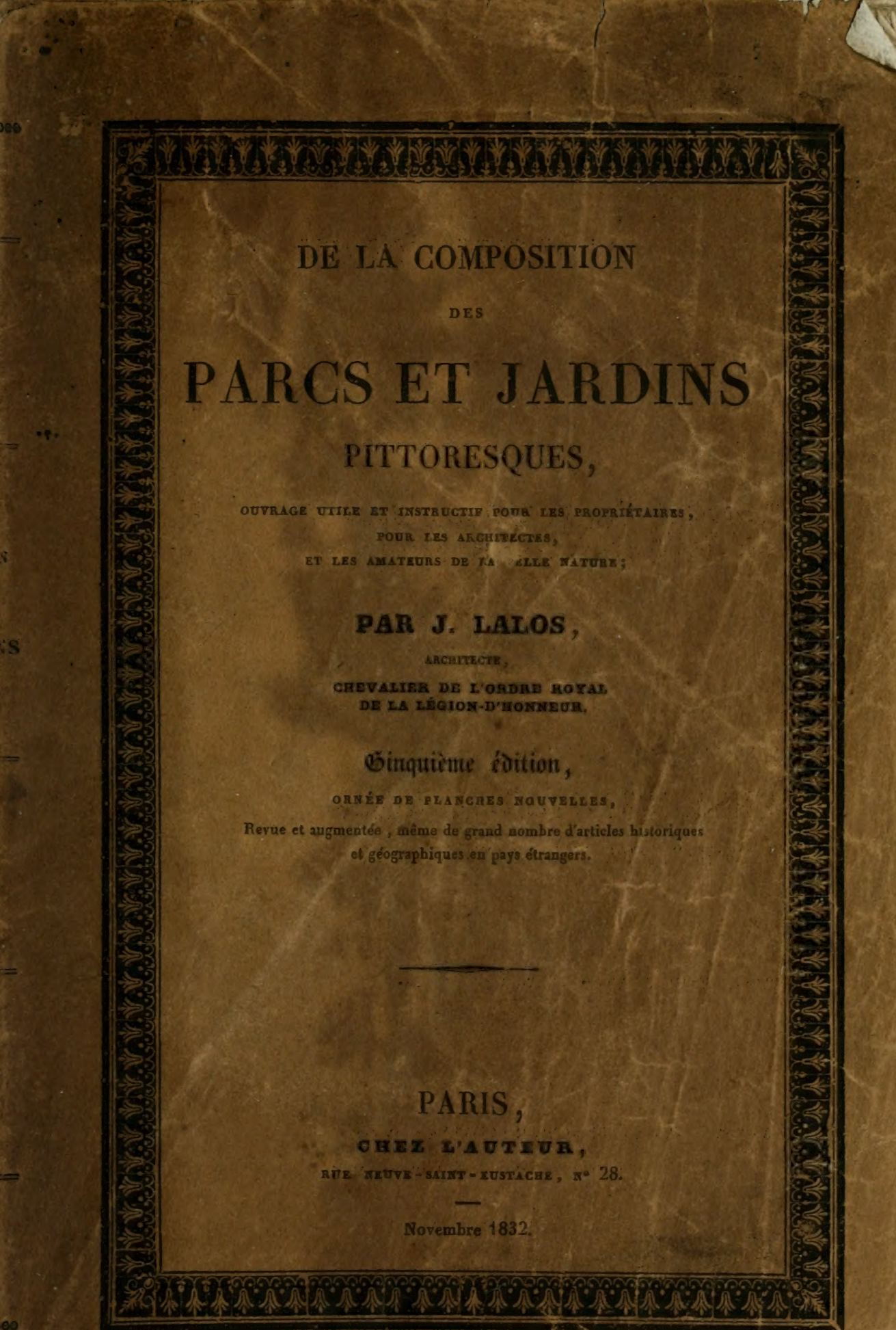





\section{SB \\ 469.2 \\ .1 .33 \\ 1832 \\ SMRS}

\section{LIVRE SECOND.}

DE LA COMPOSITION

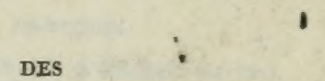

\section{PARCS ET JARDINS} PITTORESQUES. 


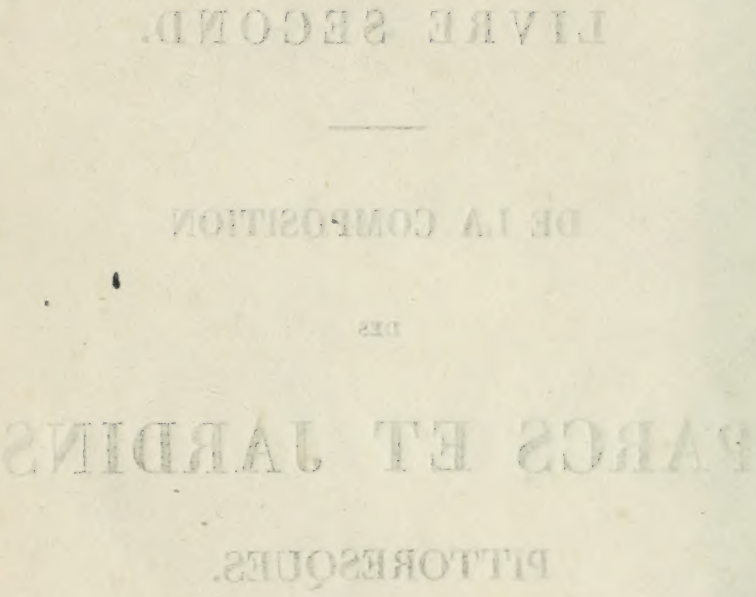

IMPRIMERIE DE FELIX LOCQUUX

Rue N.-D.-des-Victoires, $\mathrm{n}^{\circ}, 6$. 


\title{
DE LA COMPOSITION
}

\author{
DES
}

\section{PARCS ET JARDINS PITTORESQUES,}

\author{
OUVRAGE UTILE ET INSTRUCTIF POUR LES PROPRTÉTAIRES, \\ POUR LES ARCHITECTES, \\ ET LES AMATEURS DE LA BELLE TATURE;
}

\section{par J. LALOS,} ARCHITECTE,

\section{GHEVALIER DE L'ORDRE ROYAL \\ DE LA LÉGION-D'HONNEUR.}

\section{G̋inquième édition,}

\author{
ORNEE DE PLANCHES NOUVELLES,
}

Revue et augmentée, même de grand nombre d'articles historiques et géographiques en pays étrangers.

\section{PARIS,}

CHEZ I'A UTE TR,

RUE NEUVE - SAINT - EUSTACBE, N० 28.

Novembre 1832. 


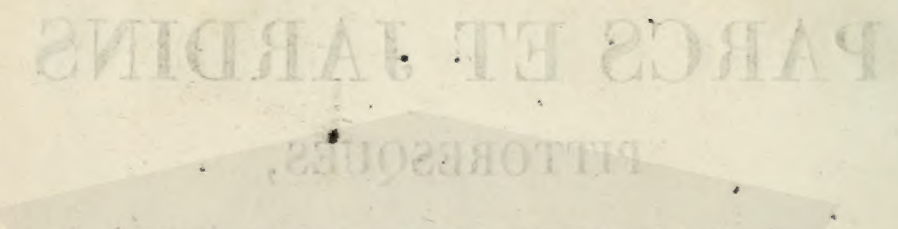

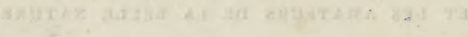

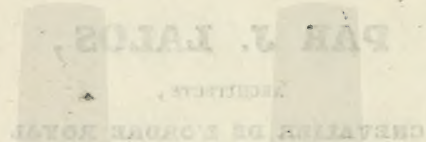

Digitized by the Internet Archive in 2010 with funding from University of Ottawa

http://www.archive.org/details/delacomposition00lalo 


\section{AVERTISSEMENT.}

Les quatre premières éditions de la Composition des parcs et jardins pittoresques, depuis long-temps épuisées, sont la meilleure preuve qu'on puisse donner qu'elles ont été jugées.

Cette cinquième édition, en grande partie recomposée, se divise en trois parties. Les précédentes éditions n'étaient divisées qu'en deux.

- La première ne doit point varier, en ce qr'elle est la partie constitutive, théorique et pratique des parcs et jardins; elle donne l'institution et la science nécessair es pour une compo- 
sition paysagiste. Mon principal motif est de rendre cette science familière et à la portée de tout le monde; j'ai désiré aussi obtenir les suffrages des dames, en leur offrant une lecture intéressante.

Cette première partie définit ce qu'on entend par belle nature. Expliquer les différentes espèces de vues, indiquer la possibilité de tirer parti de toutes les situations, des comparaisons, de limitations, des plantations, du jeu du terrain, des mouvemens de la lumière, des fabriques, des constructions, du ton des paysages suivant les différentes heures du jour, des rivières, des cascades, des sauts-de-loup, des nıcottes et boutaies des parcs d'Armenonville et de Morfontaine.

La seconde partie donne la description gérérale de tous les parcs et jardins composés et en partie exécutés par l'auteur, des beautés et des richesses pittoresques des départemens de l'Oise et de la Seine-Inférieure, du parc de la Grangeaux-Ormes, près Metz; de celui de Plessis-Villette, près Pont-Sainte-Maxence; du beau et antique château de Mennière, département de Seine-et-Oise; de son parc et de ses arbres; 
du château et du jardin des Tuileries, de ses embellissemens; des Champs-Élysées, de son ensemble avec le jardin des Tuileries, et sur leurs détails en particulier.

Je n'ai rien à observer sur les quatre éditions qui ont précédés celle-ci. Les journaux à cette époque dirent, sur la première édition, plus que je n'avais le droit d'attendre : le Journal de Paris, dans sa feuille du 13 octobre 1817 ; le Journal des Débats, dans sa feuille du 2 I novembre i 8I7; la Gazette de France, dans sa feuille du 3i octobre 1817 ; et le Journal du Commerce (Constitutionnel), dans sa feuille du 3 I mars i 8ı 8. Ces quatre journaux, presque les seuls qui existaient à cette époque, ont été unanimes sur cette première édition, qui a été réimprimée trois fois.

La troisième partie de ce livre est historique et géographique, elle traite de la nature brute et sans art, dans tous les pays où elle mérite d'être récitée, par les accidens, les montagnes, les forêts, les fleuves immenses. Le saut du Niagara, en Amérique, le fameux gouffre de la Norwège; la Suède, la Finlande, la Moscovie, Moscou, Athènes, l'Angleterre, la Dalmatie et 
la Suisse. Quelle chose immense que cette nature agreste et pittoresque! ses beaux aspects, comme ses horreurs, ne peuvent qu'intéresser l'homme, même le plus insensible: on ne peut l'être en lisant la description d'une nature aussi grandiose qu'elle est extraordinaire. 


\title{
DE LA COMPOSITION.
}

\author{
DES
}

\section{PARCS ET JARDINS.}

\author{
PREMIERE PARTIE.
}

\section{INTRODUCTION.}

LA nature et ses productions ont été le premier bienfait de la Divinité, et le jardin fut le premier séjour de l'homme heureux. Cette idée, depuis consacrée chez tous les peuples, fut inspirée sans doute par le Créateur : le Tout-Puissant indiquait à l'homme le plaisir de cultiver ses champs, comme le 
plus sûr moyen de prévenir toutes les maladies qui afligent et qui lésulent l'humanité.

Heureux si, dans cet ourrage, je puis indiquer les moyens de joindre à un exercice salutaire un intérêt de composition qui doit occuper l'esprit, enflammer l'imagination! Si mes voux sont exaucés, je m’applaudirai d'avoir payé ma dette envers la société.

Chez tous les peuples de l'antiquité qui ont cultivé l'architecture arec succès, tels sont les Égyptiens, les Grecs et les Romains, on ne s'aperçoit pas qu'ils aient jamais cherché à rendre leurs jardins autrement remarquables que par la grandeur du terrain et par des dépenses considérables. Ils ne connaissaient point ces asiles délicieux, impénétrables aux rayons d'un soleil brûlant et aux ravages des autans ; l'art était déployé partout avec ostentation; l'étalage de la magnificence avait seul le droit de plaire. Il faut donc conrenir d'une triste vérité : c'est que la ranité a de tout temps aveuglé les hommes sur leurs plaisirs.

Le célèbre Le Nostre, ce créateur des jardins de Louis-le-Grand, contraignit la 
nature en voulant tout assujétir au compas de l'architecte.

Il sut tracer un plan, et non pas un tableau.

Dès-lors on ne reconnut de mérite qu’à celui qui tirait le mieux la ligne droite. La plantation, entièrement soumise au cordeau, fit naître la froide symétrie; le terrain fut dressé à grands frais par le niveau de la trèsennuyeuse planimétrie. Les arbres furent mutilés de cent manières différentes; les eaux, qui animent le paysage et lui donnent une vie nouvelle, furent enfermées entre quatre murailles, comme la vue fut emprisonnée par la triste charmille. L'aspect de la maison fut circonscrit dans un insignifiant parterre, où le bariolage de sables de toutes les couleurs éblouissait les yeux et ne parlait point à l'esprit.

On se dégoûta bientôt de ces compositions monotones, auxquelles on était convenu de trouver un certain air de grandeur; et, malgré ce dégoût, ces jardins ridicules se sont multipliés. Heureusement ils sont si peu de 
mode, si en arrière du bon goût et des progiès des beaux-arts, qu'on a lieu d'être surpris d'en voir subsister encore; car, il faut en convenir, le riche propriétaire n'avait point de parc pour se promener : on eût dit qu'il voulait, à grands frais, s'entourer d'une enceinte dont l'effet est vraiment d'une monotonie assoupissante.

..... L'art, en se voilant sous les mains du génie;

Pournous charmer toujours, veut toujours qu'on l'oublie.

Les beaux-arts, en France, ont fleuri avec éclat à différentes époques; et tandis que les poètes de tous les âges ont chanté les charmes des bois, des prés, des lieux romantiques, que les peintres de tous les siècles ont représenté ou cherché à imiter les beaux sites, la simplicité et les richesses de la nature, on a lieu d'être surpris que les architectes n'aient pas suivi la marche que leur traçaient la poésie et la peinture. Il ne fallait. pour cela que du bon sens, car c'est de cet arantage que dépend le goût; mais aucun architecte n'a songé à réaliser ces descriptions 
enchanteresses et ces admirables tableaux dont chacun avait sans cesse les modèles sous les yeux. On sera plus surpris encore, en réfléchissant qu'il ne soit pas venu à la pensée d'offrir les moyens d'embellir le pays qui entoure une habitation, et d'imiter les beaux et sublimes effets de la nature.

La composition d'un jardin, en occupant agréablement l'esprit, est un amusement qu'il est plus aisé de sentir que d'exprimer. Les effets qui en résultent charment l'oeil, et répandent le calme dans l'âme. En effet, l'amateur cule compositeur des jardins découvre tous les nombreux attraits de cette belle nature; elle semble sourire à ses efforts par les grâces de son élégante simplicité; elle lui paraît toujours plus belle et plus piquante par ses variétés infinies; partout elle déploie des beautés et des richesses dont la vue ne pourra jamais lasser l'être sensible.

Les efforts du travail, cachés sous l'apparence

De la nature libre et de la jouissance,

Y plaisent d'autant plus qu'on les soupçonne noins;

Les laisser ignorer, c'est embellir ses soins;

Mais avant de créer, interrogez la terre,

Observez, méditez, suivez son caractère; 
Guide certain, par lui laissez-vous inspirer :

Vous devez l'embellir, et non pas l'altérer.

(Les Jardins, chant inr.)

Plusieurs ouvrages ont été publiés sur le choix des sites et sur la composition des jardins : il est à regretter que leurs auteurs n'aient point assez approfondi leur sujet. Morel et Gérardin sont les premiers qui ont posé des principes, établi des lois, et dont le code doit être consulté. Quelques écrivains ont avancé qu'il n'existait aucune règle sur l'art qui nous occupe, et que chaque architecte pouvait traiter ses plans selon le génie qui lui était propre et selon son goût. Jusqu'à un certain point cela peut être vrai, et j'en conviens. Cependant l'art des jardins doit avoir ses constitutions; il doit être conduit et dirigé par un homme de goût: la routine, née de la barbarie, est un chemin qui ne peut servir qu’à égarer. Tout art a ses principes auxquels il est subordonné, et ce sont les principes qui posent les bornes, qu'on ne doit jamais franchir, si l'on ne veut tomber dans le ridicule et dans l'extravagant. Les règles servent de point d'appui, et facilitent l'étude; elles hâ- 
tent les progrès en même temps qu'elles préviennent les écarts, et par-là mème retiennent le génie de l'artiste et l'empêchent de s'égarer.

Surtout dans son style, ainsi que dans sa forme, A ses humbles destins le manoir se conforme; Je ne saurais défendre à l'art d'en approcher, Mais je veux que, modeste, il aime à se cacher. De tous vains ornemens la ferme est ennemie; Elle ne se permet, comme son possesseur, Qu'un air simple et qu'un ton de pais et de donceur.

Morel nous la figure ainsi qu'une bergère, Qưi , naïve et sans art, d'une fleur bocagère Pare ses beaux cheveux en désordre flottans; C'est l'heureux négligé des gràces du printemps: Pluś brillante, elle perd ce qui mé plait ẹn elle.... Mais quoi! faut-il borner tous les bois de la ferme Aưx seuls plan's fructueux que le verger renferme? Nòn; sans doute; à l'éntour de ses prés verdợans Elle demande à voir les saules ondoyans, Et le flexible osier, et l'aune quii s'avive, Sur les bords toujours frais d'une onde lente ou vive. Loin donc de les bannir, je veux, de toutes parts, Qu'ils viennent se montrer, soit groupés, soit épars, Soit même prólongés en ligñes tortueuses, Qu'ils marquent du terrain les formes sinueuses; Divers, ils formeront d'intéressans tableaux. 


\section{GHAPITRE I.}

DE LA BELLE NATURE.

DEPUIs long-temps on parle de jardins, mais toujours dans l'ordinaire acception de ce mot. Un jardin présente d'abord l'idée d'un terrain cultivé, planté de fleurs, d'arbres fruitiers, d'herbes potagères, d'un terrain clos, aligné ou contourné. Ce n'est nullement la signification et l'explication du genre dont je traite, puisque la condition expresse de ce genre est qu'il ne paraisse ni clôture, ni jardin, mais au contraire une belle nature qui, d'accord avec le pays, paraisse ne former qu'un ensemble, le tout sans aucune espèce de division.

Il est d'autant plus nécessaire, avant de se livrer au travail, de méditer, de trouver un point d'appui convenable, que, sans ces précautions, on ne peut manquer d'être conduit 
à tout confondre à tort è à travers dans le terrain, et à tout culbuter à grands frais.

Dans la peinture, la disposition des objets dépend de l'imagination de l'artiste, et le tableau n'est assujéti qu’à un seul point de vue; le peintre est maître des effets de ciel et de lumière, du choix des couleurs et de l'emploi des accidens. Si la belle ordonnance du paysage est une chose difficile et rare, peuton se figurer que dans l'ordonnance d'un vaste tableau sur le terrain, le compositeur, avec les mêmes difficultés pour l'invention, ne rencontre à chaque pas, dans l'exécution, une foule d'obstacles? Il ne peut les vaincre qu'à force d'expériences, de ressources, d'imagination, par une assiduité et par un travail soutenus; peut-on se figurer, dis-je, qu’une pareille composition puisse ètre dictée par la fantaisie, abandonnée au hasard ou à l'inexpérience d'un jardinier, et conduite sans plan, sans dessein, sans principe et sans réflexion?

La symétrie naquit sans doute de la paresse et de la vanité : c'est ce que je vais prouver. Dans la première hypothèse, on a prétendu assujétir la nature ì l'habitation, au lieu d'as- 
sujétir l'habitation à la nature; dans la seconde, on s'est contenté seulement de ne travailler que sur le papier, afin de s'épargner la peine de voir, de vérifier, de réfléchir, et de combiner les effets que présente le terrain. Aussi, dans les plans symétriques, voit-on tous les aspects de l'horizon sacrifiés à un seul point de vue, les constructions, privées de toutes les dimensions de corps solides, ne présenter que des surfaces sans épaisseur comme sans variété; enfin, tous les objets ont été réduits à une seule ligne, et les terrains au même niveau.:

Le majestueux ennui de la symétrie, qu'on a trop long-temps employé pour tout renfermer, a fait passer subitement d'un extrême à un autre, et l'irrégularité a bientôt abusé du désordre pour égarer la vue, pour la faire tomber dans le vague et dans la confusion.

Le goût naturel a d'abord conduit à penser que, pour imiter la nature, il suffisait de proscrire les lignes droites, dont elle condamne l'usage, et qui ne sont point en harmonie avec elle.

Souvent le goût naturel est le meilleur juge 
des choses que l'on fait; mais pour les bien exécuter, il faut non-seulement des connaissances approfondies, mais encore de l'expérience, sans quoi on ne peut arriver à des résultats satisfaisans qu'à force de recherches et de tâtonnemens.

Des artistes ont pensé qu'ils produiraient une grande variété, s'ils entassaient dans un petit espace les productions exotiques et indigènes les moins faites pour être rassemblées, des monumens de tous les âges dont le style ne s'accorde point. On dirait, en vérité, que les compositeurs de ces jardins avaient juré de renfermer entre quatre murailles un échantillon de l'univers. Ces constructeurs n'ont pas réfléchi que si un mélange aussi disparate pouvait offrir quelques beautés de détails, il n'en présentait aucune dans son ensemble, et que cet ensemble ne devait ni ne pouvait être vraisemblable et naturel.

Bannissez des jardins tout cet amas confus D'édifices divers prodigués par la mode, Obélisque, rotonde, et kiosk, et pagode, Ces bâtimens romains, grecs, arabes, chinois, Chaos d'architecture, et sans but et sans choix. 
Dont la profusion stérilement féconde

Enferme en un jardin les quatre parts du monde.

Mais loin ces monumens dont la ruine feinte Imite mal du temps l'imitable empreinte, Tous ces temples anciens récenment contrefaits,

Ces restes d'un château qui n'exista jamais , Ces vieux ponts nés d'hier, et cette tour gothique Ayant l'air délabré sans avoir l'air antique, Artifice à la fois impuissant et grossier.

\section{(Les Jardins, chant Iv.)}

En voulant se rapprocher de la simplicité, on a imaginé qu'il ne fallait que rendre la liberté à la nature; on n'a pas songé qu'en plantant des arbres où il n'en faut pas, qu'en éparpillant çà et là des objets sans choix, sans perspective, sans convenance, on ne pourait jamais obtenir qu'un effet vague et confus.

Si la nature circonscrite, ou plutôt mutilée, semble triste et ennuyeuse, la nature indéterminée et confuse ne présente partout que l'insipidité, parce que la nature difforme est une véritable monstruosité. C'est done en lis disposant avec habileté, en la choisissant avec goût, qu'on peut trouver l'objet de ses re- 
eherches, le véritable effet de paysages intéressans.

Posons en principes les faits que nous venons d'exposer.

La peinture et la poésie ont pour objet de représenter ou de décrire les plus beaux effets de la nature; l'art de la bien disposer, de la bien choisir, de l'embellir même, ayant le même but, doit en conséquence se servir des mêmes moyens.

C'est uniquement dans l'effet pittoresque qu'on doit chercher la manière de disposer avec arantage les différens objets destinés à plaire aux yeux. L'effet pittoresque consiste dans le choix des formes les plus agréables, dans l'élégance des contours, dans la dégradation de la perspective; il consiste à donner, par le contraste bien ménagé de l'ombre et de la lumière, de la saillie et du relief à tous les objets, à répandre de la rariété sur ces mêmes objets, en les faisant voir sous plusieurs formes, sous plusieurs faces, sous plusieurs aspects. Enfin, l'effet pittoresque consiste aussi dans la belle harmonie des couleurs, surtout dans cette aimable négligence, caractère prin- 
cipal et distinct de la nature et des grâces.

Dans la composition des paysages, il s'agit donc d'intéresser tout à la fois l'oeil et l'esprit.

Laissez donc des jardins la limite indécise, Et que votre art l'efface, ou du moins la déguise. Où l'œil n'espère plus, le charme disparaît; Aux bornes d'un beau lieu nous touchons à regret.

(Jardins.) 


\title{
GHAPITRE Il:
}

\author{
DE L'ENSEMBLE.
}

$\mathrm{L}_{\mathrm{A}}$ belle nature et l'effet pittoresque ne peuvent et ne doirent aroir qu'un seul et même principe, puisque l'un est l'original, et que l'autre est la copie. Ce principe consiste dans l'accord et la liaison de toutes les parties entre elles; la moindre discordance, tant dans la perspective que dans l'harmonie des couleurs, n'est pas plus supportable dans le tableau sur terrain, que dans le tableau sur toile.

L'ubjet essentiel est de commencer par composer le grand ensemble, ainsi que les tableaux pour l'habitation, qui seront placés de tous les côtés où l'on dirigera les vues principales. Si, par exemple, rous obtenez d'un côté un paysage intéressant et pittoresque, et que de l'autre côté vous placiez une avenue en ligne droite, qui coupera l'aspect du pays, puis une 
yrille qui donne à l'habitation la tournure d'un cloître, que vous joigniez à cela l'aridité d'une cour pavée, la vue de ces derniers objets sera insupportable.

La maison est le point central où doivent aboutir les différens points de perspective; c'est l'endroit où le repos, les intervalles de la conversation donnent le plus de loisir pour observer, pour jeter les yeux sur le parc, en détailler les beautés ou les inconvéniens. "La nature, dit un de nos grands écrivains, fuit les lieux fréquentés; c'est sur le sommet des montagnes, au fond des forêts, dans les îles désertes, qu'elle étale ses charmes les plus touchans. " Ceux qui l'aiment, et qui ne peuvent l'aller chercher si loin, sont réduits à la forcer, en quelque sorte, de venir habiter parmi eux, et ce changement ne peut s'opérer sans un peu d'illusion:

C'est donc autour de l'habitation qu'il faut amener cette belle nature; c'est à l'endroit où l'on peut jouir le plus sourent de ses charmes qu'il faut l'engager à les répandre le plus abondamment.

Le coup-d'ocil de la magnificence peut sou- 


\section{7}

vent éblouir et surprendre au premier aspect. L'effet de la nature, au contraire, est de ne causer aucune surprise; plus on la voit, plus elle parait aimable; chaque jour on lui découvre des charmes noureaux. Les douces sensations, produites par son aspect, sont causées par une certaine analogie que tout être bien organisé ne peut manquer d'éprouver: ces sensations font insensiblement passer jusqu'à l'âme des impressions qu'il est plus aisé de ressentir que d'exprimer.

D'ailleurs, quel tableau pourrait présenter autant de magnificence que le grand spectacle de la nature? Penserez-rous jamais y atteindre avec des longues et interminables lignes droites, avec des clôtures, ou plutôt des murailles de charmille, qui rous privent de la vue du ciel et de la terre. Vous n'obtiendrez de grands effets que lorsque vous verrez se déployer la voûte azurée des cieux dans toute sa majesté. De brillans effets de lumière viendront embellir et ajouter à l'intérêt du tableau; chaque nuage en variera les différens tons de couleurs; et si les rayons du so. leil, par une opposition plus sensible de l'om- 
bre et de la lumière, viennent jeter un nouveata pirquant sur les teintes de verdure, on se sen entrainer au doux plaisir de la promenade, plaisir d'autant plus agréable , que rien n'offre l'idée de la prison que rappelle sans cesse la symétrie; au contraire, tout ce qu'on voit engage à voir, et prévient favorablement en faveur de ce qu'on ne voit pas.

Le principe fondamental de la nature et de tous les arts c'est l'unité ; il n'est point d'intérêt partout où l'attention se divise. Il en serait de même de plusieurs tableaux peints sur une même toile, de décorations disparates placées sur le même théâtre : n'éprouvez-vous pas cet effet, lorsqu'à l'Opéra vous voyez les enfers monter au cintre, tandis que l'Élysée descend dans l'abîme?

Tous les objets qui peuvent être aperçus du mème point doivent être entièrement subordonnés au cadre principal; ils ne sont que des parties intégrantes d'un même tout, et par leur rapport, et par leur convenance, ils doivent concourir à l'effet et à l'accord général.

C'est donc sur l'ensemble ou plan général 
ขu'il convient de réfléchir mûrement; les erreurs, à cet égard, peuvent imprimer des taches ineffaçables sur tout l'ouvrage. Vérité et nature, voilà nos maîtres et ceux du sentiment.

Avant de rien faire, il faut, au préalable, prendre une connaissance parfaite du pays environnant, s'assurer du terrain nécessaire à l'exécution du plan. Il faut, en outre, bien se garder de commencer par les détails, et de conserver particulièrement des choses déjà faites, surtout si ces choses deviennent incompatibles avec la disposition générale. Il faut enfin ne pas manquer, en traçant la composition, d'y faire entrer tous les accidens offerts par le pays, remédier à ceux qu'il refuse, surtout s'attacher à la facilité, à la simplicité de l'exécution. Eprouvez-vous à cet égard des obstacles dans un point, cherchez-en un autre, parce que ce genre, donnant le choix de tous les aspects de l'horizon, présente bien plus de facilité que l'alignement forcé de la ligne directe, pour les points de vue et la communication des promenades. 
Avant de planter, avant que du terrain Votre bêche imprudente ait entamé le sein, Pour donner aux jardins une forme pure, Observez, connaissez, imitez la nature. N'avez-vous pas souvent, aux lieux infréquentés, Rencontré tout à coup ces aspects enchantés, Qui suspendent vos pas, dont l'image chérie Vous jette en une douce et longue rêverie? Saisissez, s'il se peut, leurs traits les plus frappans, Et des champs apprenez l'art de parer les champs.

(Les Jardins, chant $\mathbf{I}^{\mathrm{er}}$.)

Ces vers du Virgile français contiennent en peu de mots toute la théorie de l'art.

Dans les arts en général, mais particulièrement dans l'architecture, on nomme plan ce qui, sur un théâtre, est appelé coulisse, et qui sert à donner de l'effet à la perspective.

C'est au point d'où le tableau aura été dessiné qu'il faut se placer pour le rapporter. Les principaux objets qu'il faut ordinairement disposer sur le terrain sont:

$1^{\circ}$. Les masses de plantations forestières ou en taillis, suivant le choix de l'artiste. Elles devront former, par leur disposition, les différens plans ou coulisses dans la décora- 
tion que doit présenter le tableau. Pour établir chacun des massifs, il faut planter des perches ou des jalons d'une hauteur proportionnée à celle de la perspective générale, it chaque point de leur saillie, avec du papier blanc ou une toile blanche.

$2^{\circ}$. Pour tracer avec justesse les contours du terrain, les lignes extérieures des plantations, les sinuosités des sentiers, des eaux, des rivières, il est convenable de planter de petits piquets suivant les lignes courbes rapportées dans le plan. Après avoir examiné de tous côtés, sur tous les sens, si les contours tracés par les piquets conviennent aux points de rue, on fait ensuite étendre sur les dehors de ces piquets, éloignés les uns des autres de cinq à six pieds, un cordeau, lequel, en se pliant sur le contour, formera la ligne sinueuse que l'on désire obtenir. Un terrassier, muni de sa pioche, trace avec exactitude ces différentes lignes en tous sens, dont les contours deviennent aussi faciles à suivre pour les ourriers que les lignes droites : sans ces dispositions, il est impossible de pouroir jamais atteindre le but qu'on s'est proposé. 
5. Quant aux arbres d'un effet particulier, quant aux groupes composés de plusieurs arbres, fixez des piquets, soit penchés, croisés ou espacés, suivant ce qu'ils doivent être. Sur la tête de ces piquets, attachez de petits écriteaux en papier, sur lesquels seront indiqués les noms et les formes des arbres qu'on veut faire planter.

A ces moyens d'une pratique générale, on pourrait, au moyen de quelques circonstances particulières, en ajouter d'autres. Quelque simples que puissent paraître à de grands cultivateurs ceux que j'ai indiqués, il m'a paru indispensable de les communiquer; ils sont les seuls qui évitent les supplémens de dépense, les doubles mémoires, enfin tout cet attirail de faux-frais toujours désagréables à discuter.

Si pour un jardin symétrique, où la ligne droite est seule employée, il faut toujours dresser un plan géométral; si, pour toute espèce de jardin contourné, où il ne s'agit que de découper le terrain, il est également nécessaire d'en lever le plan, afin de pouroir tracer les contours, a plus forte raison fat- 
dra-t-il une sorte de carte géographique fort exacte, lorsque, dans une grande composition, il s'agira de mettre en ouvre toutes les lignes et tous les objets du pays, lorsque des remuemens de terre, la direction des eaux, l'élévation de constructions pittoresques devront être déterminés dans un vaste tableau, dont l'exécution ne peut avoir lieu si elle n'est bien saisie.

Un habile décorateur, tel que Servandoni, chargé de composer les coulisses du devant sur un fond de décoration qui lui aurait été donné, eût été capable, sans doute, de produire, dans le petit espace d'un théàtre, l'illusion d'une perspective très-étendue, de même il n'est pas toujours nécessaire d'avoir un grand terrain, de faire des dépenses considérables pour obtenir le devant d'un grand tableau : il suffit simplement que les différens plans soient bien disposés et bien sentis; il faut que l'étendue de la perspective soit proportionnée à l'importance et à la masse de l'habitation. Plus une maison est grande, plus elle exige une vaste découverte de tout son ensemble, par conséquent plus il y a de ter- 
rain et de choses perdues pour l'agrément des détails. Dans une petite maison, au contraire, on peut profiter de tout, même se passer des lointains, ou du moins s'en faire aisément sur son terrain : il est même possible d'en obtenir, si vous êtes près d'un bois, par l'effet des coups de jour habilement ménagés. Un paysage entièrement bocagé pourrait, à la rigueur, suffire à la petite maison, lui procurer une foule de détails d'ombrages et d'asiles charmans. En cela, comme en bien d'autres choses, que d'arantages l'honnête médiocrité n'a-t-elle pas sur la splendeur et la richesse!

Faites votre esquisse au crayon; ce moyen laisse la facilité d'effacer, de corriger, de substituer ; il présente les principales formes des objets, et la disposition générale des grandes masses de l'ensemble. Méfiez-rous d'un dessin bien terminé; il vous séduira s'il sort de la main d'un artiste habile, vous déterminera sans doute: voyez, considérez et jugez. Craignez de rous exposer à ne pas obtenir les effets de la nature: il vaut mieux gagner que de perdre dans l'exécution. 
L'esquisse de l'ensemble étant achevée, réfléchissez, observez de nouveau le terrain, les points de vue, enfin tous les détails; portez ensuite votre attention sur l'ensemble du tableau, sur l'ordonnance générale de la disposition qu'elle présente, et toujours avec l'idée la plus simple, la plus facile. Malbeureusement cette idée simple et facile est presque toujours la dernière à se présenter.

Après l'esquisse, arrêtez votre plan, dont la facilité d'exécution vous sera entièrement démontrée. C'est alors que, d'après un dessin plus fini, l'artiste pourra terminer l'ensemble de sa composition; il exécutera le plan qu'il a conçu.

Voulez-vous faire quelque chose de grand, ne regardez pas à la dépense de quelques tableaux; il en coùtera bien darantage pour des variations continuelles et des retouches sur le terrain; retouches aussi fatigantes que dispendieuses, auxquelles rous n'échapperez jamais sans ce point d'appui.

Si des gens dépourvus de talent, d'invention, hors d'état de pouvoir rendre leursidées sur le papier, cherchaient à vous en imposer 
par leurs discours, en disant qu'il est inutile de faire des plans en ce genre, qu'il faut aller au jour le jour, et commencer par faire un tableau avant d'avoir disposé le local, ces gens-là cherchent à vous abuser, à vous tromper; suivre leur avis, ce serait commencer un roman par la fin, et une copie arant l'original. Il est aisé de juger que l'antécédent de toute composition est l'idée du compositeur: or, pour composer un paysage, et le rapporter sur le terrain, le dessin est la seule manière d'exprimer ses idées, de s'en rendre un compte exact avant l'exécution.

J'ai présenté le tableau de différentes dégradations que la prudence semble devoir exiger dans la combinaison d'un ensemble; je dois encore indiquer quelques moyens pour rapporter le plan sur le terrain. J'ose assurer d'obtenir alors les mêmes effets dans la nature, eu égard à la disposition des objets, à leur distance, à leurs proportions respectives, et surtout à la facilité de la maind'oeuvre.

Le point où le tableau a été dessiné doit servir de place pour le rapporter; il servira 
encore de point d'appui et de départ pour toutes leś opérations du tableau.

Ainsi, de la disposition naissent le charme, la fraîcheur et tous les agrémens d'un beau jardin. Les arbres sont les mêmes que ceux d'un lieu monotone. C'est donc du seul emploi des matériaux que l'on obtient les différents effets. Le génie

..... Ne compose pas; il corrige, il épure,

Il achève les traits qu'ébauche la nature;

Pour embellir les champs simples dans leurs attraits,

Gardez-yous, artistes, d'insulter à grands frais.

Ce noble emploi demande un artiste qui pense, Prodigue de génie et non pas de dépense:

Moins pompeux qu'élégant, moins décoré que beau,

Un jardin, à nos yeux, est un vaste tableau.

Soyez peintre;

Ne prêtez point au sol des beautés qu'il refuse.

Avant tout connaissez votre site, et du lieu

Adorez le génie et consultez le dieu....

Ce que votre terrain adopte avec plaisir,

Sachez le reconnaître, osez vous en saisir :

C'est mieux que la nature, et cependant c'est elle;

C'est un tableau parfait qui n'a point de modèle.....

Devinez les moyens, présentez les obstacles;

C'est des difficultés que naissent les miracles.

(Delilte, Jardins, chant ${ }^{{ }^{\mathrm{er}} \text {. }}$ ) 
Des masses vigoureuses, placées sur les devans, donnent de l'effet à la perspective; une large bordure qui termine les objets empêche la vue de se distraire et de s'égarer hors du tableau.

Le cadre d'un tableau sur le terrain est naturellement produit par son avant-scène, ou les masses de devant : ce cadre, ou avantscène, peut être composé de plantations, pourvu que les masses en soient grandes, et surtout bien appuyées. Une décoration placée derrière l'avant-scène, et de laquelle on pourrait voir dans les coulisses, ne produirait assurément aucun effet de perspective. Cherchez à rapprocher le plus possible de vos fenêtres les masses de cette arant-scène, et sans aucun intermédiaire : c'est le moyen d'amener, pour ainsi dire, le paysage jusqu'à l'appartement, et de se procurer de l'ombrage au sortir de la maison.

Vous ne pourrez jamais approprier et placer vos lointains dans un juste effet de perspective sans des massifs bien disposés, sans un cadre ou avant-scène, dont les masses vigoureuses, en faisant fuir tous les massifs subsr.. 
quens, ainsi que les lointains, rendent l'effet et l'accord d'un agréable paysage. Sans un plan bien disposé, il est impossible d'obtenir des effets intéressans dans l'ensemble, une liaison et une connexité parfaite avec le pays extérieur; enfin, une sorte de translation naturelle avec les différens effets de promenade. A la plus grande dépense, joignez le tourment d'un entretien minutieux; ajoutez des disputes interminables avec votre jardinier, tels sont les désavantages qu'offre un plan mal conçu. Vous répandez, vous imprimez même sur votre enceinte ce caractère triste et morne qu'offre toujours l'aspect isolé de la nature végétale, si vous n'y joignez pas le gai spectacle de la nature animée. Donc vous ne parriendrez jamais à obtenir cette donce jouissance des véritables beautés, des grands effets de la nature, si rous ne lui donnez d'abord de belles formes, et si vous ne lui laissez après le soin de s'arranger elle-même.

L'effet pittoresque consiste dans l'unité de l'ensemble et dans la liaison des rapports. Ce n'est donc pas assez d'avoir indiqué le véritable point d'appui pour la formation du plan 
général, et la manière de le rapporter sur le terrain ; je dois encore revenir sur la nécessité de bien lier tous lestobjets qui font partie du plan général : faisant partie du même aspect, ils doivent nécessairement concourir à former l'unité de l'ensemble et sa convenance sous tous les rapports.

On ne pourra jamais bien approprier les fonds du pays, si le terrain intérieur n'est pas entièrement confondu, et pour ainsi dire amalgamé avec le terrain extérieur. La moindre séparation, l'écartement le plus léger, formerait tache dans le tableau. Pour éviter les taches que la ligne de clôture ne manquerait pas d'y faire, on a la ressource de former devant les murs, dans le cas où il s'en trouverait, de fortes plantations, afin d'en dissimuler l'apparence et de les masquer' entièrement. Vis-à-vis les points de vue, on peut placer des fossés pleins d'eau, ou des fossés à sec, revêtus en maçonnerie, ou enfin une palissade à pointe au milieu, et dont la hauteur n'excéderait pas le niveau du sol. On peut encore remplacer la palissade par un mur; ce moyen facilitera pour s'approprier 
les fonds du pays. Un bel aspect est une sorte de propriéié d'autant plus agréable, qu'en contribuant à la beauté et à l'ensemble du local particulier, il appartient à tous, et que chacun en jouit.

\section{. . . . . . Écoutez la nature;}

Je l'entends qui vous dit: Homme faible et borné. Trop heureux de jouir, pour créer tu es né; Pygmée audacieux, tu crois dans ton délire Te jouer de mes lois et braver mon empire; Tu veux briser les rocs dont s'offense ton oil, Ils repoussent ton or, ton fer et ton orgueil. Tes pénibles efforts soulèvent-ils l'arène, Un mont factice et nain déshonore la plaine, D'un fleuve désiré tu creuses le canal, Et tu fais regretter le limpide cristal, Le mouvement pressé de ces eaux fugitives, Qui de vie et de frais enrichissent leurs rives. Mes trésors sont épars; et, riche en tous les lieux, Je présente partout des beautés à tes yeux. Vouloir les transporter, c'est vouloir les détruire; Sache m'étudier, et je saurai t'instruire.

(Jardins, chant $v_{\text {. }}$ ) 


\section{GHAPITRE 111.}

DIFFÉRENCE ENTRE LA VUE VAGUE, LA VUE PITTORESQUE ET LA VUE BORNÉE.

UN voyageur est parvenu sur des hauteurs, d'où la vue embrasse une raste étendue de terrain. Ses yeux inquiets, que rien ne fixe, s'écartent sur tous les différens aspects comme sur les divers points d'une carte géographique. Dans tout ce qu'il aperçoit, rien ne lui est familier et ne lui est propre, rien n'est à sa portée et n'arrête de préférence ou ses pas ou ses regards. Descendu de la montagne, le voyageur remarque près de son chemin un joli vallon; l'entrée est resserrée par quelques groupes d'arbres heureusement disposés. Il y porte ses pas: dans un petit bois touffu il trouve la source rafraîchissante qui va le désaltérer, 
et le tapis de verdure qui semble l'inviter au doux repos. Le voyageur, entraîné par l'aspect de ces beaux lieux, suspend sa course; un charme secret, dont il ignore la cause, le retient; il se retire lentement pour jouir plus long-temps de la vue de ces objets enchanteurs. Placé sur le sommet de la montagne, le pays qu'il découvrait était l'univers pour lui, et le vallon lui paraît un lieu de délassement, une espèce d'abri, une sorte de domicile que la nature semble lui offrir, et dont elle a fait toris les frais.

La variété des objets qui se succèdent continuellement dans un royage, dans une excursion, dans une promenade, empêche qu'on ne soit fatigué de leur disposition vague et confuse; mais le pays où l'on s'arrête avec plaisir, et à plus forte raison le lieu choisi pour sa demeure, doit être plus ou moins borné, selon l'importance du bâtiment. Une vue trop vaste ne saurait convenir à l'habitation d'un ménage : dès-lors on sentira la nécessité d'un cadre et de ses proportions relativement aux convenances du domicile. En cela, comme 
en toutes choses, l'essentiel est de savoir se borner.

Ainsị de vos dessins méditez l'ordonnance, Dessites, des aspects, méditez la puissance.

(Jardins.) 


\section{GHAPITRE IV.}

DEs TABLEAUX, DE LA dÉCORATION, ET DES EFFETS QUI EN RÉSULLTENT.

L'ensemble est toujours déterminé par deux points donnés, celui de l'habitation et celui de la situation environnante : c'est donc l'artiste 'qui doit présider à l'exécution de cet ensemble; il doit toujours se rendre un compte exact du plan qu'il a tracé : de cette négligence, il résulterait que la perspective et la multitude d'objets qui concourent à l'embellissement d'un grand espace de terrain, ne pourraient être disposées que d'une manière confuse et choquante. Les détails, au contraire, n'étant assujétis à aucun point donné, deviennent plutôt un objet de goût et de choix, qu'une affaire de combinaison et de règles. 
C'est principalement à l'artiste de choisir et de proposer les détails : on conviendra facilement de cette vérité, en réfléchissant que l'invention des tableaux et des décorations lui appartient; qu'il doit toujours indiquer une scène analogue qui parle au cour et à l'imagination; effet qui manque souvent dans de très-beaux tableaux, surtont lorsque le peintre n'est pas poète.

Horace a dit : Il en est de la poésie comme de la peinture (ut pictura poesis); il aurait également dû ajouter la musique. Ces trois arts sont inspirés par le même sentiment; ils ont tous le même but, celui de charmer et d'imiter la nature : ils ne diffèrent entre eux que dans la manière de produire des effets et d'exciter les passions. L'artiste qui négligera de toucher le coeur pour s'attacher à parler aux yeux et aux oreilles, ne sera jamais qu'un sujet médiocre.

Amans fortunés de la nature, voulez-vous en sentir les beautés, suivez mes avis ; attendez l'instant où les oiseaux de la basse-cour seront éveillés, celui où le coq orgueilleux ne fait plus entendre le chant du matin; 
choisissez, pour en bien étudier les détails, ce moment délicieux où la fraîcheur et le lever de l'aurore semblent rajeunir l'univers. C'est alors que la terre s'embellit à l'approche de l'astre vivifiant qui la féconde. Les pleurs de la rosée, attachées aux feuilles, semblent autant de pierres précieuses. Le soleil, en les animant, les pare de toutes les couleurs de l'arc-en-ciel. Les fleurs exhalent un plus doux parfum, qui se répand et se communique à l'air, qui en est embaumé. Le zéphyr léger entraîne ces douces émanations, pour les porter plusloin. Les oiseaux fontentendre leurs concerts harmonieux, chantent leurs amours, et cherchent à calmer l'ennui de leurs tendres compagnes. Déjà le jeune pâtre ouvre sa bergerie; il conduit son troupeau dans cette prairie, dont la belle verdure repose si agréablement les yeux. L'abeille industrieuse va butiner le miel de vos tables et la cire qui doit vous éclairer. Le papillon, sorti de sa chrysalide, parcourt les champs, et fait admirer les superbes couleurs de ses ailes. Tel est le tableau d'un beau matin. 
C'est derrière les cadres des grands tableaux qu'il faut chercher les promenades intéressantes : je vais en tracer les détails; ils forment, pour ainsi dire, une galerie de petits tableaux qu'il faut examiner séparément, après s'être bien pénétré du tableau principal.

Près des grandes masses du cadre ou de l'avant-scène, on doit trouver, en sortant de l'habitation, un sentier ombragé d'après un dessin agréable; il sera la route pour conduire plus aisément aux endroits les plus intéressains du parc.

Ce sera un bocage où des rayons de lumière joueront à travers le feuillage; le cristal d'une fontaine y réfléchira les couleurs de la reine des fleurs, qui se plaît sur ses bords. Le doux murmure des eaux s'unira aux accens mélodieux de Philomèle, aux chants amoureux des hôtes des forêts, et le parfum des fleurs contribuera au charme que ce lieu doit inspirer.

Plus loin se présente un autre bocage d'un genre mystérieux : une urne de forme anti-que, posée sur un stylobate, renferme les 
cendres de deux amans fidèles; un simple lit de mousse, placé dans le creux du rocher, peut servir aux lectures, à la conversation, aux rêveries du sentiment, et de retraite à l'amant malheureux.

A quelques pas de distance, un bois impénétrable aux rayons d'un soleil ardent et à la pluie, offre l'asile des amans beureux : les statues de l'Hymen et du fils de Vénus indiquent l'entrée du lieu. A l'extrémité du bois est un ruisseau qui, par le cristal de ses eaux, invite à se reposer sur ses bords, à se désaltérer et à se baigner dans ses ondes pures. Un ombrage épais procure l'avantage d'un repos salutaire.

Dans un vallon bien sombre, bien solitaire, sont des rochers couverts de mousse, dont l'âge paraît remonter jusqu'aux premières générations des hommes. L'eau, tombant à grand bruit, forme la cascade, et se convertit en écume. Bientôt le vallon se resserre; le chemin, devenu plus étroit, laisse à peine le passage par un sentier tortueux et difficile. Mais quel spectacle s'offre tout à coup! A travers les cavités des rochers éloignés, s'é- 
lancent de tous côtés des eaux limpides et brillantes; les rocs, les racines, les arbres entremêlés dans le courant, varient les obstacles, et présentent un passage chancelant. Le bruit et la forme des cascades, variées de cent manières différentes, ne laissent entendre que le cri sinistre des oiseaux voraces.

Des bois environnent la place, et leurs épais feuillages se courbent et s'entrelacent sur les eaux écumantes. Des groupes d'arbres heureusement disposés, en donnant un effet surprenant de clair-obscur et de perspective, semblent animer la scène. Le bord du lac est orné de plantes aquatiques, de plantes odoriférantes et de buissons de fleurs. Quelques rayons de lumière, réfléchis par le brillant des cascades, éclairent seuls ce réduit mystérieu, où règne ce jour si doux qui convient également à la beauté, à la mélancolie et au repos.

Dans un terrain profond et retiré, une eau calme et pure forme un petit lac: la lune, avant de quitter l'horizon, semble se plaire à contempler dans l'onde les reflets de son disque argenté. Les bords du lac sont entou- 
rés de peupliers; sous leur ombre paisible est un monument érigé à la mémoire d'un homme dont le génie brûlant éclaira le monde. Il fut persécuté, parce qu'il voulut s'élever audessus de la vaine grandeur; et depuis sa mort une foule d'insensés ont fait siffler contre lui les serpens de l'Envie... Lie profond silence règne dans cette retraite, et cet Élysée, consacré au bonheur paisible, fait naître les pensées austères et les jouissances de l'âme.

Tantôtun bois de chênes antiques rappelle les temps où les Druides allaient, chez les Gaulois nos aieux, cueillir le gui sacré. Dans le lieu le plus retiré de la forêt, est un temple qui offre à la méditation un asile silencieux. C'est là que le poète, le musicien, l'artiste, viendront rêver, pour n'ètre point distraits dans leur enthousiasme divin; c'est là qu'ils trouveront ces idées inspiratrices qu'ils doivent exprimer dans leurs compositions.

Dans un vallon étroit, et loin du bruit, coule un petit ruisseau sur un lit de mousse. Les pentes des montagnes sont couvertes de fougères, et des bois environnent cette soli- 
tude. Ce lieu renferme le petit ermitage dont un philosophe fit sa retraite.

Sur le bord d'un vaste lac s'élèvent d'arides rochers; sur leur cime orgueilleuse croissent les pins, les sapins et les genévriers tortueux. Le terrain inculte offre partout l'image d'un désert. Ce lieu semble être séparé du reste de la nature par une chaîne de monts élevés et de rochers escarpés. Le peintre vient chercher des sujets de tableaux dans cette autre Thébaïde ; l'amant malheureux, l'époux infortuné, privé de sa douce compagne, font retentir les échos de leurs plaintes, et viennent y chercher un remède à leurs peines cuisantes. On lit sur les rochers les noms des objets dont on déplore la perte, et des chiffres enlacés rappellent des temps de bonheur.

Au travers d'un bois de cèdres du Liban, un sentier peu fatigant conduit au sommet d'une haute montagne, au pied de laquelle serpente la rivière qui arrose des prairies fertiles. De cette éminence, l'oil plane sur un vaste horizon, conronné dans l'éloignement par un amphithéâtre de montagnes. Déjà le 
soleil commence sa course, et dore les campagnes de ses rayons éclatans. Les rapeurs se dissipent à son aspect; de longues ombres projettent les arbres, les fabriques et les coteaux. Sur le tapis de verdure émaillé de la fleur des champs, et encore brillant des perles de la rosée, mille accidens de lumière enrichissent cet admirable tableau. Le faux philosophe, ayant épuisé tous les systèmes, doit être forcé, après avoir été témoin de ce spectacle rarissant, de reconnaître l'Etre des êtres et le dispensateur de toutes choses.

Bientôt l'attrait des ombrages et l'aimable verdure des prairies rappellent dans la vallée pour y reposer les yeux fatigués de la vue de ce tableau éblouissant. Au pied de la montagne est un petit bois, où le lierre, uni au chèvrefeuille, au houblon, à la vigne-vierge, s'élancent amoureusement autour des arbres, et forment au-dessus de la tète des guirlandes et des festons entrelacés. Les tapis de mousse et d'herbes verdoyantes y sont rafraîchis par le cours de petites sources entourées par des buissons d'églantiers et d'aubépines. Le ros- 
signol, la fauvette, se plaisent à faire retentir le bois de leur brillant ramage. Quelques lits de mousse servent de lieu de repos pour écouter nos chantres aimables: on entend leurs concerts mélodieux avec d'autant plus de plaisir, que l'air est embaumé par le parfum de la rose, de l'aubépine, par l'odeur de la modeste violette, du lis des vallées ou du muguet. Ces fleurs croissent avec profusion dans toutes les places de ce joli bois, qui sont percées de lumière.

Sortant de ce lieu de délices, on parvient dans de rastes enclos de prairies qui s'étendent jusqu’à la rivière; elles servent de pâturages à de nombreux troupeaux. Groupés d c différenres façons, les uns bondissent sur la pelouse; les autres pâturent paisiblement; d'autres enfin sont couchés. La liberté dont ils jouissent, leur état constant de quiétude, contribue beaucoup plus à leur engrais que la saveur de l'herbe fraîche et fleurie dont ils se repaissent.

Quelques massifs de saules, d'aunes, de peupliers, présentent leurs ombrages, et conduisent vers un pont ou auprès d'une bar- 
que. C'est en cet endroit qu'on traverse les deux bras de rivière formés par une île. Un bois de myrtes et de lauriers laisse apercevoir un autel antique. Le parfum des bois fleuris, dont l'île est entièrement plantée, et les ruines d'un temple, indiquent que ce lieu fut jadis consacré à l'Amour: maintenant c'est un passage; et la cabane du pasteur, appuyée contre les ruines du temple, les rend méconnaissables.

De l'autre côté de la rivière est l'enclos de la métairie, dont on aperçoit les bâtimens sur le coteau voisin. Un sentier qui circule dans toutes les parties de l'enclos, est planté de groseillers, de framboisiers et d'arbres nains. La terre ne cesse jamais de rapporter, et produit toujours. Celle qu'on laisse ordinairement en jachère est ensemencée des plantes les plus convenables à la nourriture des bestiaux qu'on y fait pâturer, et dont le séjour fertilise singulièrement les enclos. Le bœuf et la vache y ruminent en paix ; le jeune agneau bondit auprès de sa mère, la chèrre y déploie son cáractère capricieux et insubordonné; le jeune cheval, ce compagnon de l'homme, re-' 
lève sa crinière, et s'avance fièrement; souvent il joue, et, glorieux de sa liberté et de son indépendance, il hennit, part, et dans sa course rapide le feu semble sortir de ses naseaux.

En avançant toujours dans les autres enclos, de nouveaux objets se présentent à la vue. Ici le laboureur conduit sa charrue en chantant; ses plus jeunes enfans folâtrent auttour de lui, tandis que les aînés, plus en état de travailler, arrachent les mauvaises herbes dans le champ déjà semé. Le travail épargne à l'enfance, à la jeunesse, le désordre des passions; il épargne les maladies, il soutient la santé, et il prolonge la vieillesse, qui, dans les campagnes, est rarement affligée de ces infirmités si communes dans nos villes. Le laboureur, dans son rude travail, échappe à l'ennui; il rentre à la ferme toujours gai, joyeux, et toujoux's plein d'appétit. Il semblerait que l'ennui aurait été le partage, et en quelque sorte l'apanage de la richesse et de la vaine grandeur.

Mais il est temps de terminer notre promenade. Un verger, ou même un bois d'arbustes, 
ramène au manoir, asile du bonheur et de la paix $:$

Dans ce chapitre, j'ai simplement voulu offrir un faible échantillon des beautés et des variétés qu'on peut trouver dans la nature. C'est en vain que j'entreprendrais de présenter toutes celles dont elle serait susceptible; la diversité des cultures, les inégalités du terrain, la différence des mêmes objets, considérés sous divers aspects ou aperçus de différens points, enfin la fécondité des tableaux que présente la nature, et les inventions de l'artiste, ne peuvent manquer d'offrir une telle variété d'objets de détails, qu'on ne peut ètre embarrassé que du choix.

Dans l'ensemble, comme dans les détails, on ne doit jamais contrarier la nature, et surtout vouloir imiter ses grands écarts. Vos efforts ne serviraient qu'à faire paraître votre impuissance. Faites attention que, dans les détails, tous les bâtimens, ou les places de

צ. Voyez la description du verger de Clarens, dans la Soupelle Héloïse, tome V, lettre Ire. 
repos que vous désirez établir, soient toujours déterminés par le choix des points les plus intéressans, et particulièrement par le caractère du local, caractère qu'il est souvent au pouvoir de l'artiste de renforcer, jusqu'à un certain point, dans les détails.

Pour l'intérêt de la variété, il ne faut jamais empêcher de tirer parti de la rue des cimes des montagnes. Déployés av ec ostentation, ces aspects à perte de vue et à vol d'oiseau sont rarement pittoresques; ils fatiguent les yeux et ne peuvent long-temps arrêter les regards du spectateur, qui ne les contemplera jamais avec plaisir. Il est nécessaire de s'en tenir, pour les détails, aux mêmes principes que pour l'ensemble. Ces objets doivent aroir chacun un effet qui leur est propre et un cadre particulier. Le grand ensemble sera une promenade pour les yeux et un tableau général pour la raison. Les détails que vous formez par les plantations entremêlées doirent être autant de petits tableaux à part, comme les différens points de repos établis dans la promenade. Il faut qu'on s'y arrête, et qu'ils présentent de l'agrément; car il ne suffit pas 
d'écarter la symétrie, et d'abandonner les objets au hasard, pour atteindre et produire l'effet de la belle nature, sourent défigurée de tant de manières différentes. Des vallées agréables, des prairies fertiles, sont devenues des marécages impraticables, au moyen de moulins mal établis, qui ont fait remonter le niveau des eaux au-dessus du niveau des terres. Des arbres ont été plantés là où il n'en fallait pas; d'autres ont été abattus là où il en fallait. Dans quelques jardins, les arbres ont éié taillés en raquette, en boule, en érentail, en muraille. Les buis et les ifs ont été métamorphosés en lustres, en pyramides, en cerfs, en cheraux, en chiens, en fauteuils, etc., et ne paraissaient jamais dans leurs formes naturelles, ni sous leur réritable aspect. Enfin, dans un parc de Hollande, il existe une chasse au cerf, suivie d'une meute, de veneurs, entièrement taillée dans les ifs et dans les buis.

Les Hollandais ont long-temps regardé l'if, le buis et autres arbrisseaux taillés en formes d'animaux, comme un très-bel ornement dans les jardins; et même ils y mettent quelque- 
fois des yeux d'émail. Ils ont souvent placé dans leurs parterres des formes d'animaux ou de fruits faits en fil de fer. On remplit ces moules de terre, dans laquelle on sème des gräines à travers les fils. La plante levée imite assez ce qu'on a voulu représenter. Le persil et le cerfeuil sont employés avantageusement pour cet effet.

La Fontaine a dit quelque part : on tient toujours au lieu d'où l'on vient. Au rapport de Pope, un excellent cuisinier de Londres ayant fait fortune, avait embelli sa campagne d'un dîner tel qu'on en sert à la cérémonie d'un couronnement. Le philosophe anglais critique vivement ce goût singulier, et pour se moquer des amateurs de cette sorte de merveille, il en fait un catalogue fort plaisant.

Dans des jardins, on roit, dit-il, l'arche de Noé en houx, dont les còtés sont en assez mauvais état faute d'eau; un saint George en buis, dont le bras n'est pas tout-à-fait assez long, mais qui pourra tuer le dragon au mois d'avril prochain; une reine Élisabeth en illeul, tirant un peu sur les pâles-couleurs, mais à cela près croissant à merveille; une 


\section{1}

vieille fille d'honneur en bois vermoulu; plusieurs grands poètes modernes un peu gâtés ; un cochon de haie vive devenu porc-épic, pour avoir été laissé à la pluie pendant une semaine; un verrat de lavande, avec de la sauge qui pousse dans son ventre; deux viezges en sapins prodigieusement avancées, etc.

Au-devant du manoir, jadis le froid parterre D'un dédale de buis dessina le coup-d'œil ; Les cyprès et les ifs, d'un feuillage de deuil, En globe, en vase, en mur, noircissaient les allées, Sur d'arides sablons au cordeau nivelées;

Le fer mutila tout: l'arbre sans liberté

N'osa de ses rameaux montrer la nudité.

Mais il est. une nature vierge et primitive dont les effets ne peuvent manquer d'intéresser; elle est le but qu'il faut saisir, connấtre, atteindre, pour l'imiter ensuite; elle présente les endroits épars que la peinture irait chercher, pour en retracer la belle ordonnance. Enfin, c'est la nature choisie qu'il faut s'efforcer d'introduire et de disposer dans une composition.

La vue d'un grand chemin ne laisse aper- 
cevoir que du pays, et il en est de même dans le tableau d'un artiste peu habile; mais un paysage, une scène poétique, doivent offrir une situation choisie, je dirai même créée par le goût et par le sentiment. 


\section{GHAPITRE V.}

DE LA POSSIBILITÉ DE TIRER PARTI DE TOUTES LES SITUATIONS.

Lonsqu'rl est permis de choisir, il se trouve sans doute des situations plus ou moins préférables; car plus la nature a fait pour nous, moins elle nous laisse à faire. Mais il n'est point de situation qui n’ait son mérite particulier et son caractère distinctif. D'un côté, la situation se trouvera dans la variété et dans le jeu du terrain; de l'autre, dans le brillant des eaux. Telle situation réjouira par le spectacle animé d'une population nombreuse; telle autre plaira par la richesse et la beauté de ses productions. Le talent de l'artiste consiste à bien saisir, à développer et à présenter arec avantage le mérite de chaque chose. Le ter. 
rain ressemble à la toile sur laquelle le peirtre doit faire son tableau : les choses mal faites, il les corrige, les efface, conserve les bonnes et supplée au reste. Il faut se contenter de ce que nous a donné la nature, se passer de ce qu'elle refuse, et ne jamais se laisser décourager par les difficultés qu'elle présente: il arrive souvent de voir une superbe femme ne présenter à l'oil que des beautés statuaires. Le plus grand défaut d'une physionomie est de manquer d'esprit et de mouvement. Il en est de même de la physionomie d'un terrain renfermé par des murailles, ou défiguré par la règle et par le compas.

La situation la plus difficile à traiter est la plaine entièrement plate et dénuée d'eau, telle que la plupart des plaines situées dans les environs de Paris. Ces dernières cependant offrent souvent des villages, des montagnes à l'horizon; souvent des collines et des vallées formées par l'écoulement des eaux. Rienn'empêche donc de bien choisir ses fonds, ses lointains, de bien former ses plans de devantavec des plantations, et de bien se licr au tablean général. 
Autour des écuries, cachées en partie par des arbres, et situées dans un vaste enclos, les chevaux pourraient s'ébattre en liberté sur la pelouse. Une fontaine, ou, à son défaut, un abreuvoir, avec quelques groupes d'arbres heureusement disposés, pourrait fournir le sujet d'un charmant tableau.

Dans un bois taillis, entouré de palissades, on peut construire une ménagerie, où les animaux pourraient paître en liberté; au milieu du bois, une cabane rustique servirait de logement au garde de la ménagerie.

Un verger, avec un gazon, ou de beaux groupes d'arbres et de pampres verdoyans qui monteraient et s'entrelaceraient parmi les branches, offrirait à la fois les dons de Bacchus et ceux de Pomone. Les variétés d'une pépinière sans alignement; les divers enclos de calture, ceux des jachères où l'on met les bestiaux; le tableau de la ferme, celui de la laiterie; enfin le potager maraîcher, orné d'une maison pittoresque pour le jardinier, offriraient successivement des objets intéressans. En se rapprochant de la maison, le 
compositeur peut placer un joli parterre au milieu d'un bois d'arbustes.

Un jardin d'hiver, composé des arbres et arbustes toujours verts, pourrait, du côté du midi, n'être séparé du salon d'hiver que par une serre-chaude. Dans la saison des frimas, cette serre présenterait de l'appartement l'illusion de la température et des couleurs du printemps. Les châssis de la serre, qui pendant l'été seraient supportés par une colonnade, pourraient s'enlever, et laisser, au milieu d'une rotonde découverte, s'exhaler le parfum des orangers, qui, par ce moyen, resteraient toujours plantés en pleine terre.

Un parc symétrique, renfermé comme une prison, obstrué de tous côtés par des murs de charmille, dont la hauteur ne laisse aucun passage, soit aux rayons du soleil, soit à l'influence des rents, qui, chassant les vapeurs, empêcheraient ce lieu d'être triste, humide et malsain: un endroit semblable paraîtra peut‘̂tre plus difficileà traiter qu'il ne l'est en effet. Montez au faite de la maison, et de cel observatoire réfléchissez au parti que vous prendre\%. Choisissez ce qui vous convient, regar- 
dez comme non-avenu ce qui rous déplaît, et ce que vous conserverez vous donnera l'avantage d'avoir de belles masses toutes venues. Le meilleur parti, dans cette circonstance, est de pouvoir faire entrer dans l'abatis toutes les allées droites qui pourraient être vues de la maison, et surtout si les bois sont vieux; car, en cherchant à masquer ces allées, il serait impossible d'en effacer suffisamment les lignes et les ourertures par le moyen des jeunes plantations.

Dans tous les terrains montagneux se trouvent des rallées, et très-ordinairement des eaux : ainsi le compositeur aura les matériaux les plus importans à sa disposition; c'est à lui de les employer d'une manière convenable.

Les montagnes offrent, en général, un très-grand avantage dans une belle composition; elles appartiennent toujours à un pays tourmenté, et par conséquent susceptible d'un grand nombre de variétés. Les profondeurs des vallées sont ordinairement arrosées par des ruisseaux; les sommités et les revers offrent sans cesse des aspects différens; sou- 
vent des chutes d'eau, tombant des montagnes ou des rochers, peuvent fournir de très-grands effets.

On remarque trois circonstances où les montagnes présentent des difficultés à l'artiste pour les placer heureusement dans son tableau.

. $I^{\circ}$. Si les montagnes venaient à trop se resserrer, de manière à ne laisser entre elles, devant l'habitation, qu'un vallon étroit et marécageux qui ne laisse apercevoir aucun lointain. Cette situation serait sans doute bien solitaire; mais néanmoins on peut en tirer des tableaux fort intéressans.

- Par le desséchement du marais, il est facile d'obtenir un ruisseau ou une petite rivière qui arroserait le vallon. Cette rivière, qui tantôt s'approcherait on s'éloignerait de l'escarpement du terrain, pourrait successivement recevoir la réflexion des objets plantés sur ses bords.

Si le ruisseau des bois emprunte sa parure, La rivière aime aussi que des arlores divers, Lés pâles peujpliers, les saules demi-verts, Oruent sourent son cours. 
$2^{\circ}$. Si les montagnes sont très-rapprochées de la maison, par la majesté de leurs masses couvertes de bois, elles peuvent faire les devans d'un paysage d'un grand style.

$5^{\circ}$. Dans le cas où les montagnes se trouveraient à une distance très-rapprochée et en face de la maison, c'est alors le cas de planter des arbres sur les sommités, ou de disposer les bois en amphithéâtre, de manière à profiter et à faire valoir toutes les inégalités du terrain. On ajouterait à l'agrément, s'il était possible de former un lac ou une rivière, dans laquelle riendraient se jeter plusieurs chutes d'eau. Une pareille arant-scène, réfléchie dans les eaux du lac, serait un beau plan de devant, pour repousser la vue sur le paysage de la vallée, et sur les lointains que l'on pourrait prendre tout-à-fait sur le côté de l'horizon. Ce n'est pas un avantage que de prendre en face le point de perspective; plus on recule le point sur les bords du tableau, plus la perspective serã éloignée, par la raison toute simple que la diagonale est plus longue que la perpendiculaire du carré. 
Si le sol n'offre point ces blocs majestueux, De la nature en vain, rival présomptueux, L'art en voudrait tenter une fidèle image : Du haut des vrais rochers, sa demeure sauvage, La nature se rit de ces rocs contrefaits, D'un travail impuissant avortons imparfaits.

(Les Jardins, chant iri.) 


\section{GHAPITRE VI.}

DU GRAND STYLE.

Ex examinant les admirables productions de nos grands paysagistes, tels que le Poussin, Berghem, Asselin, Paul Poter, Vernet, Ruisdael, Panini, Valenciennes et autres, il est hors de doute qu'il existe des paysages pour toutes les situations.

Riche variété, délice de la vue, Accours, viens rompre enfin l'insipide niveau; Brise le triste équerre et l'ennuyeux cordeau.

\section{(Les Jardins, chant $\mathrm{r}^{\mathrm{er}}$.)}

Les palais des souverains et des princes pourraient être environnés de paysages héroïques, c'est-à-dire dans la manière des grandes et nobles compositions du Poussin. 
Là, des groupes d'arbres majestueux; ici, des cascades et des lacs d'une vaste étendue; plus loin, des fabriques d'un grand style, ornées intérieurement et extérieurement de superbes statues; tandis qu'une immense découverte et de riches lointains donneraient à tout l'ensemble l'effet le plus grand, le plus pittoresque et le plus majestueux.

Ce genre seul peut convenir au palais des princes; et dans l'extrême variété dont il est susceptible, chacun trouvera facilement ce qui conviendra le mieux à ses facultés, à sa situation et à son goût:

Des ornemens de l'art l'œil bientôt se fatigue;

Mais les bois, mais les eaux , mais les ómbrages frais; Tout celuxe innocent ne fatigue jamais.

(Jardins.) 
63

\section{GHAPITRE VII.}

DES COMPARAISONS.

L'architecture, inventée par les peuples d'Orient, fut perfectionnée par les Grecs et imitée par les Romains. A l'époque de la renaissance des arts, le style des Grecs et des Romains se répandit en Europe, et cette introduction fit abandonner les formes gothiques adoptées par nos aieux. A cette époque, l'art des jardins était encore dans son enfance. On crut, dans le xrrr siècle, que des jardins symétriques avaient un air de grandeur, que des allées tirées au cordeau étaient ce qu'il y arait de plus noble; mais lorsque les architectes du xrin siècle eurent mieux étudié la nature, ils s'aperçurent bientôt que cette nature était préférable aux lignes 
droites; que de beaux tableaux, de beaux percés, des surprises agréables convenaient beaucoup mieux que cette ennuyeuse symé- trie, toujours triste, toujours froide, toujours monotone, puisqu'elle ne présente aucun intérêt ni aux yeux ni à l'esprit. Je suppose qu'un étranger veuille examiner un château duquel dépend un jardin dessiné d'après les idées anciennes : au premier coup-d'oeil, dès qu'il sera sur le perron, il apercevra de suite un parterre, l'extrémité des allées, des charmilles bien peignées, bien alignées : la chaleur, réfléchie par un sable brûlant, ne peut lui inspirer que le désir de rentrer dans l'appartement, ou de remonter dans sa voiture. Comment ne pas éviter une promenade qui satisfait la curiosité au premier aperçu, qui ne présente aucun intérêt et qui proroque l'ennui?

A la mode échappés, craignons un autre écueil :

Pour former d'un niveau l'uniforme coup-d'œil, Jadis interrogeant le compas et l'équerre,

A tout sol inégal le Français fit la guerre:

Il crut orner les champs, et les défigura.

Ainsi, loin du vrai but Le Nostre s'égara. 


\section{5}

La nature perdit ses formes variées;

Les pentes avec grâce aux vallons mariées,

Perdirent tous leurs jeux ; plus de lians contours :

La descente pleura ses faciles retours.

A cette froide composition comparez un jardin pittoresque et bien dessiné : le promeneur se sent, à chaque pas, entraîné par le charme des variétés que la belle nature offre à ses regards, et par l'éclat et la richesse de ses plus intéressantes productions.

Ce jardin, distribué avec goût, conduit naturellement d'abord à observer ses grandes masses, puis à les admirer. On considère avec attention jusqu'aux plus légers détails, parce que tous présentent un intérêt plus ou moins grand, et que leur aspect fait naître des sensations délicieuses. Si l'artiste a bien tiré parti des différentes situations que lui offrait le terrain, l'étranger ne cessera de rencontrer çà et là des accidens heureux. Enfin, les malades, les vieillards, les valétudinaires, et les personnes les moins habituées à l'exercice de la promenade, se laissent entrainer par un charme secret. La promenade donne 
de la force et entretient la santé : rien de plus naturel pour excitcr l'appétit et le repos, suriout dans un lieu où le parfum des fleurs, le chant des oiseaux, le murmure des eaux, rous retiennent. Des sensations multipliées vous entrainent; les charmes de la belle nature semblent vous appeler pour être les témoins de ses productions, de ses écarts, de son grandiose, de ses variétés infinies, qui se présentent sous toutes les formes, j'oserai dire sous toutes les couleurs. 


$$
\text { (1) }
$$

DE L'IMITATION.

Dars les arts, il n'est qu'un seul maître à imiter : c'est la nature, et toujours elle, qu'il faut suivre et prendre pour modèle. Les grands génies ne se sont jamais écartés de cette règle, et ont produit des chefs-d'oeurre. Les artistes vulgaires sont restés assujétis à la routine. Malbeur à celui qui copie! il sera bientôt dégoûté de son ouvrage, car une copie doit toujours être inférieure à l'original.

N'imitez jamais le jardin, même celui du voisin le plus rapproché ; car, dans les détails particuliers de chaque terrain, le premier aura des vallons, et le second des collines, et un lointain différent de la composition de l'autre.... 
Joignez encore la différence de l'étendue el des proportions du tableau; le terrain n'étant pas le même, ne peut point alor's recevoir une foule de sujets; enfin, les compositions des montagnes ou d'un pays aquatique conviennent-elles à un pays plat ou à un pays sec? Quelle différence d'intérêt, lorsque la situation de l'un ne sera pas celle de l'autre!

Lorsqu'un pays a l'avantage de posséder divers tableaux faits pour charmer les regards, on pourrait aussi trouver des sujets d'étonnement. Dans ces singuliers et prodigieux caprices de la nature, on sera frappé sans doute de ces énormes piles de rochers entassées les unes sur les autres. On ne sera pas moins étonné du spectacle imposant et gigantesque de ces vastes montagnes, dont la cime se perd dans les nuages. Les unes furent entr'ouvertes par des feux souterrains; les autres sont brisées par l'impétuosité des torrens, dont les sourds mugissemens sem. blent encore menacer de tout entraîner.

Les écarts de la nature, ses caprices, ont beaucoup d'analogie avec certains grands seigneurs. An premier abord, tout surprend. 
étonne à la vue des uns et des autres; mais, comme tout ce qui est disproportionné devient très-fatigant, il en résulte que souvent ils font naître le dégoût, l'ennui, pour ne pas dire plus. Il faut vivre au milieu de plus doux objets, et arec des hommes sociables.

Faux orgueil dont bientôt la jouissance passe ;

Mais le repentir reste, et la honte le suit.

Chez vos pareils déçus, voyez ce que produit

Ce goût qui d'un jardin fait un monde factice...

L'impuissance s'y place â côté du caprice :

Sur un sillon qu'il creuse il va jeter un pont;

Il soulève la terre..: il croit avoir un mont.

Cependant l'or s'épuise, et de son monticule

L'obscur bourgeois descend et pauvre et ridicule. 


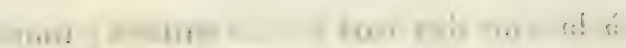

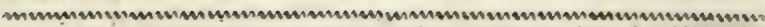

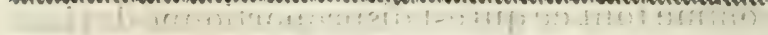

CHAPITRE IX.

DES PLANTATIONS.

Après avoir indiqué les inconvéniens qui résultent d'une servile imitation, après avoir traité de l'ensemble et des détails, je parlerai des différens mutériaux du paysage, du caractère des différentes situations, des plantations diverses, des eaux et des fabriques. Les montagnes et les rochers ne sont pas toujours à la disposition de l'homme; il est bien rare que tout ce que l'art peut faire à ce sujet puisse égaler les dépenses occasionnées par leur transport et par leur mise en ouvre.

Je commencerai par les plantations, par la raison que les bois sont la plus noble parure de la terre, comme leurs ombrages sont l'asile le plus naturel et le plus agréable. 
L'emploi de toutes les plantations, relativement à l'effet pittoresque, consiste en cinc objets principaux :

$1^{\circ}$. Etablir des plans de perspective, pour lier les plus agréables fonds du pays au point de vue de l'habitation.

$2^{\circ}$. Former dans les plantations, et par la nature même des arbres, des élévations qui puissent donner beaucoup de relief à un terrain même absolument plat.

5 . Cacher tous les objets désagréables à la vue.

$4^{\circ}$. Donner plus d'étendue aux objets intéressans, en dérobant leurs extrémités derrière des massifs de plantations : ce moyen donne lieu à l'imagination de prolonger les objets au-delà du point où on les perd de vue. Cette partie exige de grandes combinaisons de la part de l'artiste.

$5^{\circ}$. Enfin, donner des contours agréables à toutes les surfaces, tant du terrain, des eaux, que des allées.

Si des bois, cependant, le compas seul ordoune, A leur penchant natif du moins cju'on abandome 
Les rameaux, le feuillage, et qu'un art grimacier, Armé stupidement du monotone acier,

Jamais ne les transforme en verte architecture :

Même en lạ subjuguant respectons la nature;

Imitons ces héros, ces sages conquérans,

Dont le code, étranger au code des tyrans,

Laisse aux vaincus leurs biens, leurs mœurs et leur langage.

Des préjugés, enfin, que le goût nous dégage:

D'une voix de mépris et d'un oil de dédain, Malgré Le Nostre même, il bannit du jardin Ces portes, ces salons, ces remparts de feuillage,

Et ces arcs de triomphe érigés en treillage,

Et ces bustes humains, ces groupes d'animaux,

De lif pyramidal tourmentant les rameaux :

Le Nostre, en adoptant ces formes sans génie,

De ses nobles dessins détruisait l'harmonie;

Il insultait un art dont il fut créateur.

Les arbres sont de différentes espèces, qui ont toutes une destination particulière. Pour les grandes masses, on se sert de l'orme, du frêne, du hêtre, du châtaignier, du tilleul, du marronier, du vernis du Japon et de l'acacia. Les arbres qu'on appelle aquatiques, tels que les saules, les aulnes, les peupliers, les platanes, se plantent au bord des ruisseaux, des rivières, des pièces d'eau. Quant aux espèces 


\section{3}

dites montagnardes, on emploie les pins, les sapins, les genévriers, les cèdres, les bouleaux, etc.

Si la composition d'un parc exige de la méditation, des talens, de l'expérience, et particulièrement beaucoup de goût, soit dans les détails comme dans le tableau général, il n'en faut pas moins pour les plantations. Le terrain étant disposé, les pelouses dessinées avec grâce, les lointains bien représentés, les fuyans de la perspective bien conçus, et laissant toujours à l'oeil le désir de découvrir ce qu'il ne voit pas, d'alimenter l'imagination et même à l'exciter; si votre pelouse reçoit la forme naturelle qu'elle doit avoir par le moyen d'un mouvement concave, et en donnant de l'élévation aux divers massifs qui l'environnent, toutes ces précautions seront inutiles si les plantations ne répondent pas au mouvement du terrain, des eaux, et à la perspective. C'est la nature, et rien que la nature, qu'il faut suivre et imiter; elle seule doit être notre maître et notre guide : si l'on s'écarte du modèle, on se perd pour toujours. Un parc manqué est un mal sans remède; ii faut tout 
détruire, et l'on ne fait rien de bon en dépensant beaucoup.

Après avoir traité les mouvemens du terrain conformément au plan, aroir trouvé les massifs proportionnellement à la superficie du terrain qu'ils occupent, le même plan qui rous a guidé pour la distribution du parc et pour ses mouvemens, doit aussi vous conduire pour les plantations. Le plan étant tracé au crayon, la composition se trouve alors projetée. En dessinant les massifs, on indique les espèces d'arbres que chacun doit recevoir. Avant de passer le plan à l'encre, il faut encore se présenter sur le terrain. Si vous doutez de l'effet de la perspective, plantez des perches à l'endroit des plantations, et, plaçant à leur extrémité un papier pour les mieux apercevoir, rous jugez alors des détails et de l'enșemble. L'artiste habitué à ce travail peut quelquefois éviter cette double opération; s'il doute cependant d'un heureux résultat, il ne faut ni paresse ni amour-propre mal placé : il doit se convaincre par des faits. Ainsi, ayant reconnu les dispositions pour les plantations, après avoir parcouru de nouveau le terrain, s'être 


\section{5}

présenté sur tous les points et les avoir réfléchis, car souvent un tableau, un massif, vu d'un point, paraîtra merveilleux, et vu d'un autre point, il produira l'effet contraire, on change alors de place, et on examine l'objet qui occupe sous tous les aspects qu'il peut présenter. Cette opération acherée, on arrète son plan, puis on le termine. La meilleure méthode est de tracer le plan au crayon, puis de le rapporter sur le terrain : c'est alors qu'on corrige et qu'on perfectionne ; car souvent le plan sur papier ne laisse pas apercevoir les obstacles que présente le terrain, les ressources ou les contrariétés que la nature offye ou oppose:

Pour planter un chemin qui doit être ombragé, adoptez une seule espèce d'arbres, qui sera déterminée par la nature mème du terrain. C'est ainsi cqu'il faut toujours en agir, et le seul moyen de réussir en plaçant des arbres sur le terrain quileur convient. Pour les arbres isolés, propres à ombrager des chemins ou allées, on choisira parmi les plus grandes espèces qui se trouvent dans le tableau $\mathrm{n}^{\circ} 1$. A la fin de l'ouvrage, j'ai établi la division de 


\section{6}

tous les arbres qui entrent dans la composition d'un parc; elle forme cinq tableaux : $\mathrm{n}^{\circ} \mathbf{1}$, arbres de la plus grande espèce; $n^{05} 2$ et 3 , arbres de seconde taille; $\mathbf{n}^{\text {os }} 4$ et 5 , arbres à touffes et arbustes.

Le marronier, qui demande un terrain passable, convient parfaitement pour ombrager un chemin; cet arbre, peu difficile à cultiver, vient partout. Ayant plusieurs chemins à ombrager, il faut changer d'espèce d'arbres à chacun; tous les terrains conviennent à I'acacia ordinaire; le tilleul, qui ombrage trèshien, demande une bonne terre. Dans les terrains frais, mettez des platanes et des blancs de Hollande. Je renvoie au tableau $\mathrm{n}^{\circ} \mathbf{1}$, qui contient les noms de tous les grands arbres propres à ombrager, ainsi que la nature du terrain qui leur convient.

\section{DES MASSITS,}

Rapportez-vous au plan pour planter des massifs : sile premier qu'on établit est composé d'arbres tiges, mélés de touffes, on plan- 


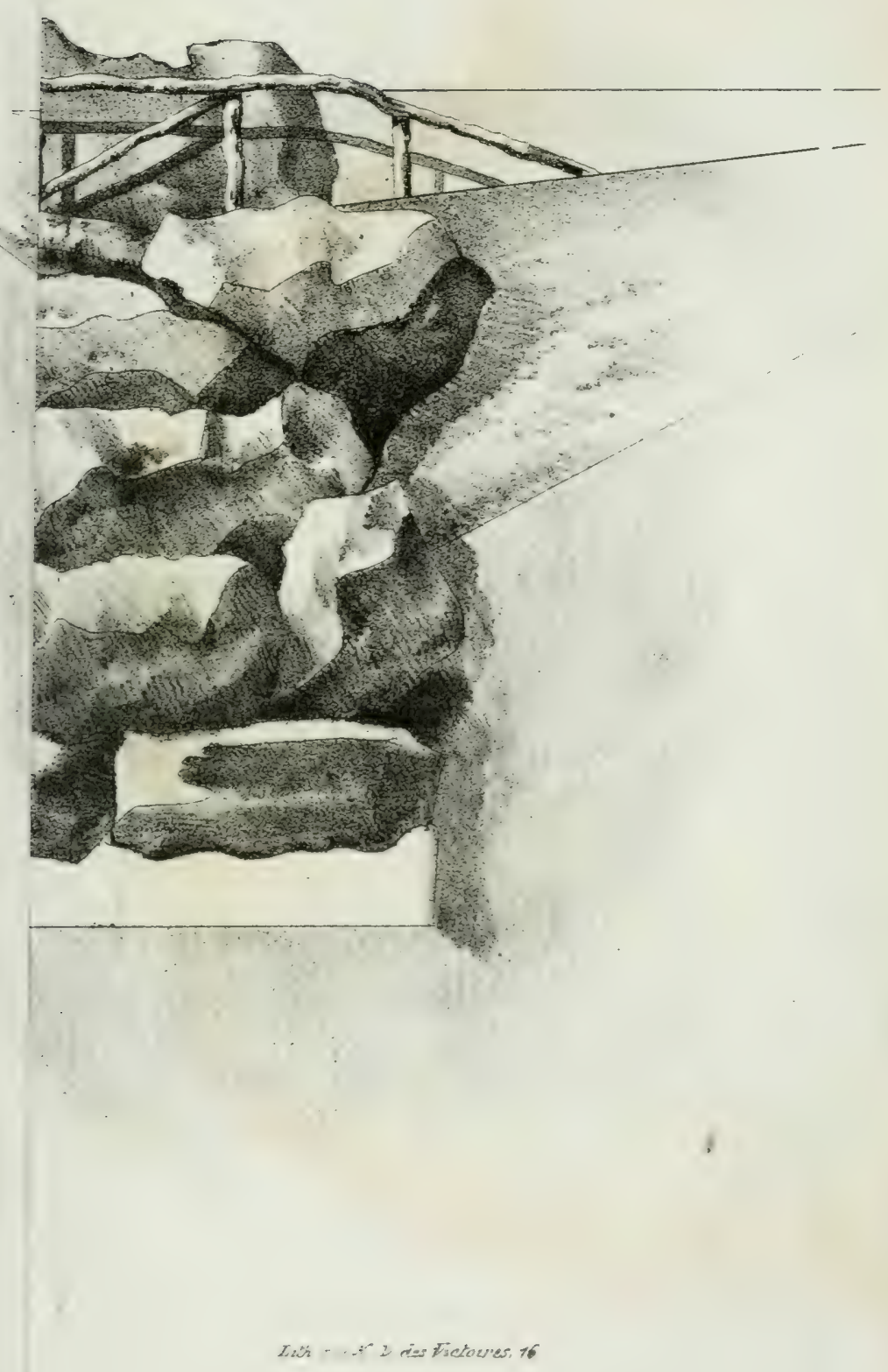




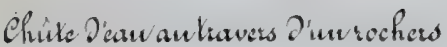

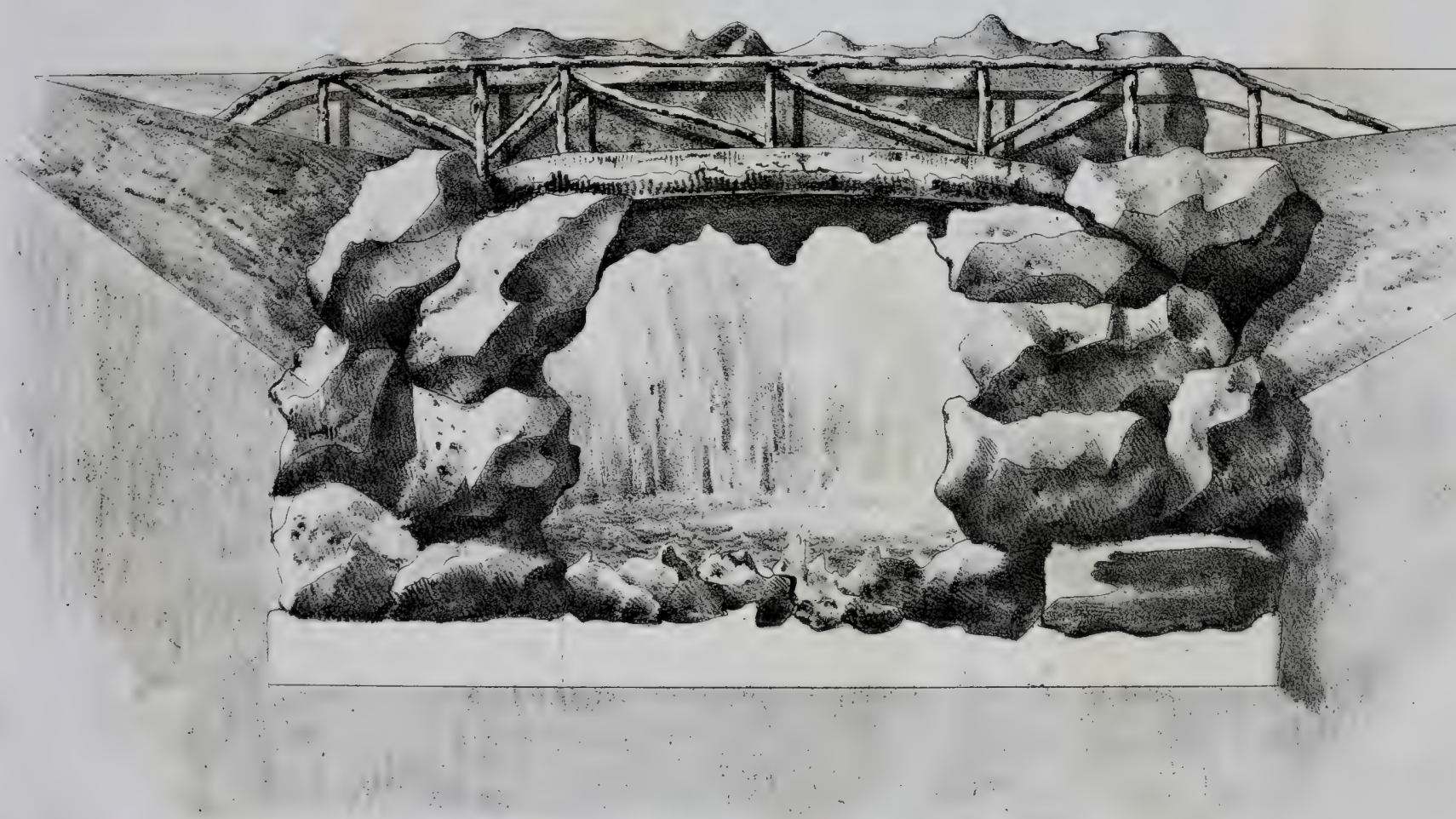


tera d'abord les grands arbres à douze ou quinze pieds de distance. Ceux du milieu seront pris dans les tableaux $n^{\circ s} 1,2$ et 3 . Ensuite, pour former les touffes, il sera fait un choix dans les tableaux n $n^{\circ} 4$ et 5 . En formant un second massif, on évitera avec soin de le rendre conforme au précédent, et surtout d'employer aucun des arbres tiges qui figurent dans le tableau $n^{\circ} 1$. Les autres tableaux laissent une grande latitude pour le choix. On ne peut former des massifs que lorsque la perspective le permet. Pour les grouper avec art, on place d'abord une forte masse de peupliers d'Italie, une autre de peupliers suisses, puis une masse de touffes sans arbres tiges, et enfin une dernière d'arbres tiges avec touffes.

Il est impossible de pouvoir indiquer à l'amateur ou à l'artiste jardinier l'emplacement des massifs; la situation du terrain peut seule servir de guide. Ce qui convient pour un endroit serait déplacé pour un autre. Ainsi le sol, la localité, le pays envirommant, sont les objets qu'il faut étudier avant que de ne rien entreprendre. 
Les massifs plantés en taillis seront cultivés. Le terrain préparé pour les massifs d'arbres tiges en futaies exige du mouvement. Il est indispensable que l'herbe orne le dessous de ces arbres et ne forme qu'un seul tout avec les pelouses. De même que les massifs de futaie, ceux formés d'arbres verts ne doivent pas être cultivés.

Les massifs de tous genres seront plantés sur un terrain préparé avec du mouvement; il en sero de même pour les arbres isolés. Rien n'imite mieux la nature et n'offre plus de grâce.

\section{MANIÈRE DE PLANTER.}

Les meilleures plantations sont celles qui sont faites depuis la fin du mois d'octobre jusqu’à la fin de décembre, si le temps le permet. On plante aussi en mars; mais cette époque est moins favorable, et l'on gagne beaucoup en suivant la première. On ne doit jamais planter, pas même les plantes aquatiques, par un temps pluvieux dans un terrain trop humide. Dans une terre détrempée, l'arbre, qui 
ne peut se soutenir, chancelle au gré du vent. S'il se trouvait de l'eau dans le trou disposé pour recevoir un arbre, il faut l'épuiser avant de planter. La terre réduite en boue se sèche au printemps, et derient tellement dure que l'arbre se trouve emprisonné dans sa racine. La sécheresse fait fendre la terre qui se racornit; et il se forme des crevasses par lesquelles cette sécheresse s'introduit et rend la terre encore plus dure. Pour ériter cet inconvénient qui fait périr les arbres, on plantera dans une terre meuble et fraîche. Les trous seront creusés de manière à ce que la racine ne soit pas emprisonnée. On doit éviter les trous faits en cul-de-lampe, c'est-à-dire larges du haut et étroits du bas. Ils seront creusés carrément, ou aussi larges du bas que du haut. Il est aisé d'en sentir la raison : c'est au fond du trou que doit se trouver la racine; c'est là où elle doit circuler et s'étendre. Cette racine doit donc trouver une situation et un terrain qui favorisent sa végétation. Dans le cas oì des pierres ou du tufformeraient le fond du terrain, le trou sera agrandi et rendu plus profond. Rapportez des terres si le sol en refuse. 
Pour n'avoir pas pris ces mesures, il arrive souvent que des plantations considérables manquent entièrement. Mais pour qu'elles soient bonnes, avant de planter, il faut défoncer le terrain de deux pieds, et pour recevoir le gazon, défoncer de dix-huit pouces de profondeur.

Les arbres verts de même espèce seront plantés par massifs, en observant toujours de placer les grands au milieu. Ne mettez jamais, ou du moins très-rarement, des arbres isolés dans la pelouse. Dans le cas où cela arriverait, choisissez de préférence des arbres à fleurs ou un tulipier, cet arbre devant toujours être planté isolément, ou bien encore quelques arbres verts. Mais, je le répète, ces sortes de plantations, qui exigent beaucoup de raisonnement et d'habitude, ne doivent être entreprises qu'après avoir été mûrement méditées. Surtout ne plantez les arbres verts que dans un terrain léger.

On ne saurait trop donner de détails pour les plantations : je répète qu'il ne faut pas planter dans une terre trop humide, et jamais dans l'eau. Les arbres aiment aussi la 
solitude ${ }^{x}$; en roulez-rous la plus grande preure que les tilleuls du Palais-Royal ${ }^{2}$ et les arbres du boulevard du Temple? Les premiers, au mois de juillet, soni à leur automne, et l'air épais qui les entoure les tue. Le mauvais air exerce sur les árbres le même empire que sur les hommes. Les arbres aiment la fraîcheur, mais jamais l'eau stagnante. Au boulevard, les urines croupissent au pied des arbres, qui n'ont pas de plus grand ennemi ; en outre, la populace les secoue, les tourmente, et l'air impur qu'ils respirent les anéantit. Ces diverses causes sont plus que suffisantes pour les faire végéter, et ensuite mourir.

L'autorité n'esti pas secondée dans ces sortes de plantations des boulevards, que personne ne surveille d'assez près : il faut une surveillance sévère, autrement point d'arbres, qui sont le plus bel ornement des bou-

"Yoyez le chapitre II, page 15 : “ La nature, dit un de nos écrivains, fuit les lieux fréquentés, elc. »

- Les ormes réussissent mieux dans les jardins que les tilleuils. 
levards. Empêchez les gens de boutique de poser contre les arbres leurs volets et contrevents et des écriteaux, enfin mille choses qui seconent et écorchent les arbres, et finissent par les faire mourir.

Le tableau d'une composition bien ordonnée dirige non-seulement le choix des arbres, mais il doit encore les indiquer. Il faut généralement de grandes masses, parce que l'effet de la perspective l'exige. Dans un parc immense il faut déployer un grand caractère; les plantations doivent être proportionnées à son étendue. Au moyen de ces grandes masses plantées de même espèce d'arbres dans un parc, l'effer des nuances se fera voir facilement; ce que vous n'obtiendrez jamais par les espèces d'arbres mélangées, excepté dans un petî̀ jardin où les objets sont plus rapprochés : c'est alors que les reflets de lumière offriront un effet complet. Fiez-vous à la nature; elle en fera beaucoup plus que l'artiste avec bien moins de peine: mais, au préalable, il faut avoir soin d'élever et bomber ses massifs arant de planter, pour donner plus de caractìre et de mouvement aux plantations. 
A tous égards, une plantation bien combinée est'la beauté d'un parc.

Si l'on désire employer des arbres exotiques, il faut les placer isolément et avec art, et suivant le terrain qui peut leur convenir.

Ainsi, tous les arbres des forêts, des montagnes, des vallées, ont un emploi qui leur est propre, et dont on ne doit pas les éloigner.

Connaissez donc l'emploi de ces différens verts, Brillans ou sans éclat, plus foncés ou plus clairs; C'est par ces tons cliangeans qu'au sein des paysages Vous pouvez avec choix varier vos ombrages.

(Jardins.) 
Dans l'ensemble d'une composition, la direction des eaux doit être ${ }^{*}$ dictée par la forme de leur placement, par la pente générale du tcrrain qui en indiquera la direction, enfin par l'effet qu'elles doivent produire dans le tableau général. Leur étendue sera proportionnée à l'espace qu'elles doivent parcourir, et où elles doivent figurer. Une large rivière devient inutile dans un bois; elle est nécessaire dans une prairie.

La quantité des eaux, leur chute, la pente du terrain, déterminent la forme que doivent avoir les cascades. Plus on a de pente et de distance à parcourir, plus on peut donner de mourement aux eaux, que l'on ob- 
tient abondamment en les faisant précipiter d'une manière violente. Ces sortes dẹ cascades forment une masse d'écume blanche sous les chutes qui tombent en bouillonnant. C'est pour cela que ce genre de cascade produirait un bon effet en se précipitant sur dès rochers. Néanmoins, si la situation des eaux obligeait à les employer dans le bois, il serait nécessaire de combiner les effets de lumière qui éclaireraient ces cascades, afin de distribuer les plantations de manière à ne répandre qu'un demi-jour sur ces eaux trop blanchâtres; car si l'on place les cascades en avant d'un fond noir, l'effet en sera manqué, et leur couleur, d'un blanc mat, formerait tache dans le paysage.

Les cascades offrant des lames d'eau peu épaisses, mais bien transparentes, laissent apercevoir en dessous, et dans leurs intervalles, les fonds mousseux et verdâtres qu'elles arrosent. Celles de cette espèce reçoivent toujours un ton de couleur locale qui se lie parfaitement avec les objets dont elles sont environnées. C'est par cette raison que les cascades de ce genre snnt préférables, 
sous tous les rapports, à ces chutes d'eau à grand fracas : ces dernières commencent par effrayer, et finissent par étourdir. Cependant la grande chute d'eau forme un accident assez heureux, surtout si elle n'est pas trop rapprochée du manoir; car le bruit qui en résulte devient insipide, monotone et très-fatigant.

Il convient de faire couler les eaux rapides au pied des montagnes escarpées; le plus petit ruisseau qui murmure sous des ombrages et coule dans les vallons resserrés, produit toujours un effet intéressant.

La rivière doit naturellement serpenter, soit au pied des coteaux, soit dans les prairies, dont elle entretient la verdure, et dont elle fait le charme. L'artiste doit combiner l'éloignement de la rivière et l'étendue du terrain qui la borde; il doit se rendre compte du volume d'eau que les orages d'été ou les pluies u'hiver peuvent produre, afin de prévenir les accidens qui pourraient en résulter; il doit enfin pratiquer des décharges par lesquelles le trop-plein prendra son cours daus de pareilles circonstances. Au moyen de ces précautions, vous éviterezune foule d'incon- 


\section{7}

véniens graves et fàcheux qui peuvent se présenter sous mille formes différentes.

On obtient des résultats en sens contraire dans une rivière factice. Loin d'avoir des débordemens à craindre, cette rivière tarira pendant les grandes chaleurs, et présentera des bords isolés et arides. Le compositeur instruit ne peut adopter ces machines artificielles qui, revenant à des sommes considérables, ne causent que des peines et des regrets. Je ne parle de cette chose que par suite d'une longue expérierce. Mais le propriétaire tient à une rivière factice, qu'il prétend être nécessaire : ayez soin alors d'en dissimuler, d'en cacher même le commencement et la fin au moyen de plantations bien conçues, ou par des rochers bien ajustés. Jé suppose que le terrain, vous favorisant, conserve une partie de l'eau que cette rivière contiendra; mais vous aurez le désagrément de la voir sale, couverte de feuilles et de plantes aquatiques. Des eaux stagnantes ne produiront jamais l'effet des eaux limpides. Je suppose maintenant que le terrain ne soit pas de niveau pour faire serpenter la rivière; 
88

que de peines et de contrariétés à éprouver? que de dépenses pour les nivellemens et les frais de terrasses! Et pourquoi? pour un caprice, pour une chose désagréable et laide, enfin pour ce que l'on peut appeler une crapaudière.

Les grandes pièces d'eau, les lacs, les étangs sont les objets qui présentent le plus de facilité dans la composition. L'artiste est entièrement le maitre, d'après le plan général, de disposer de leur forme, de leur étendue, des ornemens placés sur les bords. La chute d'un trop-plein peut devenir un avantage par le moyen d'une ou de plusieurs cascades, ou pari une rivière de décharge, laquelle donnera suite à la première cascade, et renouvellera continuellement l'eau du lac. Ciette rivière qui, en traversant un lac, sert à l'alimenter, peut présenter', dans son ensemble, des sinuosités agréables et piquantes. On peut multiplier les accidens de cette rivière, qui fuit sous l'ombrage mystérieux des bois. Cette situation est bien préférable et bien plus intéressante que celle d'une rivìre qui sex. pente au milieu de la plaine. 
Dans la composition, on appelle lac une pièce d'eau dont l'étendue est de plusieurs arpens, et laquelle est alimentée par une rivière ou par des sources qui la renouvellent sans cesse. L'étang présentel'idée d'un amas d'eaux stagnantes.

Après avoir traité de la partie des eaux, qui peuvent se composer suivant la localité et le talent de l'artiste; après aroir parlé des eaux vires et des eaux stagnantes, nous pensons que le lecteur verra avec plaisir la description d'une cascade fameuse qu'il n'est pas au pouvoir de l'homme d'imiter, de changer ou de détruiré. 
Parmi les objets de la nature végétale qui embellissent un pays, lui donnent de la vie et du mouvement, on doit particulièrement distinguer les eaux. Par le bruit de leur chute, par leur transparence, par l'action de leur courant, que l'imagination prolonge encore lors même qu'elles échappent à la rue, les eaux animent un paysage et lui donnent de la vivacité. Si, d'un côté, la possession d'une eatu, soit naturelle, soit factice, présente de grands avantages, d'un autre côté, cette possession expose à de graves inconvéniens. Pour en avoir, il en faut de belles; sans cela il vaut 
beaucoup mieux s'en passer. L'idée de monvement, cansée par la progression du cours des eaux, peut se suppléer par les différentes formes du terrain. Je sais que, dans les vallons, le cours des eaux excite toujours l'imagination à le suivre, dans l'espoir d'y rencontrer des objets nouveaux. $\mathrm{Si}$, dans la composition, les formes du terrain, les masses des plantations, les fuyans de la perspective sont ménagés de manière à ce qu'ils puissent rendre dans un degré de perfection les effets de la lumière, qui est elle-mème un fluide encore plus rapide et plus diversement coloré que le fluide aquatique, on sera tout surpris de la variété continuelle que jettera le cours de la lumière dans le paysage, surtout si l'on y joint quelque mouvement, tel que celui des passans, celui des animaux.

On a souvent lieu de s'applaudir de ne pas s'exposer en pure perte aux dépenses et aux tourmens occasionnés, toujours très-mal à propos, par les choses forcées ou trop multipliées. Combien Delille a eu raison lorsqu'il a dit : 
N'allez pas resserrer dans des cadies étroits

Des rivières, des lacs, des montagnes, des bois...

Ces effets variés sont les trésors de l'art, Que le goût lui défend d'employer au hasard. 


\section{GHAPITRE XII.}

DES FAURUUES ET DES CONSTRUCTIONS.

IL est fort inutile d'indiquer en détail les différens genres de fabriques ₹ $q u$ 'on peut employer dans les paysages; leur choix dépend absolument de la nature de chaque situation, et de l'analogie avec les objets environnans. En examinant ce qui peut contribuer à fixer les idées sur l'art et la composition des fabriques, on a lieu d'être surpris que des gens habiles, et sur les connaissances desquels il était permis de compter, se soient aussi prodigieusement écartés des vrais principes qu'ils

* Fabrique est le motigénériqué employé par les artistes pour désigner tohte espèce de bâtimens et de constructions. 
ne devaient jamais abandonner. Le motif qui, jusqu’à présent, paraît avoir retardé les progrès du goût dans les bâtimens, et surtout dans les jardins, c'est le mauvais principe de prendre l'effet du tableau dans le plan géométral, au lieu de prendre le plan géométral dans l'effet du tableau.

Je vais donc développer les vrais principes qui doivent servir de base à toutes les constructions.

Ces principes, desquels on ne doit ni ne peut s'écarter, sont au nombre de cinq : $1^{\circ}$ la convenance locale; $2^{\circ}$ la convenance particulière; $3^{\circ}$ la distance du point de vue; $4^{\circ}$ le

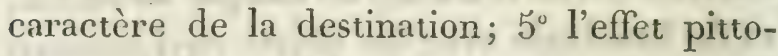
resque de l'ensemble, relativement à la masse, au genre du bâtiment, et aux objets qui l'environnent.

La convenance locale est toujours déterminée par la situation et par l'emplacement que doit occuper la maison. Une fabrique placée sur une montagne ou dans un fond, dans un grand espace ou dans un petit, ne doit pas être construite sur le même plan.

La masse extérieure et ses distributions, 
l'état ou le genre de vie et d'occupation du propriétaire, doivent dicter les principes de la convenance particulière. L'habitation d'un particulier ne doit pas présenter la magnificence d'un palais; de même que le palais ne doit point avoir la pesanteur d'un corps de caserne ou d'une manufacture.

Je me plais à rendre justice aux talens, aux connaissances de M. Gérardin, dans son excellent ourrage sur les moyens d'embellir la nature, qui m'a beaucoup servi. Cet auteur développe ses moyens avec des principes fondés sur la vérité. Mais je ne puis partáger son opinion au sujet des points de rue : il prétend qu'il faut élever et grossir un bâtiment suivant son éloignement.

Je conviens que la distance du point de vue varie tellement les proportions, qu'à trois ou quatre cents toises, il est impossible de pouvoir distinguer l'ornement d'une façade dans ses détails. Mais je demande où l'on en serait s'il fallait grossir les détails pour satisfaire la vue, lorsqu'on est placé à longue distance?

Je ne saurais être de cet avis, et je viens d'en exposer les raisons. Une maison doit ètre 


\section{6}

construite d'après la fortune et l'état du propriétaire. Je suppose qu'un particulier, favorisé par la localité, aurait devant sa maison la faculté d'en prolonger la vue; ce particulier serait donc obligé de faire bâtir un palais soutenu par d'énormes colonnes, pour être aperçues de plus loin. Ce système vicieux ne peut convenir à l'homme qui jouit d'une fortune bornée; il ne peut se ruiner pour satisfaire la vue des passans, et son habitation sera proportionnée à ses moyens, à ses goûts, à ses habitudes, enfin au tableau général de son jardin. Les personnes trop éloignées pourdistinguer les objets trop élevés, et qui ne sont point à leur portée, suirront l'avis que donnait le célèbre architecte Ledoux. Il venait de construire le bel hôtel Thélusson, et de prétendus connaisseurs lui faisaient des reproches au sujet de l'emplacement de l'arcade ' qui sert d'entrée. Il leur répondit: "Ceux qui se plaindront de ce que le cintre " de l'arcade masque la vue des bâtimens, se

Cette arcade est démolie. 
" donneront la peine d'en approcher. L'ar" cade seule est faite pour être vue du boule" vard, et non des appartemens de l'hôtel." La magnificence et les chefs. d'ourre des arts doivent être employés dans les palais des princes. L'élégance convient aux habitations des dames; la simplicité, la gentillesse, la propreté doivent appartenir aux maisons des particuliers, et doivent se retrouver surtout dans les maisons de campagne. Les édifices publics doivent tous aroir un caractère qui leur est propre, suivant l'emploi auquel ils sont destinés. Cr $_{i}$ style noble, sévère et imposant, doit se faire remarquer dans le temple de Thémis. De grands escaliers, de larges portiques doirent distinguer l'endroit où le peuple se rassemble pour entendre prononcer les arrêts. 


\section{CHAPITRE XII.}

DU 'TON DES PAYSAGES SUIVANT LES DIFFÉRENTES HEURES DU JOUR.

C'sst du contraste de la lumière que tous les objets de la nature reçoivent la couleur, la variété, et surtout ce charme secret qui commence par plaire et finit par séduire : de là vient que chaque objet, pour ainsi dire, a successivement son coup de jour.

Toutes les choses d'un grand relief, comme les masses d'arbres forestiers, les escarpemens des rochers, l'élévation des montagnes, la profondeur des vallons, conviennent à l'exposition du matin. C'est au lever du soleil que ses longs rayons s'étendent horizontalement sur la surface de la terre. Les reflets ou les oppositions que la lumière reçoit par les dif- 
férens mouremens du terrain; servent à détacher fortement tous les plans de la perspective. Alors les longues ombres et les rayons de lumière se jouent d'une manière merveilleuse sur les tapis de verdure brillans de rosée, tandis que les têtes altières des vieux arbres, les sommets des montagnes, la cime des rochers, se détachent fortement sur les douces couleurs de l'aurore. C'est donc dans l'importance des masses, dans la disposition des objets rapprochés, dans les belles oppositions d'ombre et de lumière, surtout dans le plus grand soin à perfectionner les derans du tableau, que consistent principalement l'intérèt et la beauté du paysage à l'exposition du matin.

L'éclat et la chaleur du soleil élevé sur l'horizon ne peuvent convenir, au contraire, qu'aux objets qu'il est nécessaire de faire briller séparément: telles sont les eaux rapides, les fabriques agréables. C'est toujours dans une enceinte peu étendue qu'il convient de choisir et de composer les paysages du midi. tant pour offrir, par la proximité des ombrages, les asiles contre la chaleur, que pour 
appuyer l'oeil fatigué, qui ne pourrait longtemps soutenir l'éclat éblouissant d'un foyer de lumière trop étendu.

Mais la fraîcheur du soir vient répandre le charme de sa douce teinte; elle annonce les heures du plaisir et du repos. C'est alors qu'il existe dans toute la nature une harmonie sublime de couleurs, et que la vue aime à se promener tranquillement sur un grand pays. Les masses d'arbres pénétrées du jour, sous lesquelles l'oeil entrevoit une promenade agréable; de vastes surfaces de prairies, dont le vert est encore adouci par les ombres transparentes de la soirée; le cristal pur d'une eau calme et limpide, dans laquelle se réfléchissent les objets voisins; des fonds légers d'une forme donce et vaporeuse : telles sont les choses qui conviennent le mieux à l'exposition du soir. Il semble, dans cet instant agréable, que le soleil, prêt à quitter l'horizon, se plaise à confondre, pour ainsi dire, le ciel et la terre, et ne faire des deux qu'un seul tout; car c'est au ciel qu'appartient la plus grande partie des tableaux du soir. C'est en ce moment que l'homme sensible aime à contempler cette 
variété infinie de nuances douces et touchanres dont le ciel et les fonds du paysage s'embellissent dans ces instans délicieux de paix , de calme et de recueillement.

Quant à ces beaux clairs de lune, à la tendre pâleur de cette lumière mystérieuse que répand l'astre de la nuit, combien elle sied à la nature! Mais c'est aux femmes qu'il appartient de faire la description d'une nuit d'été. Le sentiment leur donne naturellement ce goût sûr, ce tact délicat et fin, que l'art cherche en vain à imiter, et qu'il ne pourra jamais atteindre; il leur inspire mieux qu’a personne la disposition des scènes où doivent principalement régner les doux plaisirs de la tendresse, le charme de la volupté et l'ivresse de l'amour.

Le sentiment consiste dans la manière de voir les choses, comme la grâce dans la rnanière de les faire. C'est par cette raison que les femmes ont naturellement plus de goût et plus de grâce, parce qu'elles sentent plus vivement les émotions, qu'elles ont plus de sensibilité dans les organes et plus d'agrément dans les formes. Aussi, lorsqu'une femme, 
non de ces évaporées qui, gâtées par l'empire de la mode, sont devenues minaudières et maniérées, mais une femme sage et bien élevée, donne son avis, son premier mouvement, dicté par la nature, est presque toujours plus juste qu'une longue suite de raisonnemens souvent dictés par l'intérêt ou par les préjugés. 


\section{GHAPITRE XIV.}

DE L'EFFET DES PAYSAGES SUR LES SENS, ET MÊME SUR L'AME.

L'ACtion des fluides sur les solides est le balancier de l'univers; tout accroissement physique et moral vient du rapport des objets entre eux. Plus la somme des rapports connus sera grande, plus il y aura d'accroissement moral et d'industrie. Voilà pourquoi il se trouve plus de différence entre l'homme en société avec l'homme brute, que de ce dernier avec l'animal. Dès-lors, en multipliant à l'infini les rapports que chaque homme aperçoit, avec les rapports aperçus par les hommes de tous les temps, l'imprimerie doit considérablement étendre les connaissances humaines, puisqu' elle nous met en rapport avec 
tous les siècles et avec tous les pays. C'est par l'émotion de l'attrait ou de la répugnance que les sens indiquent la convenance ou la disconvenance des objets. Isa corde pincée plus ou moins fortement produit plus ou moins de vibrations : ainsi, la fibre, plus ou moins ébranlée, développe et fait naître les idées ou les réminiscences, le sentiment ou la douleur.

Puisque toute idée vient originairement des sens, qu'il me soit permis de jeter un coup d'oeil rapide sur ces premiers instrumens, ces premiers moteurs de l'industrie. Il est d'autant plus nécessaire de savoir exercer les sens, qu'ils servent à préparer les sentimens de l'âme, et à la mettre en telle ou telle disposition. Si le microscope a considérablement étendu l'organe de la rue, puisse le flambeau de la raison et du goût, éclairant nos idées sur les vrais besoins, sur les plaisirs vrais, nous faire apercevoir ces fils délicats, à l'extrémité desquels tiennent le bien-être et le bonheur parfait!

Le toucher et le goût ne sont émus que par le contact immédiat de l'objet présent; l'o- 
dorat, à une certaine distance, aspire les vapeurs émanées de la transpiration des corps; l'ouie, de plus loin encore, est frappée par l'impulsion de l'air ou de l'atınosphère agitée. Mais la vue est, de tous les sens, le plus subtil, et celui dont les perceptions deviennent les plus promptes et les plus vires : vous en sentirez bientôt la raison, si vous réfléchissez que c'est du fluide rapide de l'électricité ou de la lumière qu'il les recoit directement. "Les tourbillons d'éther, ou l'électricité, dit M. Gérardin, sont le principe de la flamme, et par conséquent de la lumière; comme le frottement, par l'interposition des milieux ou la résistance de tout solide contre le fiuide qui le pénètre, ou qui en est réfléchi, est le principe de la chaleur. Pour rous en convaincre, voyez les miroirs ardens et les fermentations chimiques. "Les idées que la rue communique à l'âme dérivent des effets de la lumière, dont la réflexion fait apercevoir les objets sous les couleurs ou des formes plus ou moins agréables, plus ou moins laides. De ce résultat naît l'impression de la laideur et de la difformité, ou ce charme de la beanté qui 
prévient favorablement, et qui agit d'une manière si prompte.

Il est deux sortes de beautés dont l'attrait est d'un genre bien différent: je veux parler de la beauté de convention et de la beauté pittoresque.

La première, assemblage de formes qu'on est convenu de trouver belles, varie selon les temps et selon les lieux; fût-il composé des formes les plus agréables, ce genre ne consiste que dans la régularité des contours et dans l'exactitude du trait; on peut dire seulement qu'il présente une belle effigie, ou la beauté immobile, celle que les gens froids dessinent avec cette perfection vraiment glaciale, et qu'ils admirent stupidement avec de grands yeux et la bouche béante.

La seconde est la beauté par excellence; elle est celle des Grâces, et servirait à les peindre. La beauté pittoresque, toujours animée, donne du mouvement, de l'expression, du caractère, de la physionomie et du coloris à tous les objets : c'est la beauté que recherche l'homme de génie; il la dessine, l'embellit, et l'homme sensible l'adore. 
Dans une situation pittoresque, où la nature développe en liberté toutes ses grâces, au charme que les yeux éprouvent par l'effet d'un tel paysage, se joignent encore d'autres émotions qui opèrent en même temps sur le reste des sens : tels sont l'odeur suave de l'herbe nouvelle, celle de la feuille printanière, ou de la fleur qu'épanouit l'électricité vivifiante d'une pluie chaude, le doux murmure des ruisseaux qui serpentent dans la prairie, qui en rajeunissent et fortifient la serdure, les concerts enchanteurs des oiseaux du bocage. L'ouie et l'odorat, moins prompts à saisir les objets que la vue, mais aussi moins distraits et plus profondément affectés, concourent puissamment à faire passer dans l'âme les impressions d'une rolupté douce et pénétrante; mais la vue, par l'effet de la distraction, se trouvera isolée de cet intéressant tableau; plus la situation sera pittoresque, plus le paysage sera solitaire, et plus les impressions de l'âme seront fortes et profondes.

C'est de ces impressions que naquirent la peinture et la poésie; ces douces émanations 
animent le génie et montent ses ressorts. Une fois animé par ces objets toujours admirables, l'homme sensible voulut exprimer ce qui l'avait si fort ému. C'est dans une situation pareille que la poésie pastorale a placé ces touchantes peintures du premier bonheur des hommes et des plaisirs toujours purs de la vie champêtre. Rencontrez-vous quelque retraite où le cordeau et le fatal croissant n'ont pas encore pénétré, l'esprit est charmé de retrouver l'image de ces descriptions que Virgile et le chantre des jardins ont tracées en vers harmonieux et si bien cadencés. L'imagination, la plus vive et la plus ardente des facultés de l'entendement humain, place aussitôt dans ces beaux lieux les divers attributs consacrés par les anciens. Ici, le dieu Therme; à côté, le temple dans le bois sacré ; là, des inscriptions sur les vieux chênes couverts de lierre et de mousse; des urnes dans les bocages, des tombeaux sur la voie, des cabanes sous les vergers, des groupes de bestiaux dans la prairie, le chalumeau du jeune pàtre, les concerts et les danses des berger's auprès des fontaines; cnfin chaque bachelette au gentil 
corsage parait la nymphe des eaux ou la divinité protectrice de la forêt.

Tel est l'effet du paysage poétique, soit qu'il soit offert par la nature, soit qu'il ait été reproduit par le compositeur habile.

La situation pittoresque enchante les yeux; mais la situation poétique intéresse le coeur et l'esprit, en retraçant à la mémoire de ces scènes délicicuses que j’appellerais arcadiennes. Mais si l'une et l'autre de ces compositions peuvent être retracées par le peintre et par le poète, il est encore une situation que la nature seule peut offrir: c'est la situation romantique, laquelle, au milieu des plus merveilleux objets de la nature, rassemble les plus beaux effets de la perspective pittoresque, enfin tout le charme de la scène poétique, sans être jamais farouche ni saurage. La situation romantique doit être tranquille et solitaire, afin que l'âme n'éprouve aucune distraction, et qu'elle puisse se livrer entièrement à la douceur d'un sentiment profond.

A travers les ombrages rembrunis des sapins et des pins, arbres consacrés à la tristesse. et au sentiment; à travers les amphithéâtres 
de rochers escarpés, une nappe d'eau limpide descend de cascade en cascade, et se rend dans la vallée pour former un lac situé entre une chaîne de majestueuses montagnes. La transparence des eaux permet à l'oeil d'en mesurer la profondeur, d'apercevoir les jeux de la truite, la marche tortueuse de l'anguille, d'admirer les brillantes couleurs de la dorade sur des fonds de rocs et de marbres de toutes les couleurs. Une île s'élève au milieu des eaux, comme pour servir d'asile aux jeux et aux divertissemens champêtres; elle forme des bocages charmans, et des ombrages placés de distance en distance entretiennent la fraîcheur apportée par les eaux, et défendent contre les rayons irrités d'un soleil brûlant. Le berger, faisant pâturer ses troupeaux, chante ses amours, et, par ce moyen, calme l'ennui de l'absence. La fraise rongit la pelouse émaillée de toutes les fleurs des champs; l'iris, le muguet, la violette, le géranium des prés exhalentleurs parfums: D'un côté, d'heureux époux que l'intérêt n'a point unis, sont assis au milieu de leur famille, et prennent un repas délicieux, que le travail, l'appétit et le 
parfait bonheur assaisonnent. D'un autre côté, les filles du hameau, accourues au son du crincrin discordant, foulent l'herbe et font admirer leur légèreté. D'autres ajoutent encore à l'effet de ce spectacle intéressant : un corset blanc, image de la candeur de leur âme, laisse apercevoir une taille bien proportionnée; de longues tresses flottent sur leurs épaules; un chapeau de paille, placé sur le côté, et orné des plus jolies fleurs de la saison, est la parure d'un visage riant, où brillent l'éclat de la santé et la sérénité de l'innocence; leurs roix douces et sonores font entendre la chanson qui rappela l'aventure arrivée dans le château voisin. Elles chantent naïvement le travestissement du comte Orry, s'attendrissent sur les malheurs du châtelain de Coucy, et racontent les exploits et les prouesses des paladins français; souvent elles y joignent le récit des bienfaits de la fée qui, dans les temps anciens, habitait le manoir féodal, et protégeait tous les habitans; ou bien les ravages du loup-garou, les attentions du follet, et tous les contes appris dans les veillées. 
La rivière, en sortant du lac, s'enfonce dans us vallon étroit, resserré et profond; de hautes montagnes et des rochers sourcilleux, couronnés d'arbres, semblent séparer cetasile du reste de l'univers. La chèvre indocile, après aroir brouté le thym et le serpolet qui couvrent les pelouses, s'élance de rocher en rocher, s'avance près des ravins profonds, et, placée sur le précipice, elle semble ignorer le danger de sa situation, dont la vue seule fait frémir. Sa sécurité, dans un lieu désert, doit rassurer sur la crainte des animaux voraces, et bannit de la pensée un abandon total, en annonçant le voisinage de l'étable et de l'habitation, où la ménagère qui la trait prépare ses fromages.

Après quelques chutes précipitées, et occasionnées par l'opposition des rochers qui se croisent sur son cours, la rivière trouve enfin, dans cet étroit vallon, un espace où ses eaux écumantes et contrariées peuvent se reposer. Leur chute impétueuse repousse l'écume sur les bords, pour laisser apercevoir les reflets argentés des vagues et des ondes. Un bois de chênes antiques s'avance et se prolonge sur 
les bords de la rivière devenue tranquille. Sous leur ombre paisible et mystérieuse est un tapis de mousse. Le cristal des eaux limpides et peu profondes retrace l'image des branches les plus élevées; cette espèce de miroir laisse apercevoir les soins du triste ramier auprès de sa compagne, ou la faurette qui apporte la pâture à ses petits, et des oiseaux qui construisent leurs nids. L'éclat des eaux qui coulent sur un sable fin de toutes les coutleurs, invite à s'y plonger et à se rafraîchir dans leur courant. Sur les bords de la rivière croissent les plantes aromatiques, les herbes salutaires, dont l'odeur balsamique, jointe à l'odeur de la résine des pins odorans, parfume l'air et dilate les poumons. A l'extrémité du bois, des rignes chargées de raisins s'élèvent dans les arbres, et laissent entrevoir une cabane. Le toit couvert de chaume y met à l'abri, sous une grande saillie, les divers ustensiles du ménage rustique. La cabane est formée de planches bien assemblées, et les joints sont remplis par de la mousse. Une vaste treille forme le péristyle et les portiques de cette habitation. Si l'architecture n'a pointdé- 
ployé son luxe et sa richesse pour la décorer, en revanche, et comme par compensation, l'intérieur en est plus propre que le palais d'un prince. Une table est simplement servie ; les mets n'y sont pas apprètés avec recherche, ni arec les épices de l'Inde, mais ils sont

- d'une qualité exquise, d'un goût pur et salutaire. Cette retraite, temple de l'amitié et de la vertu, estl'asile du bonheur. On y éprouve toute la force de cette analogie qui tient le milieu entre les charmes physiques et les impressions morales; on y retrouve cette douce rêverie, besoin pressant de l'âme sensible. Ce lieu invite à renir le visiter souvent, parce que le coeur y ressent toute la vérité, toute l'énergie de la nature.

Voilà à peu près le genre des situations romantiques; il est vrai qu'on en trouve rarement de l'espèce de celles que je viens de décrire.

C'est ainsi que des lieux habités par le faste, Le chantre des jardins passe avec volupté Aux lieux où se complaît la médiocrité.

Eh ! quel charme, en effet, sur un terrain fertile, D'unir innocemment l'agréable à l'utile! 


\section{5}

De l'art décorateur c'est l'emploi le plus doux :

Je vais donc à ce soin me dévouer pour vous.

Citoyens vertueux qui, fuyant de la ville

Les pénibles honneurs et le luxe servile, Avez brisé vos fers, et, libres dans vos cluamps, Livrez enfin vos jours à des travaux touchans, Que vous êtes heureux! que je vous porte envie!

Vous seuls vous connaissez les vrais biens de la vie;

A vous seuls appartient la force et la santé,

La droiture du cœur et la sérénité,

Tout ce qu'à l'homme, enfin, laissent de jouissance

Et la terre et le ciel. Amis de l'innocence, Venez; et s'il est vrai que, loin dè les flétrir, Souvent un art discret les fasse mieux chérir, Confiez-lui vos champs; sous ses mains, avec graàce, Les objets variés que votre ferme embrasse

Prennent d'un beau tableau les tons ingénieux. 


\section{GHAPITRE XV.}

DES MOYeNS DE RÉUNiR L'AGRÉABLe A L'Utile.

J'Ame à dire, et je ne saurais assez répéter, que le système de la nature consiste tellement dans l'unité de principe et dans l'union des rapports, que tout ce qui pourrait contribuer à l'éloignement de ces principes tendrait indubitablement à une destruction particulière dans l'ordre de la végétation. L'agréable, qui consiste dans la perfection de tous les rapports et des formes convenables à chaque objet, est absolument nécessaire à l'accroissement comme à l'utile; car il est impossible d'altérer l'un sans nuire essentiellement à l'autre.

C'est donc dans une végétation vigoureuse et active que consiste le principal agrément du paysage qui entoure l'habitation; et si l'on 


\section{7}

veut procurer de la jouissance aux propriétaires, il faut chercher les moyens les moins recherchés comme les agrémens les plus con-venables.

La substitution de l'arrangement simple ì l'arrangement forcé doit, en ramenant à la belle nature, contribuer à l'accroissement de la végétation, aux progrès de l'agriculture, à la multiplication des bestiaux, surtout à une manière de gérer plus efficace, plus salutaire aux campagnes. Elle assure la subsistance de l'homme, dont les occupations réunies servent à instruire, à défendre et à protéger la société.

Ramené dans les campagnes, où il jouit d'un air pur, l'homme de bien ne tardera pas à plaindre le sort des malheureux habitans des villes; il gémira sur le sort de ces êtres rqui respirent continuellement un air chargé de miasmes pestilentiels : ce spectacle douloureux attristera sa pensée, surtout s'il vient à rencontrer une troupe joyeuse de jeunes paysans, dont la mine vermeille, les formes musculeuses, la santé, la joie, présentent une si grande opposition arec la mine hlême, le 
teint plombé, et la taille rabougrie de l'enfan du citadin. Pour dissiper sa douleur, l'homme de bien, après aroir parcouru les paysages pittoresques, asiles de la philosophie, et qui font naître les pensées grandes, généreuses, sublimes, viendra se reposer d'abord à la ferme, puis au village. Il y trouvera partout la santé, la propreté, l'aisance et le contentement : spectacle aussi doux que touchant pour l'homme sensible.

Exposons maintenant quelques idées sur l'économie rurale; elles sont le résultat de plusieurs années d'expérience.

Il est à présumer que les premiers agriculteurs établirent au milieu de leurs champs le manoir, demeure de la famille : cette disposition, la seule convenable à l'ordre de la culture, épargne le temps, les allées et les venues, les transports inutiles. En mettant les travaux, ainsi que la conservation des produits, plus à portée du manoir, cette disposition n'oblige pas, afin de réparer le temps perdu, à chercher la vitesse dansles animaux, dont l'acquisition et la nomriture deviennent plus coûteuses. 
En diminuant d'un côté les travaux, les fatigues, les charrois, les dépenses inutiles; en multipliant d'un autre côté les produits par l'emploi des jachères, par la vigilance du maître, par l'augmentation des bestiaux, par la plus grande quantité des engrais, il est donc prouvé que les bâtimens d'exploitation. placés au milieu de la ferme et sous les yeux du maitre, doivent contribuer nécessairement à la meilleure tenue des terres, à leur amélioration, au bénéfice du laboureur, et enfin à l'avantage de la société.

Je citerai à cet égard des exemples bien frappans au sujet de cette opinion. Dans la Toscane, les stériles Apennins ont été fertilisés, et depuis que la charrue a déchiré le sein de leurs terres, elles ont rendu avec prodigalicé le grain qui leur avait été confié : des pampres verdoyans couronnent ces coteaux devenus depuis si célèbres. Dans les Alpes, de superbes jardins ont été plantés; ils s'avancent jusqu'au pied des neiges et des glaces qui ne fondent jamais, et qui semblent devoir ètre éternelles. Dans le terrain sablonneux ou plutôt graveleux de l'Angleterre, les progrès 
rapides de l'agriculture depuis un siècle présentent partout l'image de la fertilité, de la difficulté vaincue, et militent en faveur de l'opinion que j’ai émise.

Pour les terres éparses et subdivisées, il est indispensable de rappeler les cultivateurs auprès de leurs champs, ou de les en rapprocher autant que possible. Cette précaution est aussi importante pour l'intérêt général que pourl'intérêt particulier. Quelques personnes peu raisonnables se sont élevées contre cette mesure salutaire, et l'ont regardée comme une espèce d'attentat à la propriété, une sorte de violation de la liberté. Mais depuis long-temps on abuse de ce mot sacré, on le confond avec le caprice. 


\title{
CHAPITRE XVI.
}

\author{
DESCRIPTION D'ERMENONVILLE.
}

(Extrait de la Théorie des Jardins, par Mores, architecte.)

LE jardin dont j'ai nommé le pays suppose, pour le composer avec succès, une grande conception, et des talens supérieurs pour l'exécuter. Il est à l'art des jardins ce que le poème épique est à celui de la poésie. L'artiste qui se livre de préférence à ce genre est autant au-dessus de celui qui s'attache aux trois autres, que le peintre d'histoire est audessus du peintre de genre. J'ai déjà fait observer que le caractère du pays est la variété : ce genre de jardin peut présenter, en effet, tous les tableaux qu'offre la nature; il en admet tous les accidens; il se prête à ce bear 
désordre qui la caractérise; comme elle, il se plaît dans les contrastes: comme elle, il est susceptible d'une infinité de modifications et de combinaisons : ouvert ou resserré, montueux ou de niveau, sec ou aquatique, désert ou peuplé, le pays est frais et riant, ou sombre et aride; grand et imposant, ou simple et naif; inculte et pauvre, ou productif et riche. C'est de ces qualités qu'il tire son caractère; et, selon celui qui prédomine, le pays sera champêtre, cultivé ou sauvage: ce qui forme ses principales divisions.

Le pays champêtre peut être plus ou moins agreste; mais il suppose toujours de la fraîcheur et de la simplicité dans ses tableaux. Ses accidens n'ont rien de surprenant ni d'extraordinaire; ses pentes sont peu tourmentées; sa verdure est riante et animée; ses eaux coulent sans violence, mais non pas toujours sans activité. Ce genre aime les rallées couvertes de prairies et les coteaux ombragés; il se plaît parmi les saules et les peupliers, les arbres gais et légers. Il exige peu de fabriques; celles qu'il adopte le plus volontiers sont les hameaux et les chaumières. 
Le pays champêtre est le plus aimable de tous; personne n'est insensible à ses charmes : la douceur de ses effets, la fraîcheur et la simplicité de ses grâces, plaisent généralement. On ne peut rien dire de mieux que la description qu'a faite l'auteur de la Théorie des jardins et du beau parc d'Ermenonville, qui fait l'admiration des étrangers. Nous allons émettre notre opinion sur ce parc célèbre. Au surplus, ce chapitre n'est qu'un extrait qui précède sa description. 
$\mathrm{J}_{\mathrm{E}}$ ferai plusieurs fois mention des richesses en tableaux de paysages que possède le département de l'Oise; en effet, le pays arrosé par cette rivière, et l'immense vallée qui porte ce nom, en sont remplis. Parmi les plus beaux parcs, on peut citer ceux de Villette, d'Ermenonville et de Morfontaine. Le parc d'Ermenonville est surtout étonnant par sa belle nature et ses pelouses magnifiques, par ses plantations, par ses eaux et ses cascades. Du château l'on voit le tableau général, qui est admirable; le dessin cn est hardi : la pelonse est d'une raste étendue et 
d'une belle composition; la rivière qu' on traverse au moyen d'un bac, présente l'image d'un fleuve. A mi-côte sur la droite, on aperçoit une tour qui est en ruine : c'est celle dite de la belle Gabrielle; plus loin est un moulin. En s'enfonçant dans les plantations sur la gauche, on découvre plusieurs étangs, enfin le désert, qui se trouve sur le sommet de la montagne. Une seule chose désagréable, à mon aris, est qu'il y ait trop d'eau au pied de l'habitation. L'entrée du côté du village est fermée par une grille; mais, sortant du manoir pour aller dans le parc, il faut trarerser un pont: l'eau baigne le pied des murs; ce qui doit donner de l'humidité dans les appartemens, surtout dans la saison avancée.

Je préférerais à ce large canal plein d'eau des masses de fleurs qui, en détruisant l'inconvénient précité, flatteraient les yeux et l'odorat, succéderaient aux exhalaisons et à une humidité désagréables, embaumeraient les appartemens et l'atmosphère.

La rivière, qui parcourt le parc dans toute salongueur, disparaît dans le lointain à l'extrémité du parc, derrière une forte masse de 
plantations. Cette rivière attire avec intérèt les regards de l'amateur: trop d'eau retire le plaisir des yeux, cause de l'embarras pour l'esprit. Cependant l'effet en est grandiose et admirable: ce seul objet, par ses développemens, exige des méditations; enfin, placé entre deux montagnes, ce parc ne prend ses vues que dans son intérieur, et n'en possède pas moins le plus bear tableau qu' on puisse désirer.

De même que le parc d'Ermenonville, celui de Morfontaine est situé entre deux montagnes; la différence est que le premier possède une jolie rivière, des pelouses très-rastes, et que Morfontaine se compose de deux pièces d'eau qui occupent toute la vallée en longueur, en largeur et par étage. En sortant du château, malheureusement séparé du parc par la grande route, dont l'entrée offre aux regards un tableau général des plus riches et de la plus grande beauté, c'est un tableau étonnant par son étendue. Il semble que ce parc se compose de tout ce qui se fait voir à l'horizon; car la ville de Senlis, qui est à trois lieues de distance, semble en faire partie. Les 
deux immenses pièces d'eau sont situées au bas d'une montagne, qui les borde sur trois côtés : séparées l'une de l'autre par une chaussée qui soutient l'eau élevée de plusieurs pieds au-dessus du nivean de l'autre, il semble roir la Seine à son embouchure vis-à-ris Honfleur. De l'eau, des montagnes plantées de futaie, une énorme rivière, mais peu animée, sort du trop-plein d'une des pièces d'eau, se prolonge derrière une montagne, au milieu d'un désert immense. Voilà l'intérêt que présente Morfontaine. Je troure le parc d'Ermenonville bien autrement pittoresque : son aspect inspire le sentiment, et il parle mieur à l'esprit. Morfontaine occupe les yeux; car on ne peut se lasser d'admirer une masse d'eau aussi considérable : on se croit transporté dans un port de mer. 


\section{CHAPITRE XVIII.}

DES HAHAS OU SAUTS-DE-LOUP.

Pour conserver des vues dans son habitation, pour jouir du paysage extérieur, on construit des hahas ou sauts-de-loup. On appelle ainsi des fossés creusés aux extrémités d'un parc ou d'un jardin. Ces fossés portent le moins douze pieds de large, sur sept à huit pieds de profondeur. Ils sont revêtus aux quatre côtés d'un mur en maçonnerie, afin de soutenir les terres; on peut même ne les revêtir qu'à l'extérieur du parc, et faire à l'intérieur un long talus: par ce moyen, le terrain sera cultivé jusqu'au pied du mur, sans aucune perte de terrain et moins de dépense. Ces murs, qui s'élèvent en talus, d'un ou deux pouces par pied, suivant la natme 
du terrain, sont construits en moellons ou en pierre de meulière, et en mortier de chaux et de sable. Si l'on peut ajouter quelques chaînes en pierre de taille de cinq en cinq mètres, la construction en devient plus solide. Ces murs, élevés seulement de deux pieds au-dessus du sol, sont terminés par une tablette en pierre ou par un rang de briques posées de champ, à défaut de pierre de taille. Le talus indiqué est indispensable pour résister à la poussée des terres. 


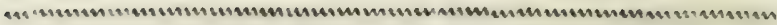

\section{GHAPITRE XIX.}

DES ARBRES PROPRES AUX JARDINS PITTORESQUES.

J'AI pensé qu'il serait utile de donner la nomenclature des arbres, arbrisseaux et arbustes d'agrément qui entrent dans la composition des jardins pittoresques. Cette nomenclature, également intéressante pour les propriétaires et les architectes des jardins, rendra le choix des approvisionnemens plus facile. Ces derniers trouveront sur-le-champ le nom et les espèces qu'ils veulent employer dans leurs compositions. J'ai cru deroir également ajouter les noms latins, la nature du terrain qui convient à chaque espèce, et l'exposition qui lui est favorable; enfin, pour se former dans son jardin une succession de fleurs pendant la plus grande partie de l'an- 
131

née, j’ai ajouté le mois où chaque espèce d'arbre donne sa fleur, afin que l'artiste puisse faire sa distribution en conséquence lors des plantations.

Je commencerai par la semence des plantes ligneuses. 


\section{GHAPITPE XX.}

DES SEMENCES.

LEs semences qui germent le plus promptement sont celles dont les lobes sont d'une peau ou enveloppe mince, ou bien celles dont l'enveloppe est épaisse ou ligneuse, mais dont les lobes sont gros et charnus. Telles sont, pour les premières, les glands, les marrons, les châtaignes, les pepins, etc.; et pour les secondes, les noix, les amandes, les noyaux de pêche, d'abricot, de prune, de cerise, etc.

Les terres de bruyère sont préférables pour faire germer les semences des plantes ligneuses. Ces terres sont le résultat de la décomposition des feuilles et des plantes des forêts, dont le sol est de sable. Dans le cas où l'on ne pourrait pas se procurer de la terre 
de bruyère, on fait alors un compost de terre de prés mêlée avec du sable et de la décomposition de feuilles. Il importe que ces décompositions soient le fruit du temps, et l'espace d'une année entière n'est pas trop pour réduire les feuilles en terreau : il faut bien se garder d'y mélanger aucun fumier de bassecour. Ce n'est absolument qu'avec des décompositions de végétaux, telles que les feuilles, les bois pourris, les débris de plantes, qu'on donne de l'humus au compost, et qu'on le rend propre à faciliter la germination des graines:

Vers la fin de l'automne, ces semencessont mises dans du sable humide. Pendant l'hiver, elles sont tenues dans un lieu frais, où la gelée cependant ne puisse pas les atteindre. Il est indispensable que les semences soient également préservées de la gelée et de la sécheresse. On les sème au printemps, savoir, les plus grosses, à un pouce de profondeur, et les plus petites à une ligne. Le jardinier enuetiendra la terre humide dans un grand état de propreté ; il préservera les plantes des rayons du soleil, et apportera le plus 
grand soin à extirper les mauvaises herbes.

Il est des semences qui ne germent que quinze à dix-huit mois après leur maturité, surtout si elles ont été tenues au sec après avoir été récoltées, c'est-à-dire, si elles n'ont pas été semées immédiatement après leur maturité ou mises dans le sable frais : telles sont la plupart des graines ailées et des graines osseuses. Malgré les précautions indiquées, il est des graines qui ne lèvent pas dans la première année, ni la seconde, mais seulement dans la troisième année.

Il est bon de faire observer que ce traitement n'est pas celui que demandent les semences ailées des conifères, qui se sèment au commencement d'avril. Pour les semer, on les tire de leurs cônes, et pour extraire les semences des cônes, on les expose à un feu doux qui, forçant les écailles à s'ouvrir, dégage les graines. Le jardinier les sème sur-lechamp dans un terrain préparé, légèrement humide, et à l'abri des rayons du soleil. Le meilleur moyen à employer est de déposer les semences dans des caisses ou des terrines remplies d'une terre légère et sans engrais, 


\section{5}

et de les enterrer à cinq à six lignes de profondeur. Ces caisses sont ensuite placées dans des couches d'une chaleur très-modérée, où l'on doit toujours entretenir une légère humidité. Il est surtout nécessaire de préserver les plants de l'action du soleil, et c'est à mesure qu'ils se fortifient qu'on les y accoutume peu à peu.

La plupart des graines des arbres exotiques exigent ces précautions, et les graines des arbres indigènes s'en trouvent très-bien. S'il arrivait que les graines ne levassent pas, il faudrait, lorsque le temps est adouci, retirer les caisses des couches, les placer à l'ombre, entretenir le terrain légèrement humide. Aux approches de l'hiver, les plants seront placés sous des vitrages au pied d'un mur exposé au midi. On les défendra des grandes gelées en les couvrant, puis au printemps ils seront remis dans une: couche.

Les graines très-fines ne demaradent pas à être enterrées, mais seulement répandues sur la terre humide. Le jardinier tamise par-dessus un peu de terre en poussière; il presse légèrement avec la main cette terre tamisée, la 


\section{6}

recourre de mousse, met les caisses àl'ombre, et y entretient un peu d'humidité jusqu'à ce que les graines aient germé.

Je crois inutile, eu égard à son peu d'usage, de parler des drageons; c'est un pauvre moyen, une bien petite ressource que celle d'éclater d'une racine ou d'un tronc d'arbre une tige qui prend très-difficilement, et qui, par son dénuement de racine, peut à peine se tenir en terre.

Outre les marcottes, on connaît encore le moyen de plier les branches d'arbres ou d'arbustes, particulièrement celles qui ont des dispositions à produire des racines plus ou moins promptement, des espèces demandant un an, dix-huit mois, deux ans; d'autres espèces demandant moins de temps. Pour employer ce moyen, il suffit, au printemps, de choisir des branches saines, d'une belle venue, d'une écorce lisse et unie; de les incliner sur la surface du terrain, sans les détacher de l'arbre, et de les enterrer, sans les rompre, à cinq ou six pouces de profondeur ; puis on les fixe avec un crochet en bois placé à la courbure. Pour réussir dans cette opé- 
ration, il faut que la terre soit bonne et meuble. Après avoir relevé perpendiculairement la branche par le bout hors de terre, on l'assujétit avec un tuteur. On aura soin de mouiller quelquefois la terre, qui sera butée autour de la branche; puis on la couvrira de mousse ou de litière pour conserver l'humidité.

Dans le cas où les branches courbées et enterrées auraient acquis assez de racines pour pouvoir être détachées de la mère, on les transportera au printemps suivant.

Il est des arbres auxquels, avant d'enterrer les branches, il est nécessaire de faire des incisions dans l'écorce ou dans le bois, pour les contraindre à s'enraciner; il en est d'autres qui demandent à être serrés par un fil ciré ou étranglés par un fil de laiton. Il est encore des arbres qu'on doit dépouiller d'un anneau de leur écorce; d'autres enfin dont il faut tordre l'écorce ou la fendre dans une longueur de deux ou trois pouces : cette opération est appelée marcotte à languette. Ces moyens, qui forcent la sève à produire des racines, se pratiquent arec plus de succès en juillet qu'en tout autre temps, surtout pour 
les jeunes bourgeons. $\boldsymbol{I}$ est des espèces d'arbres très-difficiles à s'enraciner. Les arbres verts se marcottent au commencement de l'été, et les autres, ceux qui prennent aisément racine, se marcottent pendant les mois d'octobre ou de mars. 

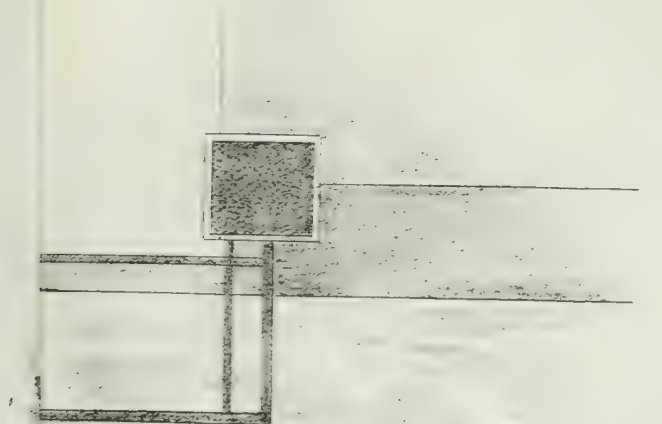

$\therefore \quad-$

3 pieds

1

1)

$\cdots$

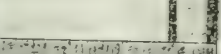

a $-1+2$

How

$: 1$

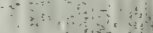

$\therefore(1)$

1)

ith

if 10

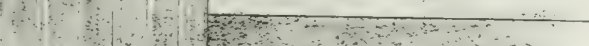

$1+x^{2}$

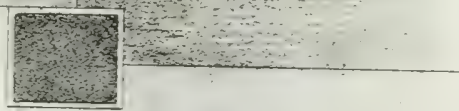



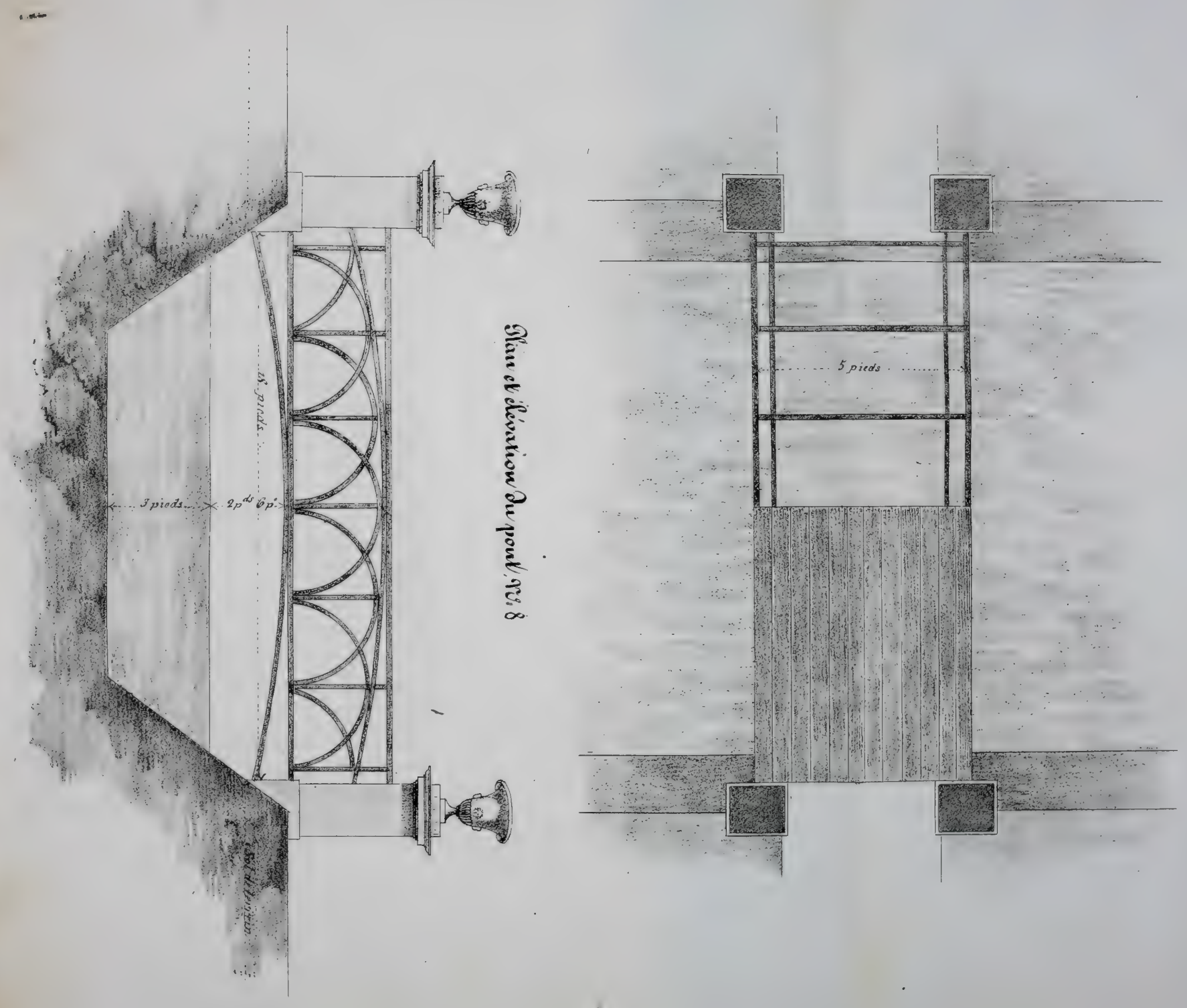


\section{GHAPITRE XXI.}

DES BOUTURES.

LEs branches d'un grand nombre d'arbres et d'arbrisseaux étant plantées dans un terrain convenable et bien façonné, défendues de la sécheresse et du soleil, multiplient promptement les individus.

Depuis la fin de janvier jusqu’à la mi-mars, coupez sur les arbres qui se dépouillent de leurs feuilles, des branches saines et vigoureuses de deux, trois et quatre ans; enlerez la pousse de l'année, à moins que le bois n'en soit dur et compacte. Retranchez les branches de neuf à douze pouces, excepté les branches d'arbres aquatiques, tels que les saules, qui se plantent dans un terrain humide; surtout coupez toutes les boutures en 
flûte, et gardez-vous bien d'offenser l'écorce en les enfonçant dans la terre; foulez la terre aux pieds, et l'arrosez; préservez la plante de la sécheresse.

Quant aux arbres verts, coupez, comme aux précédens, des branches droites, saines et vigoureuses, contenant le bois de la dernière pousse; retranchez les feuilles de la partie inférieure dans la longueur de trois à quatre pouces; plantez-les à une profondeur de trois à cinq pouces, suivant leur force et leur longueur; plombez la terre, et tenez-la dans un état légèrement humide.

Lorsque les plantes sont délicates, il vaut mieux les planter, si elles sont faibles, dans des pots remplis de terre légère.

- Plongez les pots dans une couche de chaleur modérée; on les courre de cloches, ou bien on les place sous des châssis, en les arrosant souvent. Lorsqu'on s'est assuré qu'elles sont enracinées, il faut les accoutumer peu à peu au grand air et au soleil, afin qu'elles ne s'étiolent pas. 


\section{CHAPITRE XX11.}

CONCLUSION.

LE nombre des compositeurs de jardins est fort petit; mais en récompense on rencontre une foule de gens qui prétendent avoir des connaissances dans cet art, et qui sont hors d'état de faire exécuter : l'un, par des économies mal entendues, gâtera le terrain qui lui sera confié, et n'en tirera pas les avantages qu'il présente; l'autre, voulant tout traiter en grand, ruinera le propriétaire, en lui faisant entreprendre au-delà de ses moyens. Celui-ci, après avoir fait un charmant dessin dans son cabinet, se présente à l'amateur : ce dernier est d'abord enchanté; mais sitôt que les travaux sont entrepris, il est tout désappointé de ce que le joli dessin est inexé- 
cutable, parce que l'artiste, ou soi-disant tel, arait négligé de lever son plan sur les lieux, et de tirer ses principaux points de vue d'après la nature du terrain.

Un de nos habiles architectes, se trouvant chez un de ses amis chez lequel venait d'entrer un riche propriétaire de la Normandie, le Neustrien fit part du dessein qu'il avait de changer la composition de son parc. L'ami propose notre architecte, qui est aussitôt accepté. Le propriétaire fait connaître à l'artiste l'état de situation de son parc, ainsi que les tenans et aboutissans. Le dernier se met à l'ouvrage, et au bout de huit jours il apporte son plan. Le bon Neustrien, enchanté de la beauté du dessin, termine ses affaires, part, arrive, mande les ourriers, et leur fait mettre la main à l'oeuvre. Mais, ô douleur! rien ne pouvait aller : aucun ensemble; un point de vue était placé là où il n'en fallait pas; on avait mis une prairie dans l'endroit qui exigeait une plantation; la position du château, celle qui donne le point d'appui des tableaux, était inconnue; car il faut toujours, au préalable, s'assurer de l'exposition du manoir, qui peut 
être bâti soit dans un fond, sur une éminence, ou sur un terrain plat. Il faut remarquer si le parc est entouré de vallées ou de coteaux; si le terrain offre du mouvement; quels sont les sites voisins; s'il y a des eaux, de quel côté est leur pente, quel parti on peut en tirer. Le terrain permet-il de faire serpenter une rivière? Telles sont les difficultés que présente la composition d'un parc, et pour les faire disparaître il faut absolument se transporter sur les lieux, et voir par soi-même. Si l'artiste que vous employez joint aux talens de la composition ceux de l'exécution, le propriétaire ne peut qu'y gagner, parce que personne n'entend mieux son affaire que le compositeur. Par exemple, on trouve peu d'architectes qui entendent le maniement de la ter. rasse; il ne faut cependant que de la pratique pour la faire exécuter. Si le compositeur entend cette partie, il est là pour lever toutes les difficultés qui peuvent se rencontrer, et que présente la nature du terrain tant à l'extérieur qu’à l'intérieur, le pays environnant, les eaux, les bâtimens, les pentes, les coteaux, enfin les arbres existans qu'on veut conserver. 
Aucun auteur que je sache n'a traité du style qui convient aux bâtimens de la campagne, et ne les a envisagés sous le rapport qu'ils ont avec les sites où ils figurent. Cependant, si les bâtimens ont sur les sites une influence sensible, et si, de leur côté, les sites influent sur le caractère et l'expression des bâtimens qu'on leur associe, il doit y avoir dans les formes, le caractère et le style de ces bâtimens, des différences avec les formes, le caractère et le style affectés aux bâtimens des villes. Ces différences tiennent à la convenance, partie de l'architecture essentielle et trop négligée dans les bâtimens construits à la campagne.

Quoi qu'en aient dit les auteurs qui ont écrit sur l'origine de l'architecture, je ne crois pas que ce bel art ait trouvé des modèles dans la nature. En vain ont-ils répété les uns après les autres que les colonnes avaient pris naissance des troncs d'arbres; crue l'entablement représentait le poitrail qui servait à porter des solives du plancher; que le fronton avait reçu sa forme des égouts des toits. Fort bien : mais s'ensuit-il de là que les formes de 
l'architecture aient trouvé leur type dans la nature? Où ont-ils vu que la nature eût destiné des troncs d'arbres à porter autre chose que des branches propres à transmetîre et à conduire la sève quidonne naissance et nourrit les feuilles, les fleurs et les fruits? Où ont-ils vu que la nature eût soumis ces troncs à recevoir et à supporter les abouts d'une pièce de bois écarrie? La première cabane, toute simple, toute grossière qu'elle était, fut le fruit du besoin, la production de l'industrie, et non une imitation de la nature, qui n'a jamais rien produit de semblable.

Qui nes'aperçoit, pour peu qu'il veuille y réfléchir, que les Grecs, de qui nous avons emprunté notre genre d'architecture, ont admis ces formes parce qu'elles leur ont été suggérées par celles qui avaient été employées dans leurs bâtimens jadis construits en bois? car chez eux, comme chez tous les autres peuples, l'emploi du bois a précédé celui de la pierre. Ce n'est donc pas le trone d'arbre qui a donné l'idée de la colonne; mais ce sont les principaux points d'appui de leurs bâtimens construits en bois, faits avec des tronss 
d'arbres, qu'ils ont imités, lorsque dans leurs bâtimens ils ont fait usage de la pierre. Il en fut de même de l'architrave, de la frise, du fronton, des triglyphes, des modillons, et de presque tous les ornemens qui décorent les ordres d'architecture qu'ils nous ont transmis ; et sans doute que la base et le chapiteau dont ils ornent la colonne, ne leur furent suggérés que par la nécessité de placer les liens au haut et au bas du tronc d'arbre, pour prévenir les éclats et les fentes auxquels l'eût exposé la charge qu'il portait. Les auteurs qui ont écrit sur les ordres d'architecture avouent que telle est l'origine des formes et des ornemens inventés par les Grecs. Ces formes servent encore de règle aux maîtres pour déterminer les proportions de chaque partie. Que faut-il conclure de ces observations? Il en faut conclure, non que cet art a pris de la nature les formes qu'il emploie dans les ordres d'architecture, mais que l'architecture grecque, perfectionnée, a conservé, lorsqu'elle employa la pierre, des formes qu'avaient primitivement les hâtimens construits en bois.

Les bâtimens, ainsi que les fabriques, 
ayant sur les sites auxquels on les associe une influence assez puissante pour en altérer et même pour en changer le caractère, en fortifier ou en affaiblir l'expression, que de réflexions ne doit pas avoir faites l'artiste avant que de faire entrer une fabrique dans ses compositions! quelle finesse, quel tact pour en pressentir les effets! quelle réserve dans l'emploi d'un moyen si aisé à mettre en oeuvre et si difficile dans l'application! que de précautions à prendre pour associer avec succès dans une scène champêtre des productions dont les formes lui sont si étrangères! Rien n'est à négliger quand on se propose d'associer aux tableaux de la nature cette production de l'art: masse, style, caractère, teinte, matière, position, tout est à préroir. La plus légère méprise devient une faute grave qui se fait apercevoir au premier coup-d'oeil. L'artiste qui, sans motif, sans besoin, sans discrétion, surcharge sa composition diune multitude de fabriques que rien n'appelle, que rien ne justifie, qui ne consulte ni le style, ni le caractère qui conviennent à celles que ce besoin rend indispensables, et 
que la nécessité commande, annonce peu de ressources dans l'imagination, de médiocres talens, une absence totale de goût et une ignorance profonde des premiers élémens de l'art.

Indépendamment de ce défaut de convenance, de tels manoirs, surchargés d'étages, éloignent trop des jardins ceux qui les habitent. C'est bien pis encore si la disposition est telle que l'appartement de société se trouve au premier étage. $\mathrm{Y}$ a-t-il un escalier à franchir pour aller au jardin, on balance, on hésite : c'est une sorte de barrière qui arrête; et puis, au retour, las de la promenade, on redoute le fatigant escalier. Pour mon compte, je l'avone, je voudrais trouver, au sortir de ma chambre, je n'ose pas dire de mon lit, les arbres, les gazons sous mes pas. Combien de manoirs à la campagne sont disposés et entourés de manière à faire douter à ceux qui les habitent s'ils sont à la ville ou aux champs, tant on y est peu en société avec les aspects champêtres! Que va faire à la campagne le riche citadin qui vient d'y acquérir ume propriété? Son projet est-il d'y couler 


\section{9}

ses jours en paix au sein de la liberté et de la tranquillité, de s'y livrer à des exercices salutaires? vient-il y chercher la pureté de l'air, y jouir du spectacle de la nature? Sans doute il se propose d'améliorer ses champs, de rendre ses cultures plus fructueuses, d'assainir le pays, de perfectionner par son goût les tableaux que lui présente son site, ou bien il va, par son aisance, aider les cultivateurs de son canton, et soulager les malheureux? Non, rien de tout cela; ce qui l'intéresse d'abord, ce qui fixe son unique attention, l'objet de tous ses soins, c'est son superbe manoir: l'étendue en sera immense, la décoration magnifique. En royant tant d'ouvriers, tant de matériaux rassemblés, on dirait qu'il va bâtir une cité, et ce n'est tout simplement que la retraite d'un homme, ou tout au plus celle d'un père de famille. Cependant sa maison n'est jamais assez grande, la décoration n'est jamais assez riche : dans l'intérieur, rien n'est jamais assez éclatant; il y veut les aises de la mollesse et le luxe de la ville. Plus flatté de ses lambris dorés que touché du charme de ses jardins, et des grâces naïves que lui offrent 
les scènes simples, mais aimables, dont la nature a favorisé le pays qu'il habite, il ne s'occupe que de ses grands salons, que de ses meubles somptueux; il montre ses bains de marbre, ses vestibules, sa galerie, son superbe escalier; il rante ses grands murs de terrasse, ses larges fossés, son stérile parterre, ses jetsd'eau, son éternelle avenue, ses vastes cours. Que s'ensuit-il de tant de superfluités? qu'il est bientôt las. Ce brillant étalage flatte sa vanité, sans doute; maịs qu'inspire-t-il à son couur? que dit-il à son âme? Hélas! sans la table, sans le jeu, sans la nombreuse compagnie qu'il a grand soin de rassembler, il ne resterait pas dans sa superbe campagne vingtquatre heures sans y périr d'ennui. Cela doit être ainsi.

Faisons mieux, et dépensons moins: ayons aux champs une petite maison : c'était le goût ctl'avis du sage Socrate; rendons-la propre, commode et riante; plaçons-la dans un site agréable par ses grâces champêtres, et nous jouirons d'un bonheur parfait.

Je ne terminerai point sans rendre encore hommage aux talens des deux hommes, Morel 
et Girardin, qui m’on précédé dans la carrière. C'est dans leurs ouviagés quie j'ai en partie puisé des connaissances, et cét amoiur pour les grands etsublimes effets de la nature.

Dans les diver'ses descriptions de paysage renfermées dans ce volume, on se fera une juste idée des difficultés à vaincre et des olsst tacles à surmonter, qui se rencontrent à chaque pas dans la partie que j’ai embrassée. Tantôt c'est un château moderne qu'il faut faire entrer dans l'ensemble; tantôt il faut découvrir le manoir féodal, idont l'architequre gothique indique l'ancienneté. Le style d'architecture employé par nos pères est admirable dans une composition. Ces tours, ces cnéneąux. rappellent des idées chevaleresques. Le voilit ce castel hospitalier, où les pretx, leurs mies. leurs écuyers et les pèlerins étaient reçus. A la porte du manoir se irouve le banc de pierre où le chevalier montait sur son coursier, et la châtelaine sur sa haquenée. Le paladin:s revenant du toùmoi, était reçu par les dames, qui l'aidaient à descendre. Le perron ef la motte rappellent ces temps où le seigneur; assisté de ses écuyers, de ses chevaliers et de 
ses baillis, venait rendre la justice à ses rassaux. L'imagination fait apercevoir le trouvère suivi de ses compagnons. Ils content le gai fabliau, l'aventure galante, la plaintive romance ; ils font résonner les échos de leurs harpes mélodieuses, et appellent à la danse tous les jeunes gens du hameau. La dame du château a permis la danse dans sa gentilhommière, et préside aux jeux. Un goûter champêtre termine la séance, et la troupe joyeuse, précédée des ménétriers, se retire enchantée des plaisirs de la soirée.

Les monumens construits par nos pères surprennent, étonnent à la première vue; ils causent une certaine impression, une sorte d'émotion dont on ne peut se défendre. Quel bel effet produit une tour gothique, ou une construction du moyen âge, dans un paysage! Je n'ai jamais aperçu un monument de cette époque sans éprouver une sorte de ravissement. Il est vrai qu'il en est plusieurs qui sont admirables : aussi est-il dans l'intérèt des propriétaires de les faire réparer, et de veillex à leur conservation. 


\title{
DESCRIPTION
}

\author{
GÉNÉRALE
}

\section{DES PARCS}

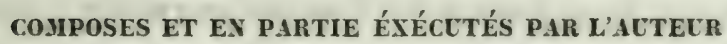

\section{DEUXIEME PARTIE.}

\section{CHAPITRE XXII.}

\section{SAINT-ŔTIENNE DU ROUVRAY,}

Département de la Seine-Inférieure.

A une lieue et demie de Rouen, en remontant la Seine, et presque sur ses bords, est la charmante propriété de madame la vicomtesse de Guercheville, dont le parc, comme le château, ont été recomposés : le château, 
par une distribution toute nouvelle d'un restibule orné de colonnes de l'ordre ionique, qui sépare ce vestibule de l'escalier nouvellement construit, dit à l'anglaise; la chambre de la maîtresse de maison, avec alcôve, ornée de colonnes de l'ordre corinthien, au fond de laquelle est une baie vis-à-vis la croisée, qui prend jour sur le parc : cette baie est fermée par une glace sans tain qui ouvre à coulisse. La baie de croisée ex- térieure en face est fermée par une glace rouge sans tain, qui forme dans la chambre un tableau étonnant: on voit la chambre, le parc et l'horizon tout en feu, surtout lorsque le soleil éclaire le parc; on se croirait transporté dans un lieu de féerie. Pour conserver à cette chambre toute sa fraîcheur, madame de Guercheville en a fait une chambre d'honneur qu' elle n'hribite point.

Le parc a été totalement recomposé : la vue plane d'un côté sur la forêt du Rouvray, avec laquelle il se lie et paraît lui appartenix; du côté opposé, on voit les montagnes qui bordent ia Seine, les unes couronnées de bois, d'autres arides: tous ces points de sue sont ad- 


\section{5}

mirables. L'intérieur du parc offre de beaux ombrages et de beaux tableaux; il ne manque à cette jolie propriété qu'un puits artésien, faute de mieux, lequel formerait un ruisseau qui ajouterait aux charmes de sa parure et en augmenterait la richesse. 


\title{
GHAPITRE XXIV.
}

\author{
SAINT-JULIEN,
}

Département de l'Aube.

Qourque la Seine borde ce jardin dans toute sa longueur, elle n'en n'était pas moinsignorée et inaperçue du jardin; on n'avait nullement l'idée ni le désir de la faire voir : une haute et épaisse charmille en dérobait la vue. Une clairière s'ouvre : ce fut un enchantement complet; on ne pouvait croire qu'on pût voir la Seine dans ce jardin, qui ne paraissait nullement la veille. C'est une bonne fortune pour le propriétaire qui en saura faire son profit. Cie jardin, embelli par cette rivière qui l'arrose, n'est pas recomnaissable...

Le Pec, au bas de la montagne de Saint- 
Germain-en - Laye, possède aussi une charmante habitation. Le jardin, qui vient d'être composé, est situé à merveille sur le revers de la montagne qui fait face à cette belle vallée que parcourt la Seine dans une autre position qu’à Saint-Julien. La vue de ce jardin suit le cours de cette rivière qui serpente jusque dans le lointain. Du côté opposé est la forêt de Chatou, et à droite sur la montagne, sont les arcades de Marly. Tous ces points de vue, admirables pour cette propriété, en font les délices. Son intérieur est très-pittoresque; tout contribue à ne rien laisser à désirer. Il y a de l'eau, mais elle est peu abondante : c'est toujours un bonheur d'en posséder. Cette propriété, comme Saint-Julien, a appartenu à M. Le Bland, avoué distingué de Paris. Saint-Julien ne lui appartient plus. 


\title{
GHAPITRE XXV.
}

\author{
FONTENAY-LE-PÉNEL, PRÉS TILLY;
}

\section{Département du Calvados.}

CE joli jardin n'est pas aussi heureux que les deux précédens: la Seine n’est pas à sa disposition pour l'arroser ni pour l'embellir; mais par compensation, il possède un autre aspect, quoique sans eau. C'est un joli paysage qui, avec le pays ehampêtre qui l'environne, paraît ne faire qu'un même tout. Ce jardin a beaucoup gagné depuis la suppression. d'un mur d'une hauteur telle qu'un rempart, qui séparait ce jardin en deux sur sa longueur ; ce qui rendait l'habitation cloîtrée, et privée de la vue la plus pittoresque.

Ce ne fut pas sans peine qu'on oblint de 
madame Vallerand mère la suppression de ce mur qui possédait deux beaux espaliers. Je conçois qu'il est dur et difficile à consentir qu'un mur qu’on était habitué à voir fût démoli : aussi je me suis vu presque au moment d'être obligé de faire une neuvaine pour obtenir sa démolition. Une seule chose est à désirer : c'est l'isolement, de l'habitation, des bâtimens de la ferme qui la touchent. Un puits artésien serait nécessaire dans ce jardin.

Cette belle propriété appartient à M. Vallerand de Lafosse, médecin distingué de Paris.

Madame Vallerand était si bonne pour ses enfans, comme elle l'était pour tout le monde, qu'elle fit le sacrifice de son mur et de ses goûts pour son fils, afin de ne rien lui refuser: le mur fut démoli. 
$\mathrm{C} e$ village, célèbre par sa nombreuse population, fait suite au faubourg Saint-Sévère de Rouen. Cesont presque tous ouvriers occupés, hommes, femmes et enfans, aux nombreuses fabriques que possède ce village, ainsi que le faubourg précité. A l'extrémité de cette commune, du côté de la forêt du Rouvray, est une propriété, lieu dit les Marettes. Le parc, d'environ quarante arpens, fort heureusement placé, possède des vues admirables : d'un côté, la ville de Rouen et ses nombreux clochers, ainsi que ses fabriques; le château de Canteleu, à l'ouest, sur le som- 


\section{1}

met d'une montagne, et du côté opposé, la chaine de montagnes qui borde la Seine toute pittoresque. Ce parc, dans la partie la plus élevée et la plus éloignée de l'habitation, possède un joli taillis qui offre de beaux ombrages; cette habitation, heureusement placée, entourée du parc qui vient d'ètre composé, est à ravir. Il est seulement fâcheux, je l'ai dit à M. Bryère, de voir un mur qui coupe sur sa largeur le parc en deux : on serait tenté de croire que ce parc appartient à deux propriétaires.

Il y a deux pièces d'eau bien carrées et rerêtues de murailles élerées au-dessus du sol, de manière à ne point roir l'eau, et qui sont dignes de l'ancien temps. Ces deux pièces d'eau, placées près de l'habitation et à dixhuit pieds l'une de l'autre, viennent de quitter la règle et le compas de Le Nostre, et sont rendues à la nature. Les murs qui les emprisonnaient vienment de faire place à un beau talus fort étendu dans leur pourtour, orné de belles plantations de saules-pleureurs, peupliers d'Italie, d'aulnes et de fleurs. Ces deux pièces d'eau, peu volumineuses à la vérité, 
présentent deux fontaines très-pittoresques, et causent même, en les voyant, une surprise fort agréable. L'une est cédée à la basse-cour, afin de servir d'abreuvoir aux bestiaux ; l'autre orne le parc; et toutes deux, quoiqu'elles n'aient point d'écoulement, possèdent une eau très-limpide, et ne tarissent jamais.

Cette jolie propriété est admirable par ellemême, par ses charmans contours, sa situation pittoresque. L'habitation, fort commode, avec une belle distribution, appartient à Mr. et madame Bryère. M. Bryère a été plusieurs années maire de Sotteville: c'est lui qui a fai: exécuter les travaux de son parc, sous ma direction. Par sa grande intelligence, il les a dirigés on ne peut mieux : du moins si c'est un compliment, c'est un compliment mérité. 
163

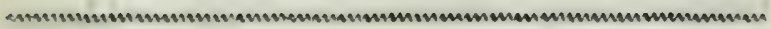

\section{GHAPITRE XXVII.}

CORNY, PRÈS METZ,

Département de la Moselle.

$\mathrm{C}_{\boldsymbol{B}}$ parc est d'une grande étendue; il est bordé d'un côté par la Moselle dans toute sa longueur, et de l'autre par la grande route de Metz à Nancy, par Pont-à-Mousson. Le château est placé, avec ses dépendances, presque au bord de la grande route. La portion du parc, entre le château et la Moselle, avait reçu une composition nouvelle, dans le genre pittoresque, que j'ai réunie à la grande partie du parc composé et exécuté en $185 ̄ 1$, et qui forme un même tout. Avant cette composition générale, ce n'était autre chose qu'un petit jardin, à peu près de la longueur du 
chàteau, à quelques toises près. Maintenant tout a changé : ce parc possède des tableaux admirables sur une vallée extrêmement pittoresque et fertile. La vue se porte sur plusieurs villages situés sur les bords de la Moselle; d'autres à mi-côte ou sur les montagnes qui la bordent. On voit leurs clochers au milieu des groupes d'arbres qui ornent cette belle vallée; sur la montagne, des rochers, des parties agrestes : tout concourt à rendre ce parc le plus beau, sans contredit, des environs de Metz, sous les rapports de sa situation heureuse et ses points de vue aussi rares qu'intéressans.

Une seule chose est à regretter, c'est de voir ce parc bordé d'une jolie et large rivière malheureusement trop encaissée, excepté dans les grandes eaux, pour pouvoir en disposer. Le parc, plus élevé que la rivière, empêche d'en tirer parti dansaucun temps. Mais il faut savoir se passer de ce qu'on ne peut avoir: aussi on en est bien dédommagé par la vue de cette rivière qui se prolonge en serpentant dans le lointain, où ce magnifique tableau, si xare par sa beauté, se termine par une mon- 
lagne très-pittoresque, et qui parait, avec la rivière, les villages, et tout ce qui l'environne, faire partie de ce parc charmant; enfin, par sa distribution intérieure, il laisse dans l'imagination des sensations profondes de ce qu'on voit, et prévient favorablement en faveur de ce qu'on ne voit pas.

Cette charmante propriété appartient à MII. Marchal de Corny père et fils, qui l'habitent une grande partie de l'année. 


\title{
GHAPITRE XXVII.
}

\author{
MONTOY, PRÈs METz,
}

Déparłernent de la Moselle.

$\mathrm{C}_{\mathrm{F}}$ jardin, situé à une lieue de Metz, offre une jolie position. Il n'y a rien de remarquable à cette propriété, qui appartient à $M$. et madame Durand d'Aunoux, qui se sont chargés de l'exécution de la composition que je leur ai donnée; mais ce jardin, qui possède de beaux points de vue et une jolie distribution, fera le charme des propriétaires, qui s'en occupent beaucoup. 


\section{GHAPITRE XXIX.}

LE CHÊNE,

\section{Département d'Eure-et-Loir.}

L'Est une chose assez rare que de trouver dans la Beauce un parc pittoresque, de beaux arbres, et qui offrent autant d'ombrage que celui de Chène. Avant de lui donner une nouvelle composition, il formait plusieurs belles masses de taillis, qui procurent un grand arantage, celui de jouir promptement. Cie parc, fort grand, étant terminé, pourra ètre mis au nombre des beaux parcs des environs de Paris; son sol est excellent, par conséquent sa végétation vigoureuse.

Cette belle propiété, qui se compose de dépendances considérables, consiste en plusieurs fermes; mais il y a deux inconvé- 
niens : le premier est d'être éloigné de trois lieues de la grande route; le second est d'être privé d'eau. Pour remédier autant que possibleà un inconvénient aussi grave, nous avons établi des gouttièresà tous les toits du château, des bâtimens de basse-cour, et des écuries et remises, et nous avons fait conduire toutes ces eaux pluviales dans un grand abreuvoir que ¡'ai fait construire dans la cour des écuries, qui contient cent pieds de long, douze pieds de largeur et six pieds de profondeur ; il estconstruit partout en maçonnerie, même de fond, afin de contenir l'eau qui sert d'abreuvoir aux bestiaux, et est d'un grand secours en cas d'incendie.

Deux entrées ont été faites au parc : une devant le château, l'autre au bout du parc, du côté de l'arrivée, afin de le traverser en sortant comme en arrivant. De beaux points de vue se font remarquer sur plusieurs villages et leurs clochers. Dans son intérieur, ce parc offre de beaux tableaux. Cette propriété appartient ì M. le comte de Biencourt ( Armand), fils de $M$. le marquis de Biencourt. propriétaire de la belle propriér d'Azai-leRidean. 


\section{GHAPITRE XXX.}

LES ESSARTS, TRÉS NOYON,

A deux lieues sur la gauche de Noyon est la belle terre des Essarts, fort bien boisée et très-pittoresque. Une petite portion du parc, devant le château, jusqu'au bois, forme une pelouse plantée de quelques arbres verts et autres; cela compose un petit jardin, en attendant cque l'on ait ouvert une vaste pelouse à la suite de celle-ci, au travers du bois, qui laisserait voir cette belle vallée, au fond de laquelle coule un ruisseau d'eau vive dans les épines; et avec un peu de dépense et de goùt on verrait du château un joli lac ou rivière qui enrichirait cette belle propriété 
à laquelle il ne manque que le secours de l'art. Les proprićtaires m'ont assuré que le moment n'était pas éloigné où je serais appelé pour mettre ce projet à exécution.

En attendant, j’ai été chargé de tirer parti d'un autre ruisseau qui, comme le précédent, coulait au fond d'un fossé creux et couvert de ronces, qu'on ne voyait qu'avec peine. Ce ruisseau parcourait une longue vallée agreste entre deux bois, et n'en possédait aucun. Il sort du bois, au fond de la vallée: j’en ai formé an très-beau lac de soixante pieds delargeur, qui est en ce moment plein d'eau et admirable. Ce lac, en prenant naissance à l'entrée du bois, se prolonge en une rivière qui forme une île, pour envelopper une cépée d'arbres énormes et de toute beauié; deux ponts ont été construits pour traverser l'île, et en montant. La rivière se prolonge avec une cascade; une allée parcourt à l'umbre cette rivière de quinze pieds de largeur, qu'on admire avec tant de plaisir. En se retournant, vous voyez l'ile et ces beaux arbres, et le lac qui s'élargit à chaque pas que vous faites; une masse d'athes laisere désirer 
ce qu'on ne découvre qu’à chaque pas que l'on fait; enfin on aperçoit une chaussée qui termine ce lac et qui le trarerse. Sous une arche de pierre, et du côté opposé, est une cascade, d'où l'eau du lac se précipite avec fracas dans une basse rivière de quinze pieds de largeur, ombragée par d'anciens arbres qui existaient dans cette partie; plus loin. on voit une autre cascade; une troisième et une quatrième et dernière sont à l'extrémité de la propriété. Ainsi, ces eaux autrefois si calmes sous les ronces, rassemblées, et parcourant une longue vallée, se débattent écumantes en se précipitant sur cinq cascades, et rentrent, après la dernière, entièrement calmes comme auparavant. Cette rivière, remplie d'accidens heureux, est parcourue dans toute sa longueur par une allée. Quelles sensations on éprouve! il n'existe rien qui puisse ètre comparé. Comme aupararant rien n'était plus monotone. Pour arriver à cette riche et riante vallée, autrefois si triste et si pauvre, on a le choix de deux bois, à droite et à gauche, très-ombragés; car cette vallée est à plus de deux cents toises du château. 
Voilà ce que l'on gagne avec du jugement et du goût. M. le baron et madame la baronne de Segouzac ont eu cent fois raison d'avoir employé cette belle vallée, qui était sans motif pour eux et sans but, mais riche en eau, qui est l'élément des jardins, qui en est l'âme : elle donne du ton, de l'éclat et de la fraîcheur. Les propriétaires ne peuvent que se féliciter de la dépense qu'ils ont faite, elle leur fait honneur. M. de Segouzac en a dirigé très-bien les travaux sous ma ảirection. 


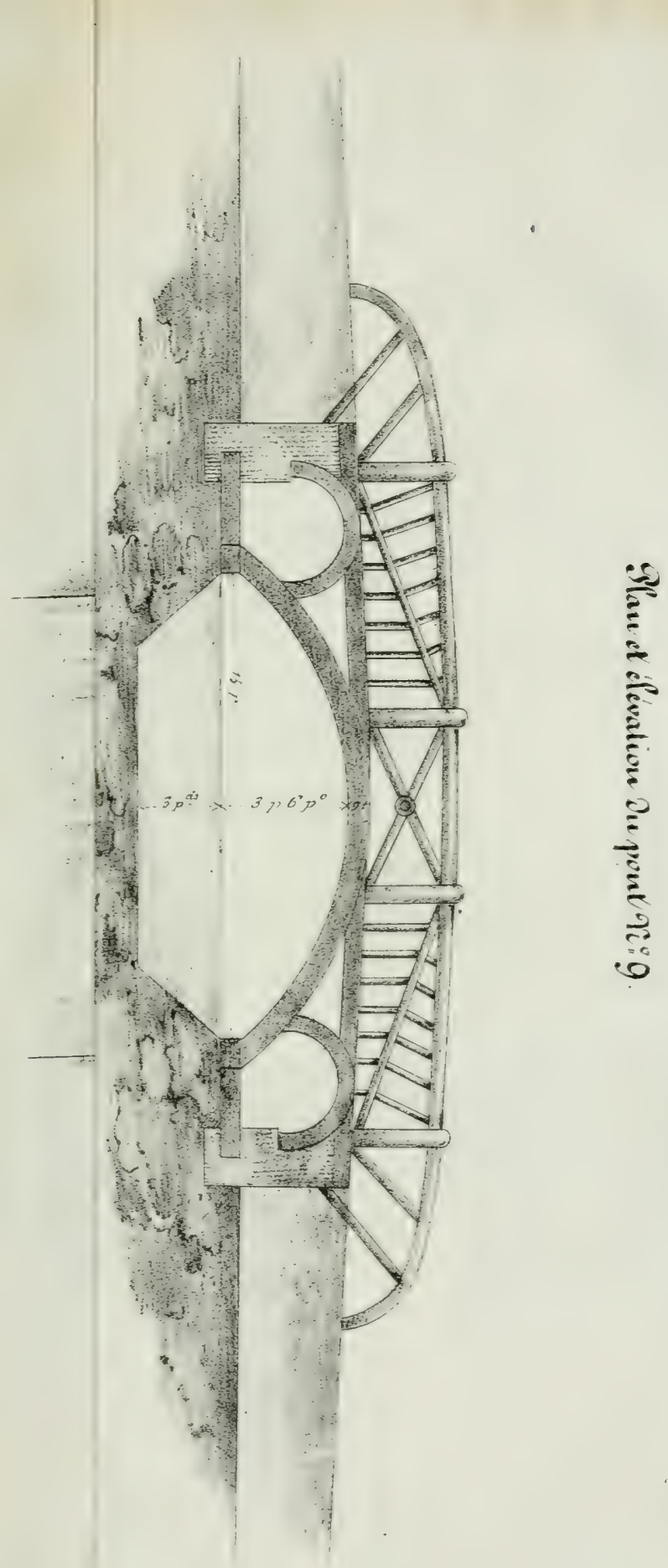




$$
\mathbb{1 1}
$$




\section{GHAPITRE XXXI.}

INGLÉGUÉVILLE, PRÈS D'ISIGNY,

\section{Département du Calvados.}

Presque au bord de la mer est une des belles propriétés de la Normandie, dont j'ai entièrement composé le parc, situé à trois lieues d'Tsigny. Le château est assez mal tourné, puisqu'il borde un chemin vicinal; mais en compensation il est extrêmement agréable et d'une belle distribution. Le parc est situé sur le sommet qui domine une des plus belles vallées de la Normandie, dont la vue du château comme du parc, sur le revers de la montagne, est d'une vaste étendue et trèspittoresque. Il y a des prairies énormes, remplies de bestiaux, et, chose étonnante! ils res- 
tent toute l'année dans les herbages, nuit ct jour, en hiver, même sur la neige: on leur porte des fourrages. Deux fois par jour des servantes de ferme ront sur des ânes avec tous leurs pots en cuivre pour les traire; et s'il arrivait qu'on les mît à l'étable, même en hiver, ils cesseraient de donner autant de lait qu'ils en donnent dans les prairies. Du parc comme du château il y a des points de vue étonnans. Un bout de la vallée près de la mer forme un demi-cercle; sur les coteaux opposés à cette rallée, ce sont des villages très-pittoresques : on voit leurs clochers, et un grand nombre sont des flèches. C'est un enchantement que cette propriété. Au fond de la vallée est une pièce d'eau, qui doit être faite, et qui se verra de tous les points du parc, qui possède toutes les beautés de la nature. Le chemin d'arrivée commence à la sortie du village, conduit au château quii est fort loin, fort bien ombragé, dessiné sur une ligne courbe; et celui qui conduit du château au bord de la mer sur une ligne droite, a environ un demi-quart de licue à parconrir pour y arriver : on ne trouve plus d'arbres 
lorsqu'on en approche. L'air de la mer ne permet pas de régétation sur ses bords.

Arrivé sur le bord de la mer, on la découvre jusqu'à l'horizon. On voit dans le lointain La Hogue, et à droite, si le temps le permet, arec une lorgnette, on devrait voir le Havre. L'escarpement du sol est très-élevé audessus de celui de la mer; aussi on la découvre avec tous les navires à la voile. Il ne faut pas oublier que de temps à autre il échappe quelque masse de rocher qui roule dans la mer. Montagnes et vallées, tout est prairie dans ce pays, qui contient plusieurs centaines de bestiaux. Cette belle propriété appartient à M. le marquis de Faudoas. Il est à remarquer qu'il ne gèle presque pas dans ce pays, ou très peu. Cette belle terre se compose de plusieurs fermes. 


\title{
GBAPITRE XXXII.
}

\author{
LAUNAY - BAFFERT,
}

Département de Maine-et-Loire.

C'est un parc d'une très-grande étendue; des eaux sur deux points du parc forment une belle rivière qui doit le parcourir dans toute sa longueur, et qui, traversée par plusieurs ponts ou rochers, formera une rare cascade d'où l'eau se précipite, si toutefois ce parc a reçu son exécution. C'est une vallée riche qui, étant exécutée, sera extraordinaire pour sa beauté, pour ses eaux, ses cascades, ses rivières et ses ruisseaux : ce serait une merveille que ses détails et son ensemble. Launay-Baffert, situé à trois lieues de Baugé et à une demi-lieue de la grande route de Laflèche à Tours, appartient à M. le comte Eugène d'Oisonville. 


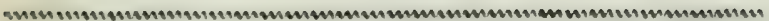

\section{GHAPIIRE XXXII.}

BISSY,

Dépártement de Seine-et-Oise.

A un quart de lieue de Bonnelle et de la grande route de Paris à Chartres, par Orsay, est la jolie propriété de Bissy, appartenant à M. Schmid fils, banquier à Paris, et gendre de MI. Cavelan, banquier à Rouen. C'est une vallée délicieuse, an milieu de laquelle sont situés le château et ses dépendances, dans une île, au moyen d'un fossé plein d'eau qui l'entoure. Le parc contient quarante arpens environ, dont plus des trois quarts sont en bois taillis, qu'il fallait ouvrir pour l'exécution du plan; mais on s'est contenté d'exécuter le pourtourdu château, à l'exception d'un percé 


\section{8}

qui fait voir une jolie montagne très-pittoresque sur un des côtés.

Près du château, à dix toises de distance, est un étang d'une belle étendue, toujours plein d'eau limpide, mais qui a très-peu d'écoulement. La vue, qui se prolonge de ce côté sur une montagne très-bien boisée et pittoresque, offre un beau coup-d'oeil.Du côté opposé, la vallée se prolonge dans le lointain jusque passé Bonnelle, qui offre un tableau de toute beauté; et en face le château, sur la montagne, la vue va se reposer sur une ferme qui fait partie de la propriété. La vallée du côté de Bonnelle est enrichie d'un joli ruisseau, qui se réunit au trop-plein des fossés du château, et formerait une jolie rivière en parcourant cette riche vallée, où la vue va se reposer dans le lointain sur des masses de peupliers.

Il est à regretter qu'au milieu de tant de heautés, un chemin public traverse cette \$:allée près du château; ce qui porte ce ruis"ciau du côté opposé au chemin, et l'éloigne

quarante toises de l'habitation. Du reste, wat y est admirable; il y a de beaux ar- 
bres; une allée parcourt la partie conservée en bois taillis, très-bien ombragée, et qui produit une promenade considérable, garantie du soleil à toute heure du jour. 


\title{
GHAPITRE XXXIV.
}

\author{
DLANDECK, PRÈS SAINT-OMER,
}

Département du Pas-de-Calais.

Pour mémoire, faute de renseignemens positifs. 



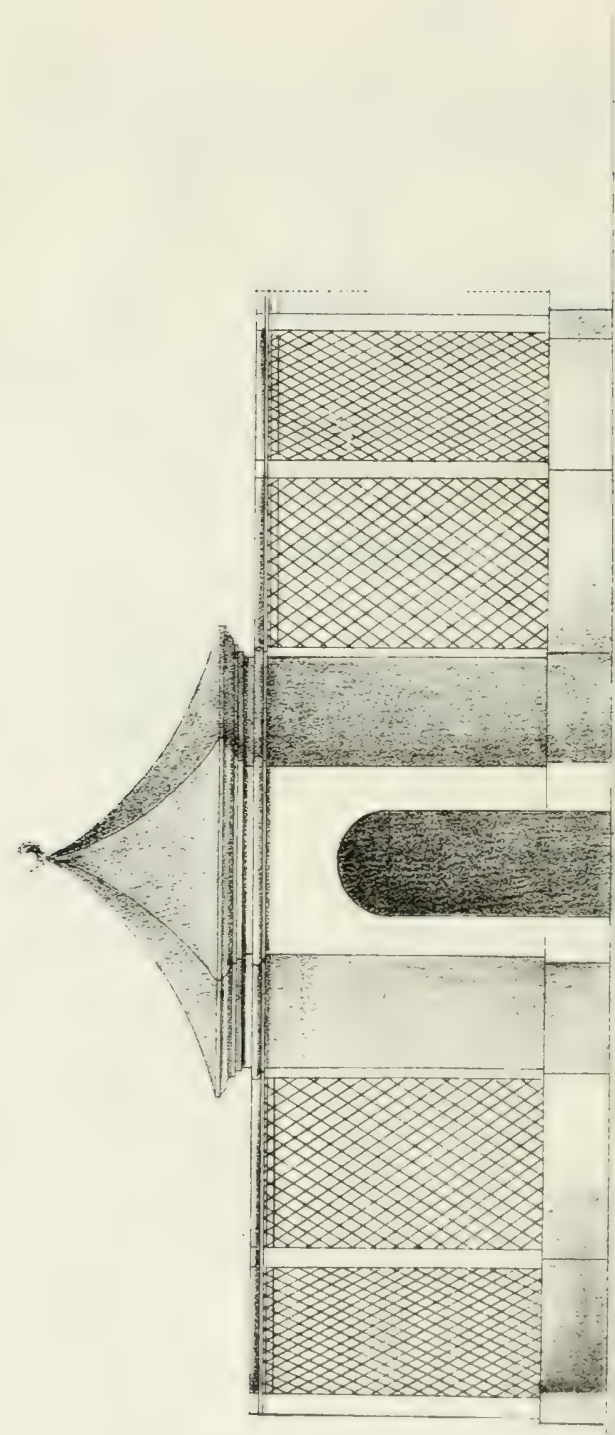


181

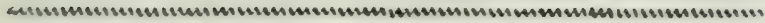

\section{GHAPITRE XXXV.}

CHARBONNIÈRE,

Département d'Eure-et-Loir.

CE parc est d'une assez grande étendue; il reçoit deux ruisseaux qui, réunis, forment une jolie rivière qui parcourt le parc dans toute sa longueur : passant devant le château, cette rivière, arrivée sur un rocher, se précipite dans une ouverture en forme de gouffre, et tombe avec fracas dans une basse rivière qui continue son cours. Ce château est aussi entouré d'un fossé rempli d'eau. Je ne saurais donner plus de renseignemens sur ce joli parc: si on a exécuté le plan, il y avait tout ce qu'il faut pour en faire une merveille de la nature. 


\section{GHAPITRE XXXVI.}

MÉNOCOURT,

Département de Seine-et-Oise.

A une lieue et demie de Meulan, sur le revers et au nord de la montagne qui borde la Seine sur sa droite, est la jolie terre de Ménocourt. Le parc est d'une étendue assez vaste, dont moitié est en bois, et l'autre a reçu une composition pittoresque; du sommet c'est un tableau admirable. Le château, qui devrait faire face au parc, fait le contraire : il est au nord, sur la partie la plus resserrée du parc; mais la vue se porte dans la plaine jusqu’à l'horizon: dans ce court espace de terrain, c'est un tableau agréable. Un étang s'y fait voir dans une clairière entre deux massifs, 
de sorte que les extrémités de ce lac sont inaperçues du château; ce qui représente une illusion très-prononcée d'un fleuve qui descend de la montagne. C'est en s'approchant sur ses bords qu'on voit ce qu'il est. Du côté de la montagne, l'effet d'un lac est vu de même, mais en sens contraire. Toutes ces illusions proviennent de la manière dont les plantations sont faites et le dessin conçu.

Sur le côté opposé, par où l'on arrive, le château se compose de deux ailes : on a supprimé celle du côté du parc, et percé le bois qui était derrière. C'est une espèce de miracle pour les yeux et l'esprit; c'est une surprise qui ne peut s'exprimer, un magnifique tableau qui se termine dans le haut du parc, très-pittoresque. Cette clairière d'une part, la suppression de l'aile du château, et l'ouverture faite au bois, d'autre part, font jouir de cette belle vue de l'aile du château conservée, qui se troure en face la partie ouest du parc.

Áu milieu de cette merveilleuse clairière, j'ai profité de deux sources d'eau que j'ai réunies, et fait un lavoir pour la maison qui en manquait, au moyen d'un ruisseau à décou- 
rert, qui, dans sa course en traversant le pare devant le château, reçoit deux autres sources, et continue son cours jusqu’à ce que, arrivé au bord de l'étang, il se trouve sur un rocher, d'où il se précipite dans cette vaste pièce d'eau. Visà-vis la clairière dont je donnais plus haut la description, ainsi que de l'effet que produisait l'étang qui paraissait être une large rivière, est un pont de bois qui y fait face : l'eau, enfoncée sous ce pont, présente l'aspect d'une rivière véritable, tandis qu'elle est factice. Il n'y a pas bien long-temps qu'un étranger, voulant satisfaire sa curiosité, pour voir plus loin cette rivière, sortit du parc, et rentra tout étonné de n'avoir vu ni rivière ni pont : il ne put s'empêcher de rire avec les personnes présentes à ce petit spectacle d'un moment.

Comme cette pièce d'ear n'a d'autre ressource que les eaux qui lui arrivent au moyen du ruisseau que j’ai désigné plus loin, il ne sort par conséquent jamais du trop-plein de cet étang, ce qui le rendrait très-monotone, et présenterait à la vue l'effet d'une mare sans mouvement; et, au moyen d'un 
pont assez vaste, établi sur un côté où passe l'allée de ceinture, l'eau s'y enfonce : on ne peut en voir l'extrémité. D'un côté, l'eau arrive sur une cascade; de l'autre, elle sort sous un pont placé sur un bras de rivière: voilà la nature justifiée ; l'oeil et l'esprit n'ont rien à désirer.

Les bords de cette charmante pièce d'eau sontà ravir : ils sont plantés de belles masses de peupliers d'Italie, aulnes, sazles-pleureurs et platanes : tout cet ensemble est admirable et parfait, la végétation étonnante ; tout y est en harmonie.

Ce n'est pas sans peine que je suis parvenu à l'exécution de cet ensemble. MI. et madame de Beaumont en sont les propriétaires. M. de Beaumont me disputait pied à pied l'arrachement d'un arbre, à plus forte raison le percé d'un bois et d'une ouverture de cinquante pieds de largeur sur toute son épaisseur. J'étais fort bien appuyé, ayant pour moi madame de Beaumont, qui aime la belle nature de préférence à ces lignes droites qui font mourir d'ennui. Je m'attendais bien que MI. de Beaumont, en revenant de Paris, se 
serait récrié contre moi d'avoir fait un pareil percé dans son bois. Madame, avant de partir pour Paris, était dans ma confidence, et elle attendait de jour en jour la nouvelle de ce percé. Aussi, comme je me doutais que M. de Beaumont allait arriver, je pars la veille.Quoique M. de Beaumont soit très-bon, très-obligeant, il n'a pas moins crié contre l'auteur du percé. Une heure après, on n'y pensait plus. Madame lui fit ses observations. Je revins; il se mit à rire, et me dit qu'il se félicitait d'avoir été absent, qu’il se serait opposé à ce percé, mais qu’il était content de le voir fait. Il m'en félicita, et tout fut pour le mieux. 


\title{
GHAPITRE XXXVII.
}

\author{
AZAI-LE-RIDEAU,
}

Département d'Indre-et-Loire:

Presque à l'embouchure de l'Indre, dans la Loire, est la belle terre d'Azai-le-Rideau, qui appartient à M. le marquis de Biencourt, père de M. le comte Armand de Biencourt, propriétaire de la terre de Chêne.

Il eśt à observer que l'Indre parcourt en serpentant toute la longueur du parc d'Azai. Sujet à des inondations assez fréquentes, non-seulement le parc en souffre, mais le château se ressent aussi de ces débordemens, qui entraînent et dégradent tout ce qui se trouve sur son passage. On avait fait un trarail assez considérable pour remédier à un 
inconvénient aussi grave ; mais cette précaution est devenue inutile : c'était quelques écluses sur une seule ligne, à l'un des côtés de l'Indre, et tout près du château : ces écluses, au nombre de cinq ou six, ne pouvaient réussir à remplir l'objet qu'on s'était proposé; l'expérience l'a prouvé. Enfin , M. de Biencourt prit le parti de m'appeler pour deux choses : d'abord, pour remédier à l'inconvénient de ces eaux, et ensuite pour donner à son parc ce qui lui manquait. Des haies le découpaient en carrés sur tous les sens. Ce ne fut pas sans peine encore que je pus faire quelque chose. Il m'avait appelé pour prolnuger la vue, pour jouir des beaux tableaux qu'on voit dans le lointain; mais il ne voulait pas que je fisse de percé à ces haies: l'un ne pouvait pas aller sans l'autre. Je fus approuvé par madame de Biencourt et par mademoiselle sa fille, comme je l'avais été par madame de Beaumont à Ménocourt. Le résultat n'était pas le même, en ce que M. de Biencourt tenait à ses arbres.

Au sujet des eaux, j’ai donné à M. de Biencourt le conseil de supprimer simplement 
toutes ces écluses faites à grands frais. C'est toujours lorsque le malade est à l'agonie qu'on va chercher le médecin. Avec des écluses, il faudrait avoir presque nuit et jour un homme en faction pour attendre les débordemens, en été par les orages, et en hiver par suite des pluies et fontes de neige. Le moyen que je proposai était tout simple : Remplacez toutes les écluses par un fort mur qui fera déversoir dans la basse-rivière qui est toute faite, et qui passe devant le château ; montez ce mur ou déversoir à la hauteur où vous voudrez que l'eau s'arrête; calculez, pour sa longueur, sur les masses d'eau qui se présentent: alors, au fur et mesure que l'eau montera, elle sautera plus haut, sans le concours de personne, et il n'y aura jamais par ce moyen d'inondations. C'est après que tous ces détails ont été donnés, et après avoir disposé dans le parc les choses qui étaient à faire, que j'ai repris, au bout de huit jours, la route de Tours, qui est à quatre lieues, et la diligence pour Paris. La route d'Azai à Tours, comme celle depuis Tours qui borde la Loire jusqu’à Orléans, sont très-pittoresques. 


\title{
GHAPITRE XXXVIII.
}

\author{
MAINNEVILLE,
}

Département de l'Eare.

Ce parc, situé sur les confins du département de l'Eure, à quatre lieues de Gisors, sur la droite de la route de Rouen, offre de trèsbelles situations dans une jolie vallée, mais étroite, où coule un joli ruisseau, dont on a formé une rivière qui parcourt, en serpentant, le parc dans toute sa longueur. Au moyen de la chute du moulin, le projet était de faire une cascade qui aurait été vue du château entouré d'un fossé plein d'eau. Mon projet était de le combler, et de le remplacer par des arbres et des fleurs. J'ignore où en est son exécution; il est constant qu'il y a ce qu'il faut 
191

pour faire un beau parc. Cette belle propriété, un peu triste, à cause de son étroite vallée, est riche en bois qui l'entourent de toutes parts. 


\title{
GHAPITRE XXXIX.
}

\author{
MARQUE-ÉGLISE,
}

Département de l'Oise.

Ce parc n'est pas d'une grande étendue, mais il possède de beaux et anciens arbres. Les nouvelles plantations ne le cèdent en rien aux anciennes, à cause du sol qui est excellent. Il est fâcheux que, dans l'ancien temps, on prenait les chosesà contre-sens; et c'est ce qui se roit tous les jours: on traite l'eau en ennemie, par le soin qu'on a de s'en éloigner. Le parc de Marque-Église forme le revers du sol en pente, et forme au pied une vallée, où coule une rivière. Ce parc est coupé en deux par le chemin du village; de sorte qu'au lieu d'avoir adopté pour le parc 


\section{3}

et l'érection du château dans la partie où sont les eaux. Il en a été tout autrement : l'habitation et ses dépendances, qui sont considérables, sont dans la partie la plus élevée du parc, et par conséquent privées du charme dont, dans la partie basse, on aurait pu jouir. Il en est ainsi des personnes qui plus ou moins entendent leurs affaires; il en est ainsi en toutes choses: c'était le goût du temps. 


\section{GHAPITRE XL.}

COULOGNE,

\section{Département da Pas-de-Calais.}

Cette moyenne, mais charmante propriété, connue sous le nom de Maison. Octogne, possède une position à ravir. Le parc borde à l'autre extrémité le canal de navigation de Saint-Omer à Calais. Sa position si belle reçoit de ce canal l'eau nécessaire pour former la rivière qui le parcourt dans toute sa longueur : belle et large derant l'habitation, elle offre l'aspect le plus intéressant. Il existe d'anciens arbres qui offrent des ombrages délicieux. C'est vraiment une propriété charmante, et elle possède une belle pelouse et une belle végétation. 
Cette propriété n'est pas éloignée du fameux pont connu sous le nom de Pont-\$ansPareil, si renommé, et que grand nombre d'artistes, amateurs et curieux, viennent de bien loin visiter et admirer.

Quatre canaux se croisent sous ce pont, qui se compose d'une seule arche sur chaque face : d'un côté, est le canal de Saint-Orner; de l'autre, celui de Calais. Sur les deux autres faces, est celui qui conduit à Dunkerque, et le quatrième à Ardues, petite ville à quatre lieues de Calais. Sur ce pont passe la grande route de cette ville à Saint-Omer. Cette propriété de Coulogne appartient à M. Louis Devot, de Calais, qui est à une lieue. 


\section{GHAPITRE XLI.}

LE BOUCHET,

Département de Maine-et-Loire.

Ce beau parc, situé sur la route de La Flèche à Tours, et à deux lieues de Baugé, est d'une grande étendue. Cette terre touche en partie à celle de l'Aunay-Baffert, appartenant à M. le comte Eugène d'Oisonville, frère du marquis d'Oisonville, propriétaire de cette terre duBouchet. Dans ce parc, il y a un peu d'eau, mais pas assez pour se soutenir pendant l'été : en hiver, elle forme un a assez helle rivière de moyenne grandeur. Le château est situé au milieu du parc ; l'on y arrive par une avenue bien alignée. Cette terre possède une grande quantité de bois faisant 
suite au parc et sur la droite de la grande route. Le château est magnifique; les écuries sont remarquables par leur beauté. Tout est fait sur une grande échelle. Mais ce château est seul au milieu des bois, où il semble qu'on a renoncé au monde entier. 


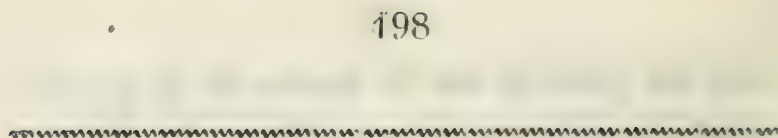

\section{GHAPITRE LXII.}

LE MADRILLET,

Département de la Seine-Inférieure.

M. Prével aîné est propriétaire de cette magnifique propriété, située dans la forêt du Rourray, à une lieue et demie de Rouen, du côté d'Elbeuf. L'habitation consiste en un joli pavillon qui vient d'être réparé complétement, tant à l'extérieur qu’à l'intérieur, où j’ai vu toutes les chambres de domestiques traitées comme les chambres de maîtres : parquets, cheminées de marbre, alcôves décorées. J'en félicite bien sincèrement M. Prével; c'est enfin une véritable bonbonnière que cette maison par ses peintures soignées; seulement le vestibule pouvait être mieux. Le 
jardin n'est pas d'une grande étendue au milieu d'une si belle propriété; il n'a tenu au propriétaire que ce jardin s'étendit davantage, puisque tout ce qui l'entoure est à lui; mais ces bâtimens existaient. Un chemin public est trop près de la maison; mais aussi la vue est très-étendue. Il semble que la ville de Rouen, dont je me suis déjà emparé plusieurs fois, fait partie de ce jardin, avec ses nombreux clochers, ainsi que les montagnes qui bordent la Seine : tout est parfait.

M. Prével fait valoir la ferme qui touche presque à l'habitation; et tout ce qui l'environne, bois et terres labourables, hi appartient. 


\section{GIAPITRE XLII.}

BRYÈRE,

Département de Seine-et-Oise.

C'Est toujours avec un nouveau plaisir que l'on quitte une jolie propriété pour passer à une autre aussi belle. Ce château, fort beau et considérahle, est situé à Bryère, à une lieue d'Arpajon, sur la route de Dourdan par Longjumeau. La vue est très-belle, et domine une vallée et ses alentours : on voit des villages et des clochers en grand nombre qui forment de jolis points de vue sur les hauteurs.

Il y avait une belle futaie dans ce parc lorsque je l'ai recomposé, qui donnait de beaux ombrages. Au bas du parc est un petit lac qui ne tarit jamais. A l'extrémité est un pont de 
bois pour le même motif que celui de Ménocourt, afin de motiver cette pièce d'eau, en indiquant une rivière sur laquelle est un pont. L'entrée du parc a été changée : maintenant on arrive sans entrer dans le village. Du salon, la vue se porte sur la route: on ne la voyait pas auparavant : aussi cette belle propriété, fort étendue et magnifique, ne laisse rien à désirer. De belles masses, de beaux arbres, et des fleurs en abondance, voilà les détails de cette belle propriété, qui appartient à M. d'Assi. 


\section{GHAPITRE XIIV.}

Ce chapitre se compose de quatorze jardins trop peu importans pour en donner une description particulière. Je me borne à citer les pays où ils sont situés, tous aux environs de Paris, savoir : Grenelle, Boulogne, Auteuil : celui-ci est encore assez important; Passy, Courbevoie, Nogent-surMarne, Fontenay-sous-Bois, Saint-Maur, Chaillot, Bellevue; à Neuilly deux; Chatenay, qui est assezimportant; Ruelle, joli jardin avec une cascade formant un ruisseau qui parcourt le jardin. Tous ces jardins sont dans le département de la Seine; un seul à Livry, département de Seine-et-Oise. 


\title{
GHAPITRE XLV.
}

\author{
VILLETTE,
}

Département de l'Eure.

Prìs la belle terre de Canappeville, appartenant à madame de Toustin, est la commune de Villette, où est la propriété de M. Grandin, qui ne possédait presque pas de jardin. Par une nouvelle composition, il va s'agrandir de plusieurs portions de terrain perdues, telles que quinconces en tilleuls et pommiers ; tout cela réuni produira un jardin d'une assez belle dimension et fort intéressant. Cette propriété n'est qu'un pied-à-terre et un provisoire en attendant mieux. L'habitation, qui n'est pas un château, est propor- 


\section{4}

tionnée au jardin, qui cependant, étant terminé, sera remarquable, par sa composition et des points de vue délicieux sur les paysages qui l'environnent. 
205

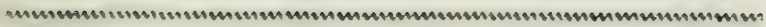

GHAPITRE XLVI.

LE MARTOT,

I'épartement de la Seine-Inférieure.

C'est un bel héritage que vient de faire M. le marquis de Biencourt, non celui d'Azaile-Rideau, mais MI. le marquis de Biencourt de Mennière, que madame sa mère rient de lui laisser par sa mort, à l'âge de quatre-ringtquatre ans.

L'âge avancé de madame la marquise ne lui permettait pas de s'occuper de ses propriétés: aussi le château était susceptible de réparations; ce que fait en ce moment $\mathbf{M}$. de Biencourt, en commençant par la construction d'un escalier qui s'exécute en remplacement d'un qui était inhabitable. Il va en être ainsi du parc, qui est d'une "belle étendue, 


\section{6}

et dont j'ai anssi fourni le plan de la composition. Ce sera une merveille de la nature que ce parc lorsqu'il sera exécuté, par sa situation heureuse, par ses jolis points de vue sur l'admirable forêt du Pont-de-l'Arche, et sur la face opposée, du côté de l'arrivée, sur la Seine d'abord, ensuite sur la chaine de montagnes qui la bordent sur sa rive droite: les unes couronnées de forêts, d'autres agrestes, d'autres enfin où sont quelques moulins à vent. Tous ces détails de points de vue sont une bonne fortune pour les personnes qui habitent cette charmante propriété, à laquelle madame de Biencourt n'a jamais pensé. Cette propriété du Martot est à moitié chemin et à gauche de la grande route du Pont-de-l'Arche à Elbeuf. Le Martot est le nom du village qui touche à celui de Fréneuse, sur le bord de la Seine : tout le monde sait qu'il est renommé pour ses bons navets. On faịt une erreur dans la prononciation: le vulgaire dit, les bons navets de Maltot, au lieu de dire Martot: les navets de Fréneuse sont les meilleurs de la France. Il ne manque à cette belle propriété que de l'eau. Le terrain est sa- 
blonneux et léger; un puits artésien y ferait merveille, persuadé, à cause des montagnes qui l'entourent, que le percement d'un puits ne serait pas sans succès. Je viens de me plaindre du manque d'eau; maintenant je me plaindrai, non pas d'avoir une église paroissiale, mais bien de ce qu'elle est trop près du château : il n'y a pas quarante toises de distance, encore est-ce du côté de l'arrivée; de sorte qu'on a une église avec son cimetière et tout son mobilier, et un chemin public qui coupe en deux la pelouse pour la traverser. Si encore l'église était du côté du village, ce chemin s'arrêterait à l'église; mais il n'en est pas ainsi.

Il était du bon ton pour les seigneurs d'autrefois d'avoir sous leurs fenêtres l'église paroissiale et les paroissiens, qui sont toujours mieux de loin que de près, et des cloches qui vous étourdissent; et ce qui me fait croire que c'est le seigneur qui a voulu l'église presque dans son salon, c'est que le terrain sur lequel elle est bâtie lui appartient. Aujourd'hui ses successeurs, qui n'ont pas le mème goût, sont obligés de souffrir le pas- 
sage en tout sens des habitans qui ront à la messe, à rêpres et au salut, ou à confesse; de ceux qui ront se marier, des nouveau-nés qu'on porte au baptême, et des morts qu'on enterre. Mais ce qui me fait croire que les habitans de ce village ne sont pas très-embarrassans, c'est que pendant trois jours que je suis resté au château, à peine si j'en ai vu un ou deux venir à l'église : le droit n'en existe pas moins, elle a pris possession, c'est une servitude acquise. Une grande partie du parc offre de beaux taillis, de superbes arbres: qui procurent d'agréables ombrages; mais le bonheur d'aroir une église et ses habitars dans son jardin n'en serait pas un pour moi. 


\section{GHAPITRE XLVII.}

LA GRANGE-AUX-ORMES,

Département de la Moselle.

Lors de mon voyage, en mars i 831, à Metz, pour le parc de M. Marchal de Corni, j'y allais également pour celui de la Grange-auxOrmes, appartenant à M. le comte Léon d'Ourches. J'ai commencé par le parc de Corni, ainsi qu'on en voit la description au chapitre XvIr de cet ouvrage; ensuite je me rendis à la Grange-aux-Ormes, où j'étais attendu pour donner la dernière main à ce parc, qui depuis si long-temps est en souffrance, et qui est réellement étonnant par ses masses énormes. Ce parc avait été commencé avec 
le propriétaire par M. Blake, auteur anglais; ensuite un architecte suisse, $\mathbf{M}$. Caillat; un troisième, M. Berthaut, architecte fameux pour le genre pittoresque : il est décédé; un quatrième, M. Vergniaud, autre architecte de Paris; un cinquième dont le nom m'est inconnu; enfin un sixième. Je me suis présenté aussi sans succès; je me suis contenté de passer vingt-quatre heures à la Grange-auxOrmes. Ce parc est extrêmement grand, bordé au fond de la vallée par la Seille, rivière qui va se décharger dans la Moselle, et dans laquelle vont se jeter ces ruisseaux qui viennent du haut du parc, qui sont autant d'eaux perdues.

Qu'il est pénible de roir tant de richesses méprisées et cachées dans les ronces et les épines, dans un beau parc où il n'y a presque ni communication ni rivière, tandis qu'en réunissant tous ces ruisseaux, en lui donnant ce qui lui manque, on aurait, je puis le dire, le plus beau parc de la France, par l'effet de ses eaux abondantes! des cascades à faire et des promenades qui manquent. Combien de mérite et de richesses pour cette propriété! 


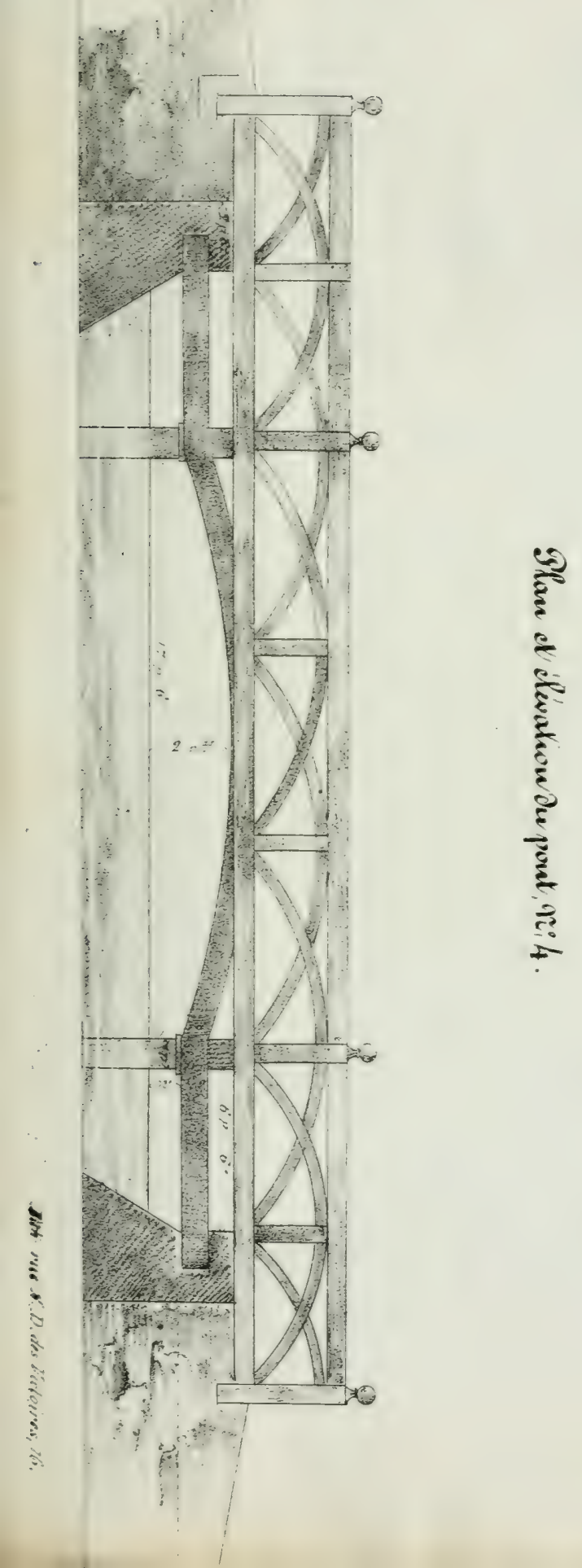



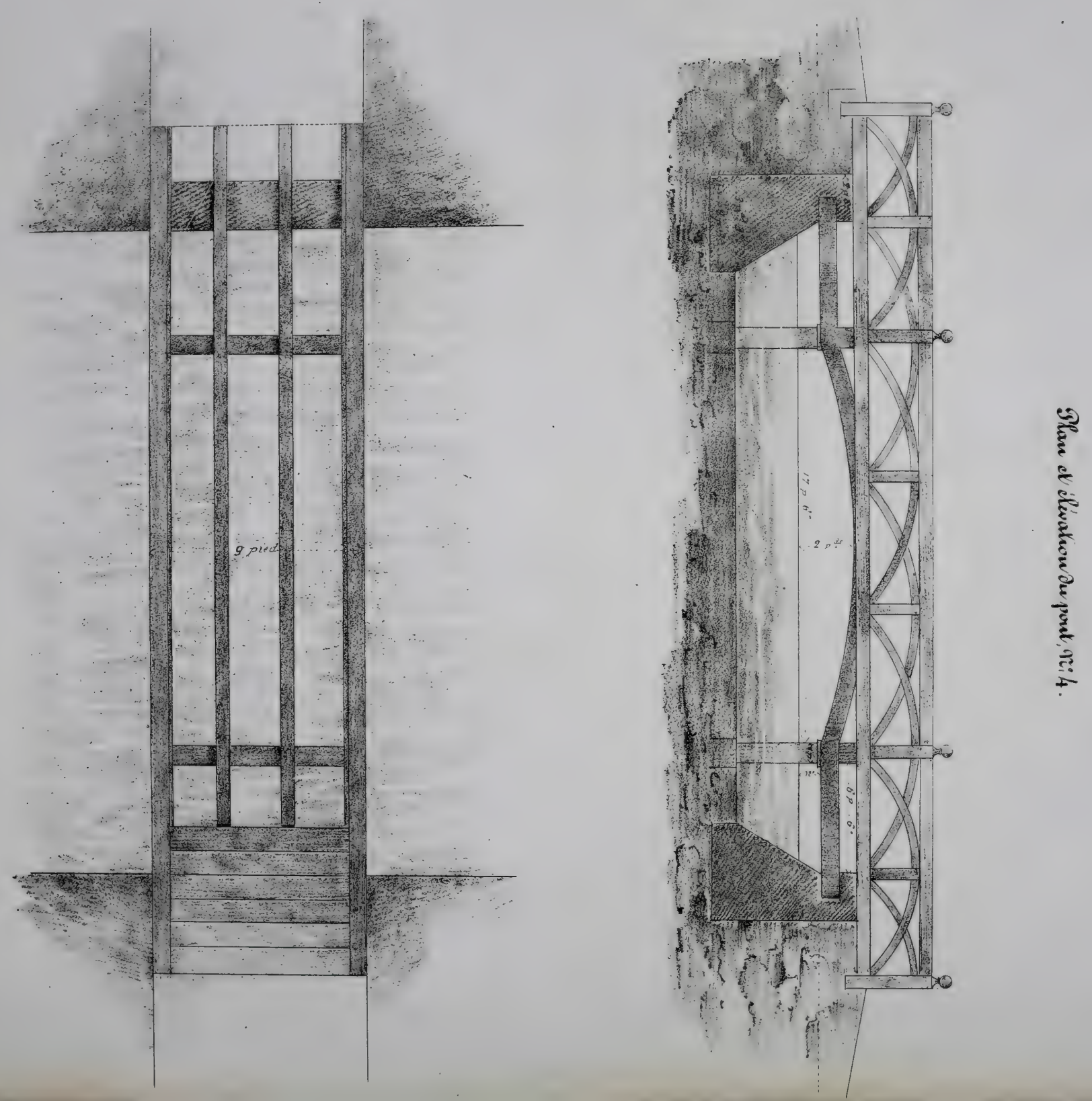
Je ne puis y penser sans être peiné jusqu'à l'âme. Si la fortune de MI. Dourches ne lui permettait pas de faire cette dépense, il serait excusable; mais MI. Dourches est trèsriche, garçon, tenant une maison toute simple et sans aucune espèce de luxe ni de dépense futile. Oì la nature va-t-elle prodiguer ses dons! chez un propriétaire qui les méprise, que tant d'autres désireraient avoir. C'est rraiment un crimeà mes yeux qu'un tel mépris de choses aussi belles, qui donnent à la scène champêtre tout le charme et tout l'éclat dont elle est susceptible. Je quitte ce sol de deuil, queje n'occupe que sur le papier, aprèsl'avoir occupé réellement; que pour l'oublier pour toujours, à cause du mépris et de la plus grande des ingratitudes envers la nature, qui vous offre en abondance tous ses dons les plus riches et les plus brillans, qu'elle refuse à tant d'autres qui en sauraient mieux profiter que M. Dourches. Hélas! pourquoi MII. Marchal de Corni ne possèdent-ils pas tous ces dons, dont ils seraient reconnaissans! Quelle richesse ils donneraient à leur propriété ! Je blâme M. Dour- 
ches d'avoir tant fait pour son parc et de ne pas finir le peu qui reste à faire : il pourrait en jouir ; car il n'y a pas de plus belle jouissance que la vue de la belle nature : elle cause des sensations agréables et profondes. 


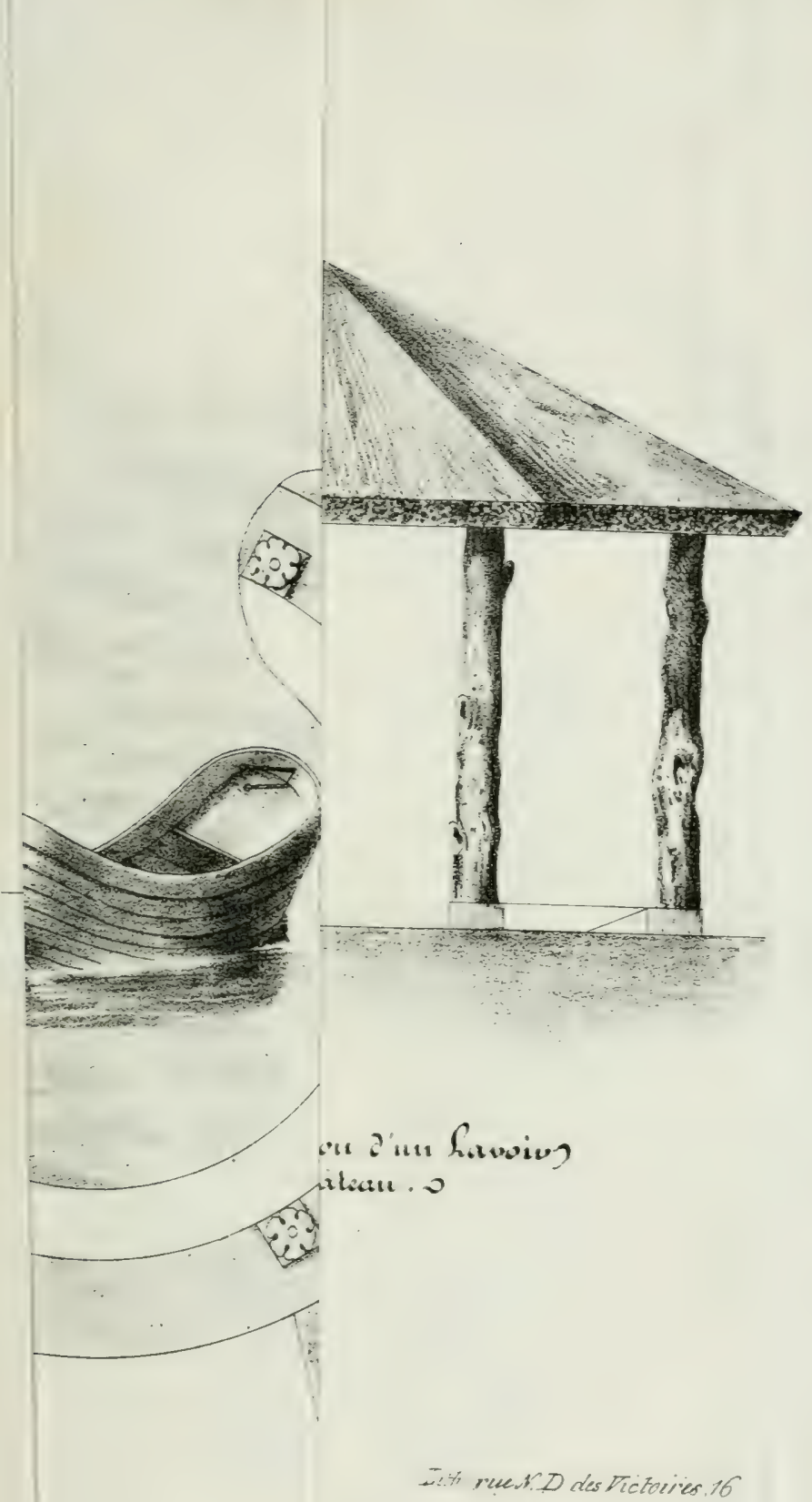




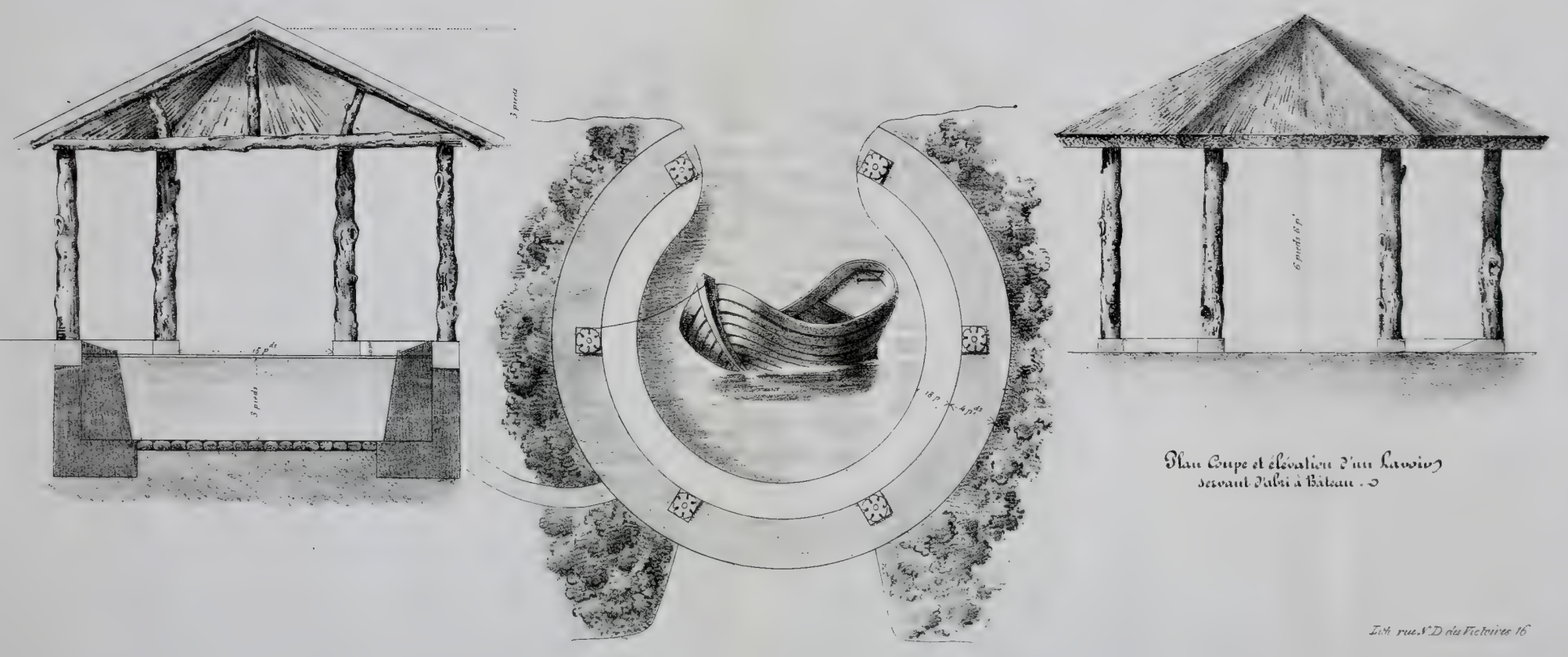




\section{GHAPITRE XLVIII.}

Ce chapitre se compose de plusieurs parcs qui n'ont rien de plus remarquable que ce qui a été dit dans les éditions précédentes, savoir :

Boulogne, département de la Seine, M. Cinot, propriétaire, décédé.

Bagneux, département de la Seine, M. Quiclet.

Vendieire, presque au bord de la Marne, département de la Marne, M. Decrousseaux, propriétaire.

Dans le département de l'Orne :

Les Routis, M.de Moucheron, propriétaire.

Longny, M. Leroy, propriétaire.

Livet, M. Aruet, propriétaire.

La Génévraye, M. de la Génévraye, propriétaire. 
O, M. Roque, propriétaire, décédé.

Guesprès, M. de Guéroux, propriétaire.

Vimer, M. le général Saint-Alphonse, propriétaire.

Moulin-Chapeİle, département de l'Eure, M. le comte de Saint-Denis.

Ciracouvilie, département de l'Eure.

Chamblac, département de l'Eure, M. Lavarende, propriétaire.

Primars, sur le bord de la rivière d'Eure, IV. de Demasis :

Mareuil, département de la Dordogne, M. Durclus.

Saint-Léger, département de l'Eure, M. de Saint-Léger.

Pinson, département de l'Eure, M. le marquis de Laporte.

Saint-Omer, départementdu Pas-de-Calais, M. le maire de Saint-Omer.

Viliette, près Meulan, département de Seine-et-Oise.

Giffre, département de Seine-et-Oisc: M. Joly a vendu.

Beaurepaire, département de l'Oise. madame de Cornieux, décédée. 
Le Buisson-de-Mai, département de l'Eure, sur le bord de la route d'Evreux, madame la marquise Dambert.

Romilly-sur-Seine, département de l'Aube, M. Worms de Romilly.

Sainte-Maure, département de l'Aube, M. le comte de Chavaudon.

Fontaine-Lavaganne, département de l'Oise.

Soisy-sous-Étioles, département de Seineet-Marne, le marquis de Bourbon-Conti.

Chatenay-les-Bagneux, département de la Seine: M. de Fontaine a vendu.

Acqueville, près Poissy, département de Seine-et-Oise, M. le baron de Latour-Foissac.

Fortoiseau, près Melun, M. de la Vigerie. Corcy, près Villers-Cotteret, M. le baron de Montbreton. 


\title{
GHAPITRE XLIX.
}

\author{
ÉTAMPE, PRÈS CHATEAU-THIERr,
}

Département de l'Aisne.

Ce parc contient soixante arpens; il appartient à M. le contre-amiral baron de Nervo, qui l'a cédé à son fils.

C'est une beauté de la nature que ce parc. De l'eau dans les caves du château placé sur le haut du parc, qui est situé sur le revers de la montagne qui fait face à la Marne et à Château-Thierry. Un puits artésien serait bien encore dans ce parc, n'ayant pas assez d'eau pour former une rivière, que j'ai eu intention de faire parcourir toute la longueur du parc, dont la vue est extraordinaire sur la Marne et sur toutes les montagnes couvertes 


\section{7}

de bois et de villages qui la bordent. Rien n'est plus beau et plus pittoresque que tous les points de vue qui se font admirer, surtout du haut du parc et du château. La Marne qui serpente de toutes parts contribue encore à enrichir ces beaux et rares tableaux. 


\title{
GHAPITRE L.
}

\author{
CÉRY-FONTAINE,
}

Département de l'Eure.

Céry-Fontarne est à deux lieues au-dessus de Gisors, sur la route de Gournay. Cette propriété possède une grande richesse, presque aussi rare qu'à Gournay (Oise). Une source dans la cour des écuries fait tourner un moulin à dix toises de distance, il y a plus d'eau qu'il n'en faut pour le moulin, car j'ai établi une rivière avec le trop-plein, avec trois cascades. M. le comte de Bourbon-Conti, qui en est propriétaire, a donné au parc et au château la composition qui en fait aujourd'hui l'ornement. Cette belle terre ne lui appartient plus : elle a été vendue tout récemment. 


\section{GHAPITRE LI.}

SOISY-SOUS-ÉTIOLES,

Département de Seine-et-Oise.

Sorsy-sous-Étroles appartient à M. le marquis de Bourbon-Conti, frère du précédent. Ce parc, d'environ vingt arpens, est placé sur le revers de la montagne de Soisy, qui fait face à la vallée où passe la Seine, à deux lieues au-dessous de Corbeil. Sa jolie position, en face de Petit-Bourg, sur le côté opposé à la Seine, fait arec son parc un riche point de vue. Ensuite on voit au hord de la Seine le château et le parc du brave général Dauménil, gouverneur du château de Vincennes, qui a si bien su le défendre en 1814 et 1815 , et que le roi et la patrie viennent de perdre. 
Un ruisseau parcourt aussi le parc dans toute sa longueur, venant de la forêt de Sénart, qui est tout près de cette propriété.

Cette habitation est une beauté : de beaux arbres, une belle prairie, des fruits en abondance; tout y est à faire plaisir; il ne reste rien à désirer. 


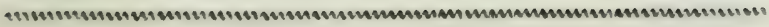

\section{GHAPITRE LIT.}

LE PARC, A SAINT-PIERRE, PRÈS ELBEUF,

Département de la Seine-Inférieure.

LE Parc est le nom de la propriété. Son parc n'est pas d'une grande étendue, mais il est admirable et d'un accord parfait; la seule chose à désirer est l'éloignement du jardin légumier, qui , à ce qu'il me semble, va recevoir son exécution; de sorte que ce parc, au milieu duquel est l'habitation, ne sera pas reconnaissable: du reste, elle possède des points de vue délicieux sur la belle forêt du Pont-de-l'Arche, et sur les montagnes qui bordent la Seine. Cette propriété appartient à M. le comte de Boussey.

A deux lieues de cette propriété est le joli 
château de Saint-Ariberoue, dont l'aspect est très-grandiose ; il appartient à M. de Guénet. Cette propriété est du premier ordre et d'une grande étendue : il y a une vallée délicieuse, entourée de bois. Ce parc n'est pas de ma composition : il offre des beautés étonnantes. 


\section{GHAPITRE LIII.}

LIVERDY,

Département de Seine-et-Marne.

Ce parc est remarquable par un étang de cent arpens qui vient d'être mis en labour par le nouveau propriétaire: c'est un malheur pour la beauté du parc, mais un bonheur pour le pays, à cause du mauvais air que cet étang produisait dans les basses eaux d'automene; du reste, le parc est beau. Lorsque cet étang existait, il semblait qu'on était transportésur lesbords de la mer, par les nombreux canards saurages qui s'élevaient par troupeanx, et qui habitaient cette immense pièce d'eau. 


\section{GHAPITRE LIV.}

LE MONCEAU,

Département de Seine-et-Marne.

Cetre belle propriété touche à celle de Lirerdy. La différence de ces deux parcs consiste en ce que le précédent perd de son éclat et de sa richesse parla perte de son étang, tandis que celui du Monceau gagne par les embellissemens que fait continuellement M. Gavet, qui en est le propriétaire. Il y a de beaux arbres et de beaux ombrages; on vient d'y construire des ponts sur un joli ruisseau qui le traverse. Ce parc, ayant d'un côté un joli taillis, est admirable; mais en s'éloignant, on est au milieu des plus beaux bois des environs: il sont en grande quantité, et appartiennent à la propriété. 


\section{CHAPITRE LV.}

LA MOTTE, EN SAYOTE, PRÈS CHAMIEÉRY.

Ce parc est extraordinaire par sa situation et la réunion de deux ruisseaux, qui forment une jolie rivière qui parcourt le parc en passant devant le château, et qui tombe dans dix-sept cascades nouvellement construites, et dont les eaux tout écumantes vont se reposer dans un étang au bas du parc, pour ensuite parcourir une rivière et reprendre leur premier cours, pour alimenter les moulins qui s'y trouvent.

C'est une chose admirable que de voir le jeu de toutes ces cascades, dans lesquelles l'eau se débat en tcut sens, pour ensuite reprendre son calme ordinaire.

C'est un coup-d'oeil charmant que de voir 


\section{6}

toutes ces montagnes énormes, ces blocs majestueux, et ensuite, dans une portion du parc, ces vignes dont les branches sont suspendues aux arbres et forment des guirlandes agréables : c'est ainsi que le raisin atteint sa maturité, dans ce pays que j’ai quitté en octobre 1813, pour revenir par Genève et Lyon. Ce parc m'a occupé trois mois pour le faire exécuter; j’y ai employé cent trente ouvriers tous les jours. Par l'immensité de ce parc, de ces travaux, de ces rivières et de ces cascades, il fait l'admiration de MI. le marquis et de madame la marquise de Costa, qui en sont les propriétaires; j'ai des lettres par lesquelles madame de Costa me témoigne toute sa satisfaction sur un parc qui fait ses délices. 


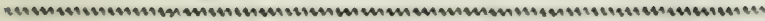

\section{GHAPITRE LVI.}

FRÉTHUY,

Département du Pas-de-Calais.

CE parc n'est pas à comparer avec le précédent, ni pour la dimension, ni pour l'élévation de ses montagnes, et encore moins pour ses cascades. Le parc de Lamotte en a dix-sept, Fréthun n'en a qu'une; mais quoique celui-ci soit sur une plus petite échelle, il n'en est pas moins admirable: à celui-ci les choses sont plus rapprochées, on peut mieux les soigner; tout en est plus recherché. MIadame Becquet, à qui appartient cette propriété, qui, comme madame de Costa de Lamotte, aime beaucoup la belle nature, ne lui cède en rien sur ce point. J'ai fait une 
remarque qui est vraie, c'est que partout les dames aiment ardemment la belle nature, et partout j'ai besoin de leur concours et de leur appui pour vaincre souvent des choses sur lesquelles les maris sont tenaces.

Le parc de Fréthun possède une île, un pont en bois pour sa communication, de beaux arbres et des fleurs. Les premiers procurent de beaux ombrages; les fleurs l'embellissent et offrent des parfums : tout y est parfait. Une nièce de madame Becquet, mademoiselle Cornélie, a, dans le temps, suppléé à mon absence; elle a dirigé les travaux à merveille après mon départ : son goût en ce genre ne cède en rien à celui de madame sa tante, pour les paysages et la belle nature. 


\title{
GHAPITRE LVIY.
}

\author{
PLessis-VILletTe, \\ Dérarteunent de' l'Dise.
}

Près Pont-Sainte-Maxence est la jolie propriété de Plessis-Villette, appartenant à M. le marquis de Villette. Ce parc, qui borde d'un côté la grande route, possède tout ce qui est nécessaire pour être un des plus beaux qui soient en France : des eaux en abondance, un sol excellent, et une végétation parfaite. Mais ce parc, qui n'offre que les matériaux nécessaires pour en faire quelque chose de bien, est mal distribué : point de chemins, par conséquent point de communication; de beaux arbres mal placés : c'est une prairie plantée tant bien que mal; point d'intérêt, ni 
tableaux; des eaux mal distribuées, une rivière mal dessinée, et sans aucune espèce d'intérêt. Villette est sur la droite de la route. Le château fut bâti par M. le marquis de Villette, père de II. le marquis de Villette, aujourd'hui vivant, en $179^{\circ}$, avec les matériaux que lui donna le prince de Condé, provenant de la démolition du château de Verneuil, près Creil, élevé par Henri IV pour sa maîtresse, la belle marquise de Verneuil. Sur le côté gauche de la route opposé, on trouve un ruisseau qui entre dans le parc de Villette, après avoir parcouru une immense prairie de dix-huit cents arpens, au milieu de laquelle on voit encore les fondemens de l'antique château de Fontaine-leComte, avec ses anciens et larges fossés à moitié remplis; on voit aussi l'emplacement de ses immenses avenues : ces restes offrent encore les débris de la magnificence royale et de la grandeur. Ce château fut bâti en 1519 , sur les dessins de feu Bellamaire, architecte du roi. Cette belle terre fait partie de celle de Villette. 


\section{GHAPITRE LVIII.}

SAINT-AUGUSTIN,

Département de l'Allier.

Ce joli parc, d'une grande étendue, a été recomposé entièrement. Un étang entouré de bois, assez considérable, m’a donné motif de faire une rivière qui, alimentée par l'étang, parcourt le parc dans toute sa longueur sous une épaisse voûte causée par des chênes magnifiques, qui font l'admiration des connaisseurs. Cette rivière, après avoir été traversée par deux ponts, va s'enfoncer sous une voûte de rochers, que l'on voit dans cet ouvrage, dans une des gravures; on ne la revoit plus; elle sort de l'étang au travers d'un rocher, où elle prend naissance, et disparaît de même 
232

dans un autre rocher. Quel beau tableau que la vue de l'étang, du château! quel admirable tableau encore que la vue de cette futaie si extraordinaire! Cette terre appartient à M. le comte de Jouville. Elle est située à deux lieues de l'Allier (rivière). 


\section{GHAPITRE LIX.}

GRANGE-MÉNART,

Département de Seine-et-Marne.

CE parc, d'une moyenne dimension, situé à trois lieues au-dessus de Coulommiers, appartenant à $\boldsymbol{M}$. de Fontaine, possède un étang de plusieurs arpens, une l̂le très-pittoresque: deux ponts y communiquent. Le château et la ferme sont dans ane île, entourés d'un fossé rempli d'eau. Des bois immenses font partie de cette charmante propriété, et entourent le château. Des points de vue admirables sur des villages, ou des bois, dans le lointain: tout est en harmonie, tout est gracieux et charmant. La description est plus complète aux quatre premières éditions. 


\title{
GHAPITRE LX.
}

\author{
MOTTREAU, PRÉs BROU,
}

Département d'Eure-et-Loir.

Ce parc, appartenant à M. de Guénet, possède une rivière, mais fort encaissée, des points de vue admirables. A mon retour, sur la route qui conduit à Chartres, et à dix pas de distance sur les bords d'un champ, entre Brou et Illiers, est une pierre brute d'environ dix pieds de hauteur, sur quatre à cinq de largeur, et d'environ deux pieds d'épaisseur, dont la bizarrerie m'a fait arrêter pour l'examiner. Cette pierre était un des autels des Druides, qu'ils avaient plantée debout; ils se prosternaient au pied pour adresser leurs 
prières à Dieu. A la vue de cette pierre, on est tout étonné de la voir en cet état depuis tant de siècles, assise sur la partie la plus frêle, et que toutes les générations ont respectée. 


\title{
GHAPITRE LXI.
}

\author{
SERMTAISE ,
}

Département de Seine-et-Marne.

CE parc est de peu d'importance; mais sa situation, qui domine une vallée de toute beauté, où l'on admire la Seine qui serpente dans cette longue étendue, à trois lieues audessus de Melun; il appartient à M. le général Lamotte. C'est un tableau enchanteur que cette riche vallée.

Le sol de Sermaise est historique, et mérite quelques détails. Du temps de JulesCésar était une ville que ce conquérant fit brûler pour punir ses habitans d'aroir maltraité quelques-uns de ses soldats. Ce hameau, car il n'est plus autre chose, esı bâti sur les 


\section{7}

anciens fondemens de la ville de Sermaise, qui était considérable. Suivant la tradition, Melun et ses environs seraient bâtis des matériaux provenant des démolitions de cette ancienne ville. On remarque encore, en outre des restes qui existent, ceux d'un pont de pierre sur la Seine.

Les habitans de Sermaise ont la réputation d'être les meilleurs cultivateurs de la contrée. 


\title{
GHAPITRE LXII.
}

\author{
NOGENTEL,
}

Département de la Marne.

Cetre jolie terre appartient à M. le général d'Ambrugeac. Le parc est immense; une rivière le parcourt dans toute sa longueur, et fait tourner un grand nombre de moulins avant de se jeter dans le Morin.

Cette rivière, que j’ai fait passer sur un large ravin, au moyen d'un aqueduc que le général a fait construire, arrose cette partie du parc, et se précipite dans une cascade pour reprendre son ancien cours. Feu Bonnard, architecte, est l'auteur de ce joli parc, qui a été exécuté sur ses dessins.

Cette terre est située entre La Ferté-Gaucher et Montmirail. 


\section{GHAPITRE LXIII.}

GOURNAY,

Département de l'Oise.

CE parc, d'une contenance de cent vingt arpens, est sans contredit un des plus beaux de la France : il appariient à M. Auguste Perrot. On pourrait faire à ce parc l'application d'une des villes d'Amérique, dans le Canada,, qui se nomme Trois-Rivières, par la raison que cette ville a pris son nom de trois rivières auprès desquelles elle est placée, et qui se déchargent dans le fleuve Saint-Laurent.

Gournay possède aussi trois rivières et un grand nombre de ruisseanx; toutes, excepté une, prennent leur source dans le parc. Rien 
n'est plus beau que ces eaux abondantes. Une de ces rivières a soixante et quatre-vingts pieds de largeur; elle se voit du château, et produit un effet admirable : des arbres magnifiques, des tableaux étonnans. 11 reste encore à ce beau parc quelques travaux à terminer, qui touchent à leur fin. Une de ces rivières, qui vient de l'extérieur, fait tourner un moulin à l'ex trémité du parc; les autres sont moins élevées que celle-ci : ce qui m'a ôté les moyens d'augmenter celle du moulin avec les eaux des autres rivières moins élevées.

Un tableau principal se termine dans le fond du parc par un pont sur un bras de rivière. Derrière ce poit, esı un fort massif de peupliers d'Italie, qui terminera ce tableau. Cette rivière prend sa source à cent toises sur la gauche du pont, au pied d'une montagne, dans un circuit d'environ douze pieds de diamètre; deux fortes sources, extrêmement abondantes, font bouillonner tout ce bassin, qu'on ne peut mieux cornparer qu'à une chaudière placée sur un grand feu: aussi ce circuit d'eau se nomme le Bouillon. Une infi- 
nité de sources, dans son cours jusqu'au pont, se remarquent à chaçue pas, et si l'on reut se: donner la peine de suivre le cours de cette rivière jusqu'à sa sortie du parc, qui a, sans contredit, plus d'un quart de lieue de longs, on en remarquera encore des quantités.

Ce bouillon, très-rare, n'est pas cependant sans exemple; je ne puis mieux le comparer qu’à la source du Loiret; cette dernière est beaucoup plus forte, puisqu' elle porte bateau; moi-même a été sur cette source en bateau. Cette rivière du Loiret n'a que deux lieues de cours pour aller se décharger dans la Loire, au-dessous et à peu de distance d'Orléans; sur son cours de deux lienes, commc la rivière du Bouillon de Gournay, qui prend de trois rivières réunies le nom d'Arronde: celle du Loiret a aussi des sources très-multipliées jusqu’à son arrivée dans la Loire. Ainsi la nature, si belle, si pure et si riche, est quelquefois comme certains pères de famille dans l'ancien régime, qui, sous le titre de droit d'aînesse, donnaient à l'aîné de leurs enfans toute leur fortune, et les antres, quoique les égaux de l'ainé, étaient souvent privés 


\section{2}

du nécessaire pour ce frère ainé, qui n'avait d'autre titre que d'être né le premier de la famille. La nature en fait autant; elle donne aux uns toutes ses richesses, des eaux en abondance, et aux autres rien. M. Auguste Perrot est traité en cette qualité, par la nature, en fils aîné; il possède des eaux en abondance : aussi il ne se plaint pas.

Je m'empresse de rectifier une erreur qui s'était glissée aux premières éditions, du nom de la rivière du parc de Gournay, qui se nomme Arronde; et non Odon.

L'entrée du parc, sur la grande route, a besoin d'une clôture, en une grille, qui serait nécessaire pour être chez soi. Je ne saurais finir ce chapitre sans parler encore des richesses de ce parc : des îles, des ponts, des canaux qui se communiquent, des tableaux ad̀mirables; et le château, en partie démoli dans la première révolution, rétabli, forme maintenant les bâtimens des écurjes et remises dans ce qui est le souterrain d'un côté, et rezde-chaussée sur la cour, à cause de l'inégalité du sol; et ce qui était autrefois le bâtiment nommé le Commun, est maintenant le châ- 
teau. Voilà donc la véritable égalité dans l'habitation de Gournay. L'ancien château et le Commun se cèdent réciproquement les honneurs; ce qui a causé des dépenses au propriétaire pour mettre les choses à leur place: il le fallait bien, puisqu'il les a trouvées en ce triste état. Aujourd'hui tout est beau, et chaque chose est ce qu'elle doit être. 


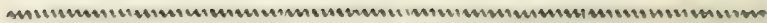

\section{CHAPITRE LXIV.}

CAPPY, PRÈS VERBERY,

Département de l'Oise.

CE parc est merveilleusement situé, depuis le fond de la vallée jusqu'au sommet de la montagne qui lui fait face, où coule l'Osse, qu'on ne sait trop admirer. La vue se prolonge sur cette belle vallée, occupée en partie par la forêt; ce qui n'empèche pas la vue de s'étendre jusqu'aux portes de Compiègne, qui est à trois lienes. Il n'y a pas de tableau plus riche, lorsqu'il est vu de la montagne. Arrivé au fond, dans la partie basse du parc, la scène change : une belle verdure, une jolie pelouse, une île entourée d'eau, des promenades de toute beauté. On 
voit d'un côté l'église de Saint-Vast, de l'autre la grande route. Il est seulement fâcheux cu'un chemin public sépare la partie haute da parc de la partie basse et du château. Cette jolie propriété appartient à MI. le vicomte Desfossés, homme rempli de talens et de goût. 


\section{CHAPITRE LXV.}

OBSERVATIONS SUR LE DÉPARTEMENT DE L'OISE.

On ne peut disconvenir que le département de l'Oise possède de grandes beautés de sites et des paysages charmans. Les principaux pares de la France appartiennent à ce département : Cappy, dont nous venons de parler, Villette-Plessis, Gournay, Beaurepaire, Vilİers-Saint-Paul, appartenant àMI. le maréchal Gérard, Morfontaine, Armenonville, les Essarts, nouvellement composé, et dont il reste encore à faire; mais je parle de ce qu'a fait la nature, qui est la part la plus difficile à obtenir : c'est à l'art à faire le reste. La nature a tout fait pour les propriétés que je viens de nsmmer, et qui ont acquis tant de célébrité. 
Villers-Saint-Paul, Morfontaine, Armenonville et Villette ne sont point de ma com. position; ils n'en sont pas moins remarquables : c'est en cette qualité que je les rappelle ici au lecteur.

Cequi n'est pas parc, mais pays pittoresque sans art, c'est une vallée admirable que l'on rencontre sur la route de Creil à Clermont, encore du département de l'Oise. Après aroir passé Nogent-les-Vierges, on arrive à Ningueville. Une vailée à droite de la route s'offre à vos regards : l'effet pittoresque en est charmant; c'est une merreille de la nature. Cette vallée sublime se prolonge dans le lointain derrière une forte masse de peupliers, où elle disparait en laissant des regrets de ne la pouvoir suivre plus loin. Cette vallée romantique remplit le royageur d'idées qu'il emporte avec lui, et qui, après aroir occupé ses yeux, ne cessera de long-temps d'occuper son esprit. 


\section{GHAPITRE IXVI.}

MA curiosité ne s'est pas seulement arrêtée sur la vallée que je viens de citer; mais aussi, cn sortant de Rouen par la route de Neufchâtel, entre cette route et celle de Dieppe, au haut de li montagne, le Mont-aux-Malades, charmant village pittoresque, où il se tiouve un petit séminaire, se fait voir en entier ; beaucoup de jolis pavillons et un assez grand nombre de jardins. Cette position est à ravir, et sans contredit ure des plus belles des environs de Rouen, et sur une des monlagnes les plus élevées qui bordent la Seine.

De la route de Neufchâtel, position superbe pour jouir de la vue du joli village de Mont-aux-Malades, on voit à droite la jolie vallée de Darnetal, arrosée par deux pelites rivières quila parrourent: l'une prend 
sa source à Fontaine-sous-Préaux, et porte le nom de rivière de Robec; elle traverse la commune de Saint-Martin. Cette rivière est précieuse parles nombreux moulins à blé qu'elle alimente, des filatures de coton, des fabriques d'indiennes et des teintureries, et une grande quantité de moulins à foulon pour les fabriques de draps.

L'autre rivière, qui prend sa source dans la vallée de Saint-Aubin, est moins considérable: elle se nomme Arbette. Elle traverse le village de Saint-Léger avant de se jeter, comme la première, dans la Seine, presque auprès du pont de pierre.

En contimuant cette route jusqu'à Neufchàtel-en-Bray, toujours dans le département de la Seine-Inférieure, à dix lieues de Rouen, la vue est souvent pittoresque par ces riches vallées et montagnes (qu'on ne cesse de rencontrer, et couvertes de bois.

A une lieue sur la gauche de Neufchâted, et à six de Dieppe, est la jolie propriété de Mennière, appartenant à $M$. le marquis de Biencourt, petit parent de M. le marquis de Biencourt, propriétaire de la terre d'Azai- 
le-Rideau. !l est très-heureux pour les arts que le superbe chateau de Mennière, par son antiquité, ne soit pas passé dans les mains qu'on appelle bande noire, réunion d'hommes destructeurs de tous les beaux monumens anciens et modernes, que la cupidité entraîne à ce désastre.

Loin d'en souffrir la destruction, M. de Biencourt vient de faire la restauration des façades, que le temps avait dégradées. Ce château, situé à mi-côte sur le revers qui fait face, au midi, à la jolie vallée de la Béthume, vulgairement appelée vallée d'Arques, où coule une petite rivière qui l'arrose et fait tourner plusieurs moulins, est entouré d'un immense fossé de soixante pieds de largeur, enrichi d'une eau très-limpide qui donne naissance à un ruisseau : il y a deux ponts pour le traverser. Ce château se compose de deux ailes : dans l'une est une immense galerie; dans l'autre, les pièces de représentation. Sa construction remonte à la fin du quatorzième siècle. Ayant subi plusieurs changemens importans, il n'a été terminé que longtemps après l'érection des deus ailes: du 
moins l'architecture grecque, très-élégante, ornée de colonnes ioniques aux croisées, sur la façade qui décore la cour d'honneur, fait présumer qu'il n'existait en France aucun édifice de ce genre arant le règne de MIédicis, excepté ceux qui existent dans les provinces méridionales de la France.

Mennière est donc le seul monument qui soit décoré de cette architecture grecque dans toute la partie septentrionale, et qui possède, comme Athènes, de ces beaux portiques, de ces immenses vestibules construits du temps de Périclès. En royant les immenses galeries et restibules de Mennière, on serait tenté de croire que ce fut le fameux architecte Phidias qui en donna le dessin et en eut la direction, comme il a eu celle des immenses restibules et portiques d'Athènes sous Périclès.

Tout est grand dans ce château, en richesse comme en sourenirs; les souterrains sont en harmonie avec tout le reste, et voûtés en pierres de taille en arc de cloître. On se croirait transporté dans une cathédrale. Tout y est grandiose et lans une admirable proportion et de propreté. 


\section{Rez-de-chaussée.}

Deux entrées existent: l'une, au midi, où l'on arrive au pied d'un perron immense en dehors du fossé, qu'il faut franchir, de vingtune marches pour arriver sur ce pont, qui est à la hauteur du sol de la cour, qu'il faut traverser à pied, si mieux l'on n'aime, en temps de pluie, arriver à la porte nord, où l'on n'a que ce pont de soixante pieds à traverser. Par cette entrée, on entre au pied d'un escalier qui vient d'être construit par M. de Biencourt, en remplacement de l'ancien. Celui qui vient d'être fait par un architecte habile de Paris ${ }^{x}$ est admirable; mais il a un grand défaut, c'est de ne pas avoir de vestibule quile précède : telle beauté que possède un escalier, il n'est rien sans en être précédé. Celui-ci est enfermé ; il faut ouvrir

Mi. de La Barıe, qui a terminé le palais de la Bourse de Paris. 
une porte, de quelque còté qu'on entre, pour le voir. Je regrette aussi que ce ne soient pas des colonnes au rez-de-chaussée en place de piliers, plus faciles à circuler et plus agréables à la vue. Revenons à l'entrée du côté de la cour, ou, pour mieux dire, du jardin qu'il faut parcourir, fort agréablement orné d'orangers et de fleurs. On entre au milieu d'une grande galerie qui vous conduit à droite dans une autre galerie de cent pieds de long sur dixhuit pieds de large. A gauche, en entrant, est une très-belle chapelle voûtée en pierre. A l'autre extrémité de cette grande galerie est la chambre de Henri IV , très-fraîche et décorée de colonnes. Du côté opposé, en revenant sur ses pas, on parcourt les deux galeries du rez-de-chaussée; on arrive à un beau vestibule, qui conduit aux pièces de représentation. La salle de billard a quarante-cquatre pieds de long sur vingt-huit de large. Le premier étage possède presque les mèmes galeries, toutes décorćes de tableaux magnifiques. On voit, dans les archives déposées au château de Mennière, que ce fut un sire Jean de Boay qui commença, en 1580 , les 


\section{4}

premières constructions de cet édifice, qui ne fut pas achevé de son temps.

Il vendit au seigneur de Fautrot, famille très-puissante en Picardie, ce domaine, qu'ils ont possédé pendant plus de deux siècles, qu'ils augmentèrent et embellirent beaucoup. Ce sont eux qui appelèrent, à l'époque de la renaissance des lettres, des artistes italiens pour décorer par de riches peintures l'intérieur des appartemens, et élever les deux ordres d'architecture qui décorent la cour d'honneur. En 1ว̆ 99 , époque de la bataille d'Arques, Henri IV y fixa son séjour, pendant les combats d'Aumale et de Bure, qu'il livra an duc de Nirernais, près le château de Tourpe, qui appartenait aux ancêtres de Gabriel d'Estrée.

Les seigneurs de Fautrot, en 1690, le vendirent à M. d'Arey, peintre du roi, père du président de IIIennière, duquel M. le marquis de Biencourt l'a acquis en 1765 . Son fils, qui le possède aujourd'hui, eut l'honneur d'y receroir madame la duchesse de Berri en $18_{2} 4$. Ce même M. le marquis de Biencourt a fait des acquisitions considérables 
pour augmenter le parc. L'ancien, dessiné par Le Nostre, possédait, avant la composition symétrique qui existe, des arbres qui surpassent aujourd'hui tout ce qu'on en peut dire; il date de plus de deux siècles, et on peut dire sans crainte que ce sont les plus beaux arbres de la France. Ceci, comme la restauration des façades du château, fait l'éloge de 11. de Biencourt; sans ètre artiste, il aime les arts et est amateur du beau. Combien de propriétaires auraient fait de largent de ces arbres majestueux, et laissé dégrader les façades du chàteau! Honneur à M. le marquis de Biencourt! Ces arbres si majestueux font arec le château un monument historique mille fois plus rare que tout l'argent qu'on en pourrait tirer; on n'en saurait trouver assez pour en acheter de pareils; il n'en existe nulle part.

Voici ce que j'ai trouvé sur. un mur près de l'autel, dans la chapelle de Mennière, et que j'ai cru devoir rapporter ici tel qu'il est :

"L'an de gràce mil cinq cent quarante-six, " avant Pâques, le quatrième jour d'apvril, 
" fut béniste ceste chapelle par révérend " père en Dieu monseigneur l'évesque de "Péneuse, suffragant de monseigneur le très") révérendissime cardinal d'Amboise, ar" chevêque de Rouen. A tous braves repen" tans qui n'ont ledit jour baisé l'autel d'icelle " chapelle, et dyront trois fois Pater Toster. " et Ave Mariu, ledit évesque a donné annucl"lement quarante jours de vray pardon."

\section{Sur le parc de Mennière.}

L'entrée du château, que des personnes pourront critiquer et blâmer de ce que des voitures ne peuvent entrer dans la cour, quoiqu'elle soit très-vaste, en raison de la situation du château et de son architecture; je suis d'un avis différent. Il faut observer cqu'il n'y a rien à ce château de ce que nous arons en France; par conséquent la cour ne peut ètre autrement que d'être analogue au château. Loin de blâmer, j'applaudis à ce système neưf et nouveau pour nous : cette position est, et j'en suis sûr, la seule qui soit en France en ce 
genre. On arrive au pied d'un perron, lorsqu'on croit entrer au grand trot en voiture; on est arrêté pour monter ringt-une marches placées au pied d'un pont suspendu, d'un effet neuf, et d'un joli jardin, ou une cour que j'appelle jardin, au premier étage du châteaur. Les Grecs, qui nous valaient pour les arts avant qu'ils soient Turcs, diraient de ces jardins suspendus ce qu'ils disaient de ceux de Babylone, ru'ils regardaient comme une deśs merveilles du monde, pour avoir du neuf et du positif. C'est cette cour et ce pont l'un et l'autre qui paraissent suspendus; il y en a pour tous les goûts. Du côté nord, on arrive sur un pont de niveau avec le parc, comme arec la cour. Voilà mon avis sur cette partie, comme aussi sur le parc, que je trouve monumental à cause de ses énormes arbres, qui n'existent nulle part.

La partie opposée, qui est la vallée, est admirable comme prairie, et non comme parc. Des eaux en abondance partout, et toutes sont perdues. La rivière, à l'autre extrémité de la prairie, est encaissée, de sorte qu'on ne peut la voir qu'étant placé surle pont 
qui la traverse: au moycn de sa rapidité, une cascade éleverait l'eau au niveau de la prairie, en élargissant cette rivière de cinquante pieds. Quelle richesse elle procurerait à cette propriété! quel éclat en place d'une chose monotone? La cascade du moulin est très-belle; mais elle n'est vue que du meunier. J'ai donné les moyens de la rendre agréable du château : je supprimerais le chemin public qui est en face de la grille, et, à partir du pont, je le détournerais sur l'angle du mur; à droite ; une pelouse remplacerait le chemin; la grille suivrait le même sort au coin du mur. Tous ces petits bâtimens isolés, il faudrait les changer, ou les masquer par des plantations; les supprimer cela serait mieux; donner à cette prairie, par un plan raisonné, une autre vue par des plantations bien entendues, et la récolte des foins serait la même. Je ferais la clôture du parc par un bras de rivière qui suivrait le nouveau chemin jusqu'au mur, et, au moyen de la cascade, éleverait l'eau, qui se ferait voir depuis le pont jusqu'à l'angle du mur. Une chute d'eau se fait voir de l'ile, qui offre un beau tableau. Cette 


\section{9}

partie, qui borde la rivière du moulin, est la plus agréable du parc.

Je me résume pour répéter que si la partie de prairie qui est en face du château recevait la composition qu'elle attend, que des chemins fussent dessinés pour pouvoir habiter cette partie, si belle et si riche à partir du château, sans passer sur les gazons, chose fort incommode, surtout lorsqu'il y a de la rosée. Cela fait, il n'y aura qu'un Mennière en France. L'ancien parc resterait tel qu'il est , afin qu'il appartienne au siècle de Louis XIV. plus en harmonie avec le château; et de la prairie en faire un paysage qui serait de notre siècle : l'un et l'autre ne seraient pas disparates.

Un mur ennemi, la vallée qu'il efface, J'applaudis aux jardins élevés en terrasse. L'escalier, du valon cherchant la profondeur, De la pierre et du fer emprunte la roideur.

Tous mes pas sont comptés, j’arrive, et la vallée Sur un plan monotone est encore étalée. Mais le vrai goût enfin vous parle; respectez Des mouvemens du sol les inégalités. 
N'en désordonnons pas le jeu futile et libre;

Des fonds et des hauteurs que le souple équilibre Soit cher à vos jardins, et que le même accord. Aux aspects d'alentour les associe encor.

L'on m'observera peut-être que la prairie ne peut recevoir une autre composition que celle du parc déjà existant au nord du château, afin que rien ne soit disparate; ma réponse est toute simple. S'il fallait pendant des siècles rester dans l'état où l'on était à l'époque que le château a été bâti, les progrès des arts seraient anéantis. Conservez ce qui est fait; si vous pourez faites mieux, c'est là l'intelligence humaine; au moins on rerra les sciences des deux siècles, et on donrera raison à celui qui l'aura le mieux mérité. Si rous ne voulez pas départir du vieux principe, c'est-à-dire que rous ne puissiez souffrir un parc moderne à côté de l'architecture ancienne, il faut aussi, pour ne pas fairc les choses à demi, que maître et maîtresse du château, domestiques, ouvriers et gens de journée, prennent le costume du temps. 


\section{GHAPITRE LXVII.}

T.E JARDIN DES TUILERIES ET LES CHAMPS-ÉLYSÉES.

JE n'avais point l'intention de m'occuper du jardin des Tuileries et des Champs-Élysées, que tout le monde connaît ; mais deux choses m’ont décidé à ne pas dédaigner ce bel ensemble, auquel peut-être beaucoup de monde ne fait pas assez d'attention. Un second motif est que tout le monde de Paris n'est pas tout le monde en général, et que les personnes qui ne connaissent point la capitale de la France ne verront pas sans intérêt la description de deux objets bien distincts. Le jardin des Tuileries, dessiné av ec l'équerre et le compas, appartient au roi; les ChampsÉlysées, plantés aussi symétriquement, ap- 
partiennent à la ville de Paris. Pour les yeux, ils sont un même tout; placez-vous de tous côtés, sur la rive gauche comme sur la rire droite de la Seine, la vue de ces deux masses, celle des Tuileries en marroniers, et les ormes des Champs-Elysées, dont les reflets de lumière sont différens. Combien de fois je me suis placé sur l'extrémité de la terrasse des Tuileries, du côté de la rivière, pour admirer ce bel ensemble, et la Seine qui les borde et qui se prolonge dans toute son étendue! Placé encore à la barrière de Neuilly, le tableau se présente sous un autre aspect : partout c'est la nature qui étale ses charmes. C'est une chose extrêmement rare dans une capitale de posséder une forêt; et si le roi de Syrie, régnant à Babylone, eût possédé dans cette ville fameuse la forêt de Paris, il se serait dispensé de créer ses jardins suspendus, pour plaire à sa femme, et se serait épargné des millions.

Je n'ai parlé ici que des masses de ses arbres, et nullement de son sol, ni de sa distribution intéricure. Le jardin des Tuileries, quoique je reponsse tous ces jardins a ligne 
droite, qui défigurent la nature, j'approuve ceux des Tuileries, de Versailles et du Luxembourg, comme jardins publics, et non autrement, à cause des mours, dont il ne faut pas s'écarter. Quelques personnes, heureusement en petit nombre, ont voulu blâmer, non le changement, mais l'embellissement fait cet hiver au jardin des Tuileries. Ce qui est bien singulier, c'est que ces personnes criaient avant de savoir ce qu'on allait faire : cela ne prouve pas à leur avantage. $\mathrm{Si}$ M. Fontaine, qui en est l'architecte, homme de talent, eût sorti du style du jardin en y substituant du pittoresque, qui ne pourrait être que ridicule, on aurait eu raison de le blâmer : ce n'est pas M. Fontaine qui ferait une faute aussi déplacée.

Ce qu'on a fait a embelli cette partie de jardin qui était triste et monotone en raison de ce qu'elle est maintenani; on a autant blâmé l'arc de triomphe du Carrousel dans le temps de sat construction; mais il parait que c'est un besoin de blâmer, qui passe du jardin aux embellissemens qu'on fait au châ. teau. Le mieux est de n'y pas répondre. 
Il a existé un poème sur les jardins, qui ne verra jamais le jour, sorti de la plume de l'infortuné Rioucher, englouti sous la hache révolutionnaire, à qui l'on doit le poème des Mois. Quelques fragmens échappés à la fureur destructive qui a anéanti tant de chefs-d'oeuvre, nous sont restés de lui sur les Champs-Élysées. L'auteur avoue que cette plantation régulière ne rappelle dans son sein que quand tout un peuple entier y circule, et il dit :

C'est toi que j'en atteste, ô symétrique espace, Toi sous l'heureux nom des Champs-Élysiens, Mêle ton riche onbrage aux murs parisiens.

Où trouver, de l'aveu même de l'Angleterre, Un bois plus enchanteur, suspendu sur la terre; Un bois qui dans son sein rappelle plus souvent Quand tout un peuple entier, tel qu'un tableau mouvant, $\mathrm{Va}$, circule, revient, et paré de sa joie, Sur des tapis rians folâtre et se déploie;

Que tout est confondu, quand des jeux et des ris, Femmes, vieillards, enfans, se disputant le prix, Il est, peuvent-ils dire, il est donc sur la terre Des lieux où le malheur ne vit point solitaire. Distrait par le présent de ses maux à venir, L'homme ici du passé n'a plus le souvenir. 


\title{
LE PAYS, \\ o U
}

\section{LA NATURE SANS ART.}

\section{TROISIEME PARTIE}

\author{
HISTORIQUE ET GÉOGRAPHIQUE.
}

\section{GHAPITRE LXVIII.}

J'ATME par goût à rappeler le nom des hommes qui se sont fait admirer par leur amour pour les jardins. Alcinoüs, fils de Nansithoüs, roi des Phéaques, de l'ille de Corcyre, a rendu son nom célèbre par son amour pour les 
jardins et l'agriculture. Ce fut Alcinoüs qui reçut Ulysse avec affection sur les côtes de Corcyre, où une tempête l'avait jeté, et le traita avec tant d'humanité. Ulysse, fils de Laërte, et petit-fils de Sysiphe, était roi d'Ithaque, petite île de la mer Ionienne. Il était mari dePénélope, et fut contraint d'aller au siége de Troie, où il passa dix ans; il fut encore dix ans errant sur la mer; enfin, il revint à sa maison, où il rentra avec l'aide de Télémaque, son fils. Ce fut lorsqu'il était errant sur la mer qu'Alcinoüs le sauva du. naufrage. 


\section{CHAPITRE LXIX.}

L'arrorr des jardins est si naturel, qu'il est des choses qui surpassent l'imagination. Lorsqu'un roi de Syrie, régnant à Babylone, fit ériger ces jardins fameux sur le sommet du château, en faveur de sa femme, qui aimait passionnément les jardins, les bois et les forêts, pour jouir dans la ville du plaisir de la campagne, persuada à son mari qu'en imitant les beautés de la nature, en plantant un jardin sur cet édifice, en formerait un d'un genre nouveau et d'un rare artifice.

Sur l'Euphrate, qui traversait la ville de Babylone, il y avait un pont de pierre que l'on comptait aussi pour une des merveilles de l'Orient.

Le château sur lequel étaient ces fameux jardins suspendus avait ringt stades de cir- 
cuit, et ses tours trente pieds dans terre, et quatre-vingts de hauteur au-dessus du sol. Ces terrasses étaient soutenues par des colonnes ou piliers carrés, sur lesquelles on avait mis une grande quantité de terre qu'on arrosait par des pompes et des aqueducs secrets. Ces voûtes portaient ces arbres, qui sont parvenus à huit coudées de tour et cinquante pieds de hauteur. Cette grande masse, quoique entr'ouverte par les racines des arbres, aussi imposante et chargée de cet énorme fardeau, s'est conservée entière pendant plusieurs siècles : parce qu'elles étaient soutenues par vingt larges et fortes murailles, à la distance de onze pieds l'une de l'autre; de sorte que les personnes qui la regardaient de loin pouvaient voir plusieurs montagnes couvertes de forêts.

Ce sont ces jardins suspendus que les Grecs ont fait passer pour une des merveilles du monde. 


\title{
GHAPITRE LXX.
}

\author{
SUISSE.
}

Ce pays est plein de montagnes, dont quelques-unes ont des pâturages sur le sommet. Le reste du pays est assez stérile. Il y a un grand nombre de lacs et de rivières. Mollet fait une ample description du Plain, avec ses Tables géographiques des provinces et des pays cqu'il arrose.

Reuther, dans ses Observations historiques et géographiques, décrit particulièrement ses embouchures. Mauconis parle ainsi des chutes de ce fleuve: Le Rhin, coulant fort large et peu profond entre les montagnes, se précipite, auprès de Schaffhouse. dans la Suisse, sur des rochers, dans un second lit plus bas de soixante pieds, en cinq cascades, dont 
l'eau, à celle du milieu, passe entre deu. rochers. Droite et fort élevée, cette chute fait un bruit épouvantable, et attire avec raison la curiosité même des étrangers.

Le Rhin prend sa source dans les $\mathrm{Al}_{\text {pes, }}$ au mont Adula ou Saint-Gothard, à deux ou trois lieues de la source du Rhône, qui naît de deux fontaines : l'une, dite Rader-Rhin, ou le premier Rhin; l'autre, Hinder-Rhin, ou le second Rhin, qui se joignent ensemble. Ce fleuve commence à être navigable près de Cheu, en Suisse, et, entrant dans le lac de Constance et de Celle, coule à Schaffhouse, à Bâle, etc. , etc.

Le Rhône, fleuve de France qui a sa source au mont Saint-Gothard, près celle du Rhin, sort de deux fontaines augmentées par quelques torrens, traverse le lac de Genève, où se décharge la Lave, assez forte rivière en été, et presque à sec en hiver. Cette rivière provient de la fonte des glaciers du Mont-Blanc, qui en est à dix lieues. On le croirait dans un faubourg de Genève, tant ces glaciers et ces neiges le rapprochent par sa blancheur! En sortant du lac, et à cinq lieues 
de Genève, au lieu dit Bellegarde, le Rhòne disparaît pour reparaître plus loin. J'ai moimème parcouru le terrain qui le couvre, depuis sa perte jusqu'à sa renaissance, où il arrive à propos pour séparer la France de la Savoie, ensuite passe à Lyon, où il reçoit la Saône. Ce fleuve est le plus rapide qui soit en France. 


\section{GHAPITRE LXXI.}

DESCRIPT:ON DE LA CASGADE DE SCARDONA;

EN DALMate.

Le spectacle imposant et majestueux de cette cascade est, après le Niagara, un des plus beaux qui puisse ètre offert aux regards de l'homme. Les ornemens gracieux que la nature offre ont des beautés étonnantes: des massifs de saules et de peupliers, une forêt touffue, des monts sourcilleux, des rochers arides, un millier de ruisseaux, quelques chaumières éparses, au milieu desquelles se trouve l'humble toit d'un saint ermite; tout concourt à rendre cette scène aussi grande qu'extraordinaire.

Le fleuve de la iierka, qui semble dédai- 
gner d'unir ses eaux à celles des innombrables ruisseaux qui serpentent dans la vallée, est d'abord caché par le tapis de verdure placé sur le derant de la scène; ce n'est qu'au moment de sa chute qu'il est réellement visible; tandis qu'enfoncé diagonalement à droite ai milieu des montagnes qui bordent ses deux rives, et que, par l'effet de la perspectire, on suppose étre éleré derrière la cascade, il se fait deviner à une espèce de vapeur lumineuse que la limpidité de l'eau, frappée par l'azur céleste, reîlète horizontalement sur ie pied des montagnes. Il réunit à gauche toute sa force et toute sa majesté, pour descendre noblement, et franchir ensuite avec hardiessc les divers obstacles qui s'opposent à son passage.

Ses flots argentés coulent tour à tour, comme une glace polie, et, sous la forme d'énormes cylindres de cristal taillés à facettes, s'approchent, s'élargissent insensiblement, et arrivent enfin sur une terrasse en forme de fer-à-cheval arrondi, et dont la colossale saillie se prolonge sur l'abime qu'elle domine. 
Alors toute résistance devient vaine, toux frein est rompu; l'impétuosité succède à la marche triomphale: le fleure se précipite, l'air siffle, la terre tressaille.

Mais si cette avidité de spectacles, de craintes et de dangers qui tourmentent la plupart des hommes, porte le voyageur à s'approcher de

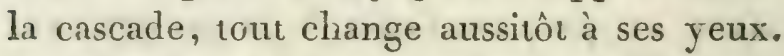
Ce n'est plus cet ordre, cette harmonie, cet accord parfait dont la distance lui donnait l'apparence trompeuse; c'est un désordre, une confusion, un chaos épourantable. La terreur succède à l'enchantement, et cet amas de rochers rompus, brisés, écroulés, au milieu desquels le fleuve se débat en mugissant, remplace, dans l'imagination frappée, l'élégant et paisible tapis de verdure dont l'aspectremplissait l'âme de joie, d'espérance et de bonlieur. 


\section{CEAPITRE LXXII.}

VATELY, auteur anglais, a donné un ouvrage sur cette matière, dans lequel il parle des eaux, des rochers, qu'il nomme majesıteux, terribles et merveilleux. Après avoir passé en revue tous les matériaux de la nature qui concourent à la formation des jardins, l'auteur traite des fabriques; il parle de leur genre et de leur caractère. L'on serait tenté de croire que l'auteur, d'ailleurs si judicieux pour ce qu'il approuve, s'est laissé sćduire par l'usage abusif que font les Anglais dans la composition de leurs parcs: presque tous ont en profusion des temples, des églises, des colonnes, des pyramides, des ponts, des portiques, des arcs de triomphe, et sur- 


$$
276
$$

tout des ruines, sorte de construction qui n'est qu'un accident de hasard, totalement étranger à l'objet auquel on l'approprie; enfin impossible à l'art de créer ce qu'on veut qu'il paraisse ce qu'en effet il n'est pas.

Valenciennes, peintre jadis connu et trèsestimé par ses talens, blâme, arec tous les gens sensés, ces productions fruit du caprice et de la fantaisie, qui, sous le nom de jardins anglais, veulent avoir nécessairement une rivière, un vieux château, un moulin, une montagne, un tombeau, une pyramide, un obéisçue, une tour, un pavillon chinois, mn pont rompu.

Passons dans le parc de Slowe, près Buchinghram, appartenant à lord Temple. Ce qui a rendu ce parc remarquable, et qui lui a sans doute donné sa célébrité, c'est le nombre et l'importance des fabriques qu'il renferme, et surtout l'énorme dépense qu'elles ont occasionnée. Il est tellement considérable, qu'on ne croirait pas être dans un parc, mais dans un très-fort village, où les maisons sont très-multipliées, et cela sans aucun motif ni raison. On passe devant un pavillon; on se 
demande ce qu'il représente, personne ne te sait. Dans ce parc, chaque scène représente une et deus fabriques, sans but, sans motif et sans choix.

Blenheinı, magnifique château, et son vaste parc, furent donnés par la nation au fameux duc de Marlborough, en reconnaissance de ses services. Ce parc, planté régulièrement, a été recomposé depuis et rendu à la nature par Brown, un des meilleurs artistes qu'ait produits l'Angléterre.

Le château, que, vu sa grandeur et sa somptuosité, on pourrait appeler un palais, a été placé près d'un vallon qui divise le parc en deux parties. Pour sa communication, on a corstruit sur ce vallon, dont le fond n'était qu'un marais, un pont d'une dimension telle, que la seule arche du milieu pourrait, par sa hauteur et sa largeur, le disputer avec celle du Rialto, sur le grand canal de Venise.

Ce pont sans eau, étant sans doute une fabrique déplacée, fut long-temps le sujet de la criticque. Brown, appelé pour recomposer ce parc, imagina de la faire taire. Il cherche, il trouve et amène une rivière, la fait couler 
dans le vallon : voilà le pont justifié; ct la grande arche, maintenant en partie dans l'eau, ne paraît plus d'une hauteur démesurée : voilà un résultat heureux.

S'il existe peu de jardins en Angleterre où les véritables règles de l'art soient aussi exactement observées et aussí heureusement appliquées qu'à celui de Blenheim, il en esı d'autres, tel que celui de Rowe, où elles ont été négligées.

Dans le nombre de ceux qui jouissent de quelque célébrité, il faut citer Kiew, à quelques milles de Londres, appartenant au roi; Stored, à madame Holl; Wilton, à lord Pembrock ; Hoatslands, au duc de Newcastre; Hagley, à lord Litlcton. Tous ces parcs et beaucoup d'autres offrent des ruines, des ermitages, des grottes, des rochers, des tours, des bâtimens gothiques et chinois, et encore des temples antiques, des arcs de triomphe, des colonnes isolćes, surmontées de statues. Il n'y a presque pas une de ces fabriques qui ne pèche par sa disconvenance avec le site où elle est placée.

L'Angleterre, où la culture, dit avec raison 
un auteur, est en recommandation, où le plus grand nombre des hommes qui s'en occupent jouissent des arantages de l'instruction et des charmes de l'aisance, devrait nous fournir de meilleurs modèles de ce genre de jardins.

Permettez du moins, messieurs les artistes anglais, qu’à la suite de mon observation au sujet de la multiplicité de vos fabriques, que vous construisez abondamment dans rosparcs, qui ressemblent plutôt à un fort village qu'à un jardin :

Pour faire la part à chacun, et ne puint rous priver de vos goûts, voici un moyen tout simple qui vient à l'appui de ros fabriques, qui ne possèdent et ne représentent rien d'historique qui puisse intéresser le promeneur, ni même le propriétaire qui paye. Trouvez un pays historique, une ville qui jadis ait laissé à la postérité des souvenirs dont les arts doivent s'empresser de renouveler le nom, afin qu'il soit éternel, Athènes, par exemple, cette Athènes si riche en souvenirs. Pourquoi les artistes anglais n'en feraient pas leur profit? En construisant vos fabriques, appliquez-leur le nom de tel ou tel moumen: 
ou reste de la ville d'Athènes; que le nom du monument soit inscrit sur son frontispice, afin que le promeneur prisse, au premier abord, voir le nom de chaque monument; placez-le suivant la place qu'il occupe à Athènes; désignez les allées du parc par des noms sur un poteau à chaque extrémité: Chemin qui conduit à tel ou tel monument.

Pour faciliter l'ariste qui voudra, le premicr, ériger en souvenir dans un parc anglais les anciens monumens d'Athènes, les auteurs trouveront ici la description de ces monumens, afin qu'ils puissent avoir les matériaux nécessaires pour rapporter les restes de cette ville faneuse, berceau des sciences et le théâtre de la valeur. Ce parc, par sa rareté, offrira des variétés et des vérités que tontes les fabriques du monde, gothiques et autres, n'ont jamais offert, que des objets isolés sans but et sans choix. 


\section{1}

Antens

\section{GAAPITPE IXXII.}

ATHÈNES.

L'ACropolis d'A thènes, qui occupait autrefois le centre de la ville, qu'elle dominait de tous côtés, fut la première demeure des Athéniens, qui la firent entourer en grande partie par des Pélages, pcuples fixés dans le voisinage, et qu'ils chassèrent ensuite, parce que ces hommes grossiers insultaient leurs filles et leurs femmes.

Comme la querelle entre Minerre et Neptune est censée aroir eu lieu dans la citadelle, son sol fut réputé sacré, non-seulement par les Athéniens, mais par la Grèce entière.

Minerve, la protectrice de l'Attique, y fut honorée d'un culte particulier. Ses temples furent encombrés de riches offrandes, et 
l'Acropolis fut remplie de monumens de la gloire des Athéniens et de toutes sortes d'objets précieux. Enfin, lorsque le peuple d'Athènes fut parrenu au plus haut degré de prospérité, il crut ne pouvoir faire un plus noble emploi de ses richesses qu'en autorisant Périclès à dépenser ces sommes considérables pour bâtir dans ce lieu vénéré des temples superbes et des vestibules qui, par leur magnificence, fussent en harmonie arec les autres édifices.

Phidias eut la direction de tous ces travanx, dont l'empreinte de son immense génie se fait encore remarquer.

Le temple de Minerve, connu sous le now de Parthénon, du mot Parthenis, surnom de Minerve, fut bâti sous Périclès, à la piace d'un autre que les Perses avaient brûlé, et fut exécuté par les deux architectes Collicrates et Utinus.

Ce qui nous reste de ce temple nous fait connaitre qu'il était d'ordre dorique et orné de colonnes cannelées, sans base, et furmait un parallélogramme alongé, décoré d'un péristyle et d'un portique qui régnait tout an- 
tour, dont un des côtés se trouve en ce moment encombré.

Athènes, devenue chrétienne, convertit le temple de Minerve en une église dédiée à sainte Sophie. Alors ses dispositions intérieures furent changées : un autel fut placé à l'Orient. Les Turcs, après leurs conquêtes, en firent une mosquée qui, pendant plusieurs siècles, a joui d'une grande célébrité.

La montagne qui s'étend des deux côtés du Parthénon est l'Hymette.

C'est sur le mont Hymette que Céphale tua de son javelot la jalouse Procris, son épouse, qui, pour l'épier, s'était cachée dans un buisson, près d'une fontaine, et près du monastère de Saint-Cyprien.

A droite du Parthénon, dans l'intérieur de la citadelle, parmi tous les restes, on remarque encore l'emplacement de la maison du gouverneur Disdard. A droite, sont des débris des propylées placés à la porte de l'Acropolis, qui étaient les vestibules que Périclès fit construire par l'architecte MIuésiclès: ils furent achevés en cinq ans, et coûtèrent près de onze millions de notie monnaie. 


\section{4}

Ce vestibule se composait de cinq issues; au-devant de chaque aile était placée une statue équestre.

Pausanias, qui a mieux connu que personne les monumens de la Grèce, dit positivement que ces propylées surpassaient tout ce qu'il $\mathrm{y}$ a eu de plus beau dans ce genre.

Aux deux côtés des propylées étaient autrefois deux édifices : celui de droite était le temple de la Victoire, construit à la place de celui où Égée, roi d'Athènes, en proie aux plus vives alarmes, allait chaque jour promener sa vue sur la mer pour tâcher de découvrir le vaisseau qui ramenait de Crète son fils Thésée. Ce fut de ce temple qu'il se précipita sur des rochers en apercevant la voile noire que Thésée avait promis de remplacer par une roileblanche, à son retour, si son royage arait été heureux. Ce temple ayant servi anx Turcs pour y déposer de la poudre, fut détruit par la foudre il n'y a pas encore longtemps.

C'est près de l'Ilissus, torrent sec en été, qui traverse le chemin, qu'Erithie, fille d'A- 


\section{5}

rectée, sixième roi d'A thènes, jouant avec ses compagnes, fut enlevée par Borée.

Diane, arrirant de Délos, prit le plaisir de la chasse dans les environs de l'Ilissus. En mémoire de cet événement, on lui fit ériger au pied du mont Hymette un temple que l'on voyait encore il y a moins d'un siècle.

Derrière une tour, sur la pented'un rocher, était le temple d'Aglore, ćlevé à sa mémoire. C'était dans ce temple que les jeunes Athéniens, parrenus à l'âge de virggt ans, venaient jurer de donner leur vie pour défendre la patrie, les lois et la religion.

Là est aussi le cap Colias, où leś damés athénicnnes allaient tous les ans offrir un sacrifice à Cérès.

Dans cette direction est l'île d'Egine.

Derrière Égine se troure cachée la petite île de Calaurie, célèbre par la mort de Démosthènes.

Les montagnes que l'on roì dans le lointain sont celles de Morée, ou le Péloponèse des anciens.

Du côté de la colline du Musée, on aperçoit trois petites ouvertures taillées dans le roc: 


\section{6}

ce sont les portes des cachots de l'Aréopage. Cette prison consiste en deux chambres, qui se terminaient en forme de cloche : par-là descendait la nourriture des accusés, et sur la muraille on peut encore reconnaître la place où étaient scellés leurs fers.

Les deux hommes les plus vertueux d'Athènes, Socrate et Phocion, ont bu la ciguë dans cette prison.

Le chemin qui traverse la campagne dans cette direction conduit à la rade de Phalère, aujourd'hui jonchée de débris. Il comprenait autrefois trois bourgs fameux : celui de Phalère à l'orient, celui de Munichie vers le milieu, et le Pyrée à l'occident.

En-deçà du Pyrée, dans les vignes, est le tombeau de l'amazone Antiopé, mère du malheureux Hippolyte. M. Fauvel, consul français, résidant à Athènes, a fouillé ce tombeau, où il a trouvé des objets semblables à ceux que, du temps d'Homère, on plaçait dans des sépultures: des ossemens de victimes et des vases qui avaient servi au repas funèbre.

L'enceinte, sur un plan élevé, où se tenait 


\section{7}

l'assemblée du peuple. Un socle taillé dans la pierre indique la tribune où Solon, Pinistrate, Thémistocle, Aristide, Simon, Périclès, Alcibiade, Démosthènes et tant d'autres, ont prononcé des harangues.

C'était dans cette enceinteque les A théniens se réunissaient pour traiter de leurs affaires, et qui, d'après une loi formelle, devait être couronnée toute personne à qui un décret avait décerné cet honneur. C'était aussi İa que le peuple choisissait ses magistrats, et qu'il votait pour l'élection des préteurs par l'ordre exprès d'un oracle.

Nous ne devons point omettre de citer la montagne d'Athos, en Macédoine, où est l'isthme que Xercès, roi des Perses, en venant faire la guerre aux Athéniens, fit percer pour passer ses navires au travers. On la nomme le mont Saint, parce qu'elle est habitée par des Clloyens, ou moines grecs, où ils vivent séparés comme des ermites.

Il n'y a que ce seul endroit dans la Grèce où les chrétiens schismatiques souffrent et révèrent une image en relief : c'est celle de la Panagia, ou de la vierge toute sainte, qui 
est placée sur une des pointes de cette montagne, en marbre blanc, la plupart du temps environnée de neige, sur un rocher fort escarpé.

Phidias, excellent sculpteur grec, la quatre-vingt-huitième olympiade, 408 ans avant Jésus-Christ, acheva la statue de Minerve, faite d'ivoire, et la plaça dans la citadelle d'Athènes.

A l'emplacement du temple de Minerve, on voit encore un bloc de marbre sur le point de crouler, appuyé sur les épaules de deux statues mutilées, les senles dont il soit resté quelque chose qui mérite d'êtré cité.

Le Parthénon, ou temple de Minerve, est à 5 - degrés 55 minutes 1 seconde de latitude nord. Le monument entier avait 218 pieds de longueur et $9^{8}$ pieds et demi de largeur. Phidias ou ses élèves avaient sculpté sur les métopes le combat des Cientaures. 


\section{GHAPITRE LXXIV.}

AMÉRIQUE SEPTENTRIONALE.

J'ARRIVE au Canada, je commence par le lac supérieur du Houteau, et je passe à celui des Hurons, auquel on donne environ quatre cents lieues de circuit. On a dans cette route à descendre le saut Sainte-Marie : c'est une cascade de deux lieues de long où les eaux, du lac supérieur se déchargent; on y passe dans le village d'une nation nommée Outchipoués, auquel le voisinage de la cascade a fait donner le nom de Sauteurs'.

Québec est la seule ville du monde connu qui ait un port d'eau douce à cent vingt lieues de la mer, capable de tenir cent vaisseaux de ligne, placé sur le fleuve le plus navigable de l'univers. Le premier objet qui frappe les 
jeux en entrant dans la rade, est une belle nappe d'eau d'environ trente pieds de largeur et quarante de hauteur, qui est immédiatement l'entrée du petit canal de l'ile d'Orléans.

Cette cascade a reçu le nom de Saut de Montmorency. Québec est situé entre l'embouchure d'une rivière nommée Saint-Charles, qui vient du nord-ouest, et le cap aux Diamans, qui avance dans le fleure SaintLaurent.

En montanı ce fleuve à vingt-cinq lieues de Québec, on trouve la ville des Trois-Rivières, qui prend son nom de trois rivières qui, près de cette ville, se déchargent dans le fleuve.

En quittant Trois-Rivières, on arrive à Saint-Francois; on passe à Mont-Réal, et à vingt-cinq lienes plus loin, en montant le fleuve, on arrive au Rapide, nommé Ploc, éloigné du Long - Saut d'environ sept lieues et cinq des Galops ; de là au Rapide du Moulinet, cnsuite au Long-Saut. Le lac de Liticaca fameux, est le plus grand de tous les lacs connus : il a quatre-vingts lieues de circuit et quatre-vingts brasses de profondeur. Dix 
grandes rivières y portent leurs eaux. Après avoir vu tout le pays avec admiration, on troure à gauche, au - dessus de l'ìle des Galops, une rivière qui est à quatorze lieues; six autres rivières à une lieue de la Pointe de Traverse; celle des Sables, celle de La Planche. Trois lieues au - delà de celle de la Grande-Famine, et à deux de celle de la Petite-Famine, à une lieue de celle de la Grosse on est sur la frontière du pays des Iroquois.

De la baie des Goyogoniens, sur la frontière des Iroquois, on décourre la rivièrè fort curieuse de Cascouchiagou. Une chute se présente, de soixante pieds de hauteur et de même largeur; un peu plus loin, une autre, mais moins élerée et de même largeur ; et une demi-lieue plus loin, une troisième de cent pieds de hauteur et en largeur beaucoup plus considérable; plus loin encore, une quatrième qui ne cède en rien à la troisième.

Cette rivière est de cent lieues de long, et, lorsqu' on la remonte, de soixante. Il ne reste plus que dix lieues à faire, en prenant à droite, 
pour arriver à Lochio. Ensuite on arrive dans le détroit du Niagara. Puis, dans la rivière de cenom, on monte d'affreusesmontagnes, pour arriver au fameux Saut; mais peu de personne ont osé le franchir. La chute du fleuve Saint-Iaurent, dans ce détroit, forme une des plus belles et des plus extraordinaires cascades de la nature, connue sous le nom du Niagara. Il est certain que si l'on mesure sa hauteur par les trois montagnes qu'on a d'abord à franchir pour arriver au Saut, il n'y a pas beaucoup à rabattre de six cents pieds que Delille donne dans sa carte; et sans doute il n'a risqué ce paradoxe que sur la foi du baron de Lahontal et du père Hennepin.

Le terrain de trois lieues que l'on fait à pied pour arriver au Saut, et qui se nomme le Portage du Niagara, n'est ni bon, ni revêtu de beaux bois; et l'on ne saurait faire dix pas sans rencontrer des serpens à sonnettes, surtout pendant la chaleur du jour.

Si l'on peut parvenir au sommet, on se trouve dans une situation effrayante: à cette vue, la tête se perd. On prétend que Bolivar: 
seul a osé s'y présenter. Sur un rocher de six cents pieds d'élévation, ce n'est pas tout le mugissement qui se fait entendre; le bruit de ces eaux qui tombent avec un fracas épouvantable, présente une horreur qui fait trembler: l'homme le plus robuste et le plus déterminé ne peut en supporter la vue sans frémir. Cette cascade est sur un plan en forme de fer-à-cheval.

Mauchac, sur le bord du Mississipi; quelle magnificence! Ce fleuve, nommé le GrandPère des rivières, à son point le plus bas, est de quatre-vingts brasses. Le cours rapide de cette eau profonde, les arbres qui la bordent, les forêts qui l'avoisinent; tout porte ensemble un caractère de perfection et de supériorité. Toutse réunit pour donner uneidée du majestneux et du sublime. Les bords du fleuve à Mauchac, quoique souvent surmontés par les crues du printemps, ont environ cinquante pieds de hauteur perpendiculaire au-dessus du niveau ordinaire de l'eau: ainsi le courant, au temps des inondations, doit avoir environ deux cent quatre-vingt-dix pieds de profondeur, ces rivages n'étant 


\section{4}

composés que du sédiment accumulé que les eaux vaseuses laissent chaque année aprês leur passage.

Ce fleuve si majestueux, qui reçoit le Missouri, forme le plus beau confluent du monde. Ces deux rivières sont à peu près chacune d'une demi-lieue de largeur. On roit le Missouri beaucoup plus rapide, qui semble entrer dans le Mississipi en conquérant, dans lerfuel il porte ses eaux blanches à l'autre bord sans les mêler, ensuite lui communique cette couleur que le Mississipi ne perd plus, et l'entraîne avec précipitation dans la mer. 


\section{GHAPITRE LXXV.}

AMÉRIQUE MÉRIDIONALE.

PÉROV.

Dars le Pérou, près de Tarigagna, lieu nommé Mama-Rubi, est une des plus belles cascades que l'imagination puisse représenter. L'eau y tombe d'enriron cinquante toises de hauteur (trois cents pieds), d'un rocher taillé à pic, et bordé d'arbres extrèmement touffus. La nappe dé si chute forme, par sa hlancheur et sa clarté, un spectacle qui étonne et fit l'admiration de la fameuse Compagnie envoyée par Louis XV pour décider la-grande question terrestre en 1735 .

Pinchincha, montagne sous l'écruateur, 
près de Quito, où se fit l'opération des savans sur les angles.

C'étaient messieurs Condamine et Godin. Résultat qui n'est pas contesté, que si les degrés vont en s'alongeant vers le pôle, la terre est un sphéroïde aplati. Retour par la rivière des Amazones. Ce fleuve, le plus grand de tous les fleuves du monde, a trente lieues de largeur à son embouchure.

François Orelhan, lieutenant - général de Gonzale Pizarre, gouverneur de la province de Quito au Pérou, qui entreprit en 1540 de découvrir tout le cours de la rivière des Amazones, l'appela d'abord Orelhane, de son nom; mais, après avoir navigué quelques jours sur ce fleuve, et avoir appris d'un cacique ou prince des Sauvages, nommé Aparia, qu'il y avait sur les bords de cette rivière des femmes belliqueuses, qui s'étaient rendues redoutables dans les guerres contre leurs voisins, il publia en Espagne la rencontre qu'il fit dans une contrée où il vit des femmes qui commandaient des troupes. Il s'ensuivit que le nom d'A mazone est resté à cette rivière célèbre, qui a sa source dans les montagnes 
du Pérou; et son cours, qui s'étend jusqu'à la mer du Nord, vers la ligne équinoxiale. après avoir parcouru près dehuit cents lieues, elle reçoit dans cet espace un grand nombre de rivières, comme la Putamayo, l'Acacio, la Curaray, le Maragnon, le Madera, etc. Les provinces de ces contrées sont très - peuplées, et les habitations si fréquentes, que l'on entend dans un village le bruit de ceux qui travaillent dans un autre. 


\section{GHAPITRE LXXVI.}

Moscovie.

Ex quittant l'Amérique, ses fleuves et ses cascades, qui épouvantent en mème temps qu'elles intéressent, nous continuons notre promenade dans la Moscovie. Ici, ce sont des eaux calmes et tranquilles; ce ne sont plus ces torrens impétueux, ces fracas produits par la chute des eaux provenant du sommet des montagnes. La Moscovie, en général, est un pays marécageux, rempli de forêts, d'étangs, de lacs et de rivières: il y a des lacs qui ont jusqu'à cinquante cinq lieues de longueur. Le Ladoga et l'Onèga, qui confinent ì la Finlande, som les plus grands de l'Europe. On y trouve encore le lac de Biéla. 
Ozéro ou Biclosero, qui donne son nom à une province.

Les rivières les plus considérables sont le Volga, le Borysthène, le Tanaïs ou Don, la Duwna, le Jag-murco. La Míoscovie est située dans des climats extrêmement froids. Ces marais inhabitables, et les forèts qui occupent une grande partie du terrain, font que le pays est mal peuplé, surtout rers le septentrion, où le peu de grain qu'on y sème n'arrive jamais à une parfaite maturité. Il n'en est pas ainsi de la partie méridionale, fort peuplée, en y cumprenant la Pologne, qu'un le serpent à somettes du Nord vient de dépeupler. 


\section{GHAPITRE LXXVII.}

Moscou.

Ev sortant des marais de la Moscovie, de ses immenses forêts, joffre au lecteur un abrégé historique de la ville de Moscou, sa capitale, fameuse par son étendue, ses palais, ses huttes et ses richesses.

Moscou est situé sur la Moskiva, dans une plaine très-étendue, agréable et fertile; au $37^{\mathrm{e}}$ degré 2 I secondes de longitude du premier méridien de Greenwick, et au $55^{\circ}$ degré 35 secondes 43 tierces de latitude septententrionale. La distance de Paris est de six cent cinquante lieues environ.

En sortant de Viasma, on entre dans la vaste forêı de Volkouski, qui s'étend de là, sans interruption, dans un espace de cent cin- 
quante milles, presque jusqu'aux portes de Moscou. Quand on arrive à Malo-Aviasma, lieu agréablement situé au milieu de la forêt, surlebord d'un petitlac, on n'est plus qu'àsix milles de cette capitale, et l'on y arrive par une large ar enue coupée en droite ligne. Ses arbres qui la bordent, plantés des mains de la nature, sont des chènes, des bouleaux, des frènes, des peupliers, et des sapins mêlés ensemble; ils offrent les nuances de vèrdure les plus variées et les plus riches; de distance en distance, des champs et des prairies viennent ensuite égayer l'uniformité majestueuse de cette longue avenue vraiment pittoresque. Au moment où vous y entrez, Moscou s'annonce déjà à vos regards par les pointes de quelques clochers. A trois milles plus loin, vous êtes arrèté par le magnifique spectacle de cette immense ville qui s'étend en forme de croissant, et présente une quantité innombrable d'églises, de tours, d'aiguilles de clochers, de dômes, de bâtimens blancs, rouges, verts, que les rayons du soleil rendent éblouissans; et, pour contraster avec tant de pompe, vous voyez à côté de 


\section{2}

ces brillans édifice un nombre infini de misérables cabanes de bois. Le pays que vous traversez alors est inégal et pittoresque, et la forêt ne se termine qu'à un mille du rempart de Moscou.

Dès que rous êtes dans la ville, sa vaste étendue et la variété qui y règne, l'irrégularité de ses constructions, les contrastes extraordinaires qu'elles présentent, rous frappent d'étonnement. Les rues en sont longues et larges : mais quelques rues seulement sont pavées; d'autres sont jonchées de troncs d'arbres ou planchéyées comme une chambre. De superbes palis sont entourés de huttes qui servent d'abri à l'indigence. Ici des maisons de bois se présentent couvertes de peintures; là, d'autres ont des portes et des toits de fer. Rien de plus discordant, de plus bizarre, que l'architecture des édifices; à chaque pas vous y rencontrez des églises, des dômes, dont quelques-uns sont courerts de cuivre, d'autres d'étain, d'autres peints ou dorés; plusieurs ne sont que de bois. Enfin, en parcourant les différens quartiers de MIoscou, vous passez tour à tour du désert sau- 
vage dans une ville florissante et peuplée, dans un misérable village, et vous arrivez enfin dans un lieu où tout annonce la magnificence d'une grande capitale. On doit considérer Moscou comme une ville bâtie d'abord dans le goût asiatique, et qui, par degré, est devenue européenne.

La population de Moscou ne répond pas à son étendue. On n'en sera pas surpris quand on saura que cette ville renferme des parcs très - rastes, peuplés de cerfs, de sangliers et autres bêtes faures; un nombre considérable de gुrands jardins, et même, dans certains quartiers, des terrains qui se labourent et donnent à la ville un aspect très-pittoresque. Moscou ne contenait donc que trois cent à trois cent ringt mille habitans; mais ce nombre s'élève à près de quatre cent mille en hiver. Cette différence vient de ce que les seigneurs ront passer l'été dans leurs terres , et emmènent arec eux beaucoup de monde, et de ce que les négocians voyageurs reviennent chez eux à la fin du carnaval.

Les cloches de Moscou ne doivent pas être oubliées. Le plus ou moins de temps qu'on 


\section{4}

les sonne marque la plus ou moins grande solennité du jour. Quelques-unes sont d'une grosseur énorme: l'impératrice Anne en fit fondre une du poids de quatre cent trente deux mille livres; elle a dix-neuf pieds de haut; sa circonférence en bas est de vingt et une verges onze pouces; sa plus grande épaisseur est de vingt - trois pouces. La poutre à laquelle elle était attachée ayant été brûlée, la cloche tomba, et il s'en cassa un morceau vers le bas, qui a laissé une ouverture assez large pour que deux hommes de front y puissent entrer sans se baisser. Cette cloche est encore enfoncée au pied de la tour d'Ivan, la plus haute de la ville, située dans le Kremlin, et la plus magnifique de Moscou ; elle est surmontée de neuf tours couvertes de doubles feuilles de cuivre doré. Dans l'enceinte est suspendu à la voûte un lustre d'argent massif, qui pèse deux mille neuf cent quarante livres. La Khitaigorod offre une singularité curieuse : elle renferme vingt autres églises, dans lesquelles la lumière a été ménagée avec beaucoup d'art. Pour ajouter 


\section{5}

une espèce de merveilleux à cette construction, on débite que le czar Vasilides fit crever les yeux à l'architecte, pour le mettre dans l'impossibilité d'en construire une autre semblable.

Moscou semble contenir deux nations: l'une habite des palais, parle français, s'occupe de modes, de tailleurs, fait de la musique, dresse des chevaux, va au bal de l'Opéra, donne mille roubles pour une loge à l'année, et cent pour un serin bien instruit; l'autre loge dans des huttes, à la manière des Sauvages, porte de longues barbes, ignore s'il y a des spectacles, s'enivre d'eau-de-vic les dimanches, se querelle et s'apaise aussitôt qu'on a jeté sur les disputeurs deux on trois seaux d'eau qu'on tient toujours en réserve pour cet usage dans les lieux où s'as. semble le peuple. C'est, d'un côté, la civilisation dans tout son luxe et avec tous ses excès; de l'autre, le degré qui touche à la barbaric. Le besoin d'être amusé paraît ètre le besoin dominant des habitans de Moscou. Le 2 a mai soute la ville est sur pied, toutes les voitures 
306

brillantes sont en évidence, toutes les livrées neuves en étalage sur le chemin de la promenade appelée les Tables allemandes, où l'on mange sous les tentes et sous les arbres. 


\section{GHAPITRE LXXVII.}

FINLANDE, SUÈDE ET NORWÈGE.

LA Moscovie n'est pas le seul pays qui soit rempli de lacs, fleuves, rivières et forêts. La Finlande à droite, le golfe de Botnie à gauche; la Suède et la Norwège jusqu'à la mer, suivant la côte septentrionale depuis le golfe Christiania, jusqu'au cap Nord, en y comprenant toutes les Laponies; et ensuite la mer Glaciale, jusqu’à la mer Blanche; le lac Onéga, jusqu'au fameux lac dit Ladoga, près de Saint-Pétersbourg, qui donne naissance à la Néva, rivière qui va se décharger dans le golfe de Finlande. Toute cette terre immense, si extraordinaire par sa position, son climat, ses quantités d'animaux sauvages, ses immenses forêts, lacs, fleuves, montagnes 
et rivières.Quelle singularité de la nature de voir toute cette terre immense bouleversée, entrecoupée sur tous sens! On ne saurait trop juger à cet aspect si c'est une mer remplie d'îles, ou si c'est une terre remplie de lacs, dont on peut croire, sans se tromper, à certains endrois, qu'il y a presque autant d'eau que de sol. Les Laponies possèdent des montagnes et des chutes d'eau étonnantes. On ne peut calculer le nombre d'îles qui bordent la côte septentrionale, depuis la Norwège jusqu'au cap Nord. La Norwège est un pays fort vaste, très-montueux et stérile, à cause de son terrain pierreux et sablonneux, et un froid excesif qu'à peine on peut suporter. Des milliers de rivières, en tous sens, vont se décharger dans la mer.

Les bornes de la Norwège sont, au levant, à la rivière de Glema, la scule qui porte de gros bateaux, suivie d'une chaîne de monlagnes dite le mont Sevo ou Savo. C'est là qu'on place le pays des peuples dits Sithones. Près de l'île nommée Hiteren de Norwège, est le famenx gouffre de Malstron, dans lerpuel les raisseaux se pierdent comme dans 
un abîme. Ce gouffre est appelé ordinairement le Nombril de la mer, ou le Charybe septentrional ${ }^{\prime}$.

Le père Kircher lui donne 13 milles de circonférence. Ce gouffre a un mouvement qui, en descendant, engloutit ses eaux pendant six heures, et les rejette en montant, pendant le même espace de temps, avec un bruit si horrible, qu'on l'entend de plusieurs milles lorsque la mer est calme; et quand il se meut avec violence, il est impossible de retirer et de sauver un vaisseau entré dans son circuit. Les baleines ne réussissent pas mieux : quelques efforts qu'elles fassent, elles sont aussitôt entraînées qu'englouties, et leurs corps, après avoir été mis en pièces contre les rochers, sont rejetés au premier retour des eaux, comme les débris des navires.

La Suède a beaucoup de rivières, des lacs, des rochers et des montagnes.

La Laponie n'a ni pommiers, ni poiriers,

- Les Chinois nomment un de leurs fleuves, Likiang, le Fils de la mer. 
ni cerisiers, ni aucun arbre à fruit, l'air n'és tant pas assez doux et la terre trop stérile pour produire aucun' fruit. On n'y trouve même presque pas d'arbres de forêt qui peuvent résister au grand froid, comme le chêne, -le noyer, le hêtre, le tilleul; il y a seulement des pins, des sapins, des genévriers, des bouleaux.

Il y a quelques rivières où on pêche des perles.

On découvrit, en 1633 et en 166o, quelques mines d'argent et de plomb dans la province de Pitha.

La Laponie est remplie de lacs et marais , de forêts et de montagnes; ce qui présente un pays pittoresque et sauvage.

Les Lapons ont en hiver trois mois de nuit, et autant de jour en été; ils ont, pendant ces longues nuits, un crépuscule le matin et un autre le soir. Le froid y est insupportable en hiver, et la chaleur ne l'est guère moins en été.

Plusieurs cataractes existent en Laponie. Les fleuves passent souvent par des montagnes, d'où ils tombent dans des précipices 


\section{1}

arec une impétuosité et un bruit épourantables; mais quoique ces chutes d'eau causent de grands empêchemens à la navigation, elles sont utiles aux forges des métaux.

Entre les lacs de la Laponie, le plus grand est celui de Naretrek, dans la province de Kiémi. On y voit une infinité d'îles, toutes inhabitées. Ce sont tous ces lacs qui donnent à ce pays tant d'oiseaux, d'eau et de bois, comme des cignes, des canards, des hupes, des faisans, des perdrix, des fracolins et des gelinotes.

Les Lapons ne sont hauts que de trois coudées, du côté du septentrion, et cette courte taille leur vient du froid, qui est excessif dans ce pays. Ils sont, la plupart, laids et courbés; mais les Laponnes ne sont pas difformes, et ont sur le visage un rouge naturel, mêlé de blanc, qui est assez agréable.

La force des Lapons surpasse celle des autres hommes. Leurs exercices ordinaires sont de courir, grimper sur les rochers, et de monter sur les plus hautes branches d'arbres. Ils sont lâches et timides : ce qui fait 
qu'on ne se sert point d'eux dans les armées. Ces peuples ne peuvent vivre hors de leur pays: ils tombent malades sitôt qu'ils s'en éloignent. Le pain, les viandes que nous mangeons, et le sel, nuisent autant à leur estomac, que leurs poissons secs et leur chair à demi-crue nuiraient à notie santé. 


\section{TABLE DES MATIERES.}

Afertissement sur cette cinquième édition.

\section{PREMIÉRE PARTIE.}

INTRODUCTION .

Canpitre I. De la belle nature.

II. De l'ensemble.

III. Différence entre la vue vague et la vue bornée.

IV. Des tableaux, de la décoration et des effets qui en résultent.

V. De la possibilité de tirer parti de toutes les situations.

VI. Du grand style.

VII.-Des comparaisons. $\quad 63$

VIII. De l'imitation: $\quad 67$

IX. Des plantations. 70

Des massifs. $\quad 76$

Manière de planter. $\quad 7^{8}$

$X$. Des eaux.

$\mathrm{XI}$, Du jeu du terrain et des mouremens de la lumière. 
XII. Des fabriques et des constructions.

XIII. Du ton des paysages suivant les différentes heures du jour.

XIV. De l'effet des paysages sur les sens; et même sur l'âme.

$\mathbf{X V}$. Des moyens de réunir l'agréable à l'utile.

XVI. Description d'Ermenonville.

XVII. Observations sur Ermenonville et Morfontaine.

124

XVIII. Des hahas ou sauts-de-loup.

XIX. Des arbres propres aux jardins pittoresques. 130

XX. Des semences. 132

XXI. Des boutures. 13

XXII. Conclusion.

SECONDE PARTIE.

XXIII. Saint-Étienne-du-Rouvray.

XXIV. Saint-Julien et Le Pech.

XXV. Fontenay-le-Penel.

158

XXVI. Sotterille.

160

XXVII. Corni, près Metz.

163 .

XXVIII. Montoy.

166

XXIX. Le Chêne. 167

XXX. Les Essarts.

169

XXXI. Ingulequeville.

173

XXXII. Launay-Baffert.

176

XXXIII. Bissy, Seine-et-Oise.

177

XXXIV. Blandeck. 


\section{5}

XXXV. Charbonnière. 18I

XXXVI. Ménucourt. $\quad 182$

XXXVII. Azai-le-Rideau. $\quad 187$

XXXVIII. Mainneville. 190

XXXIX. Marque-Église. $\quad 192$

XL. Coulogne. $\quad{ }^{194}$

$\begin{array}{lr}\text { XLI. Le Bouchet. } & 196\end{array}$

XLII. Le Madrillet. 198

XLIII. Bryère. 200

XLIV. Plusieurs parcs et jardins. 202

XLV. Villette, département de l'Eure. 203

XLVI. Le Martot. 205

XLVII. La Grange-aux-Ormes. $\quad 209$

XLVIII. Plusieurs parcs et jardins anciens. $\quad 213$

XLIX. Étampes, près Château-Thierry. $\quad 2$ ×6

L. Léry-Fontaine. 218

LI. Soisy-sous-Etioles. $\quad 219$

LII. Le parc à Saint-Pierre. $22 \mathrm{I}$

LIII. Liverdy. $\quad 223$

LIV. Le Monceau. $\quad 224$

LV. La Motte, en Savoie. 225

LVI. Fréthau. $\quad 227$

LVII. Plessis-Villette. $\quad 229$

LVIII. Saint-Augustin. 23 r

LIX. Grange-Ménant. $\quad 233$

LX. Mottereau. 234

LXI. Sermaise. $\quad 236$

LXII. Nogentel. $\quad 238$

LXIII. Gournay. $\quad 239$

LXIV. Cappy. $\quad 244$

LXV. Observations sur le département de l'Oise. $\quad 246$ 


\section{6}

LXVI. Observations sur le département de la Seine-Inférieure; Mennière. 248

LXVII. Jardin des Tuileries et Champs-Élysées. 26 r

\section{TROISIEME PARTIE.}

LXIII. Alcinoüs. 265

LXIX. Babylone. 267

LXX. Suisse. 269

LXXI. Cascade de Scardona. 272

LXXII. Jardins fameux d'Angleterre.

LXXIII. Athènes. 281

LXXIV. Amérique septentrionale. 289

LXXV. Amérique méridionale, Pérou: 295

LXXVI. Moscovie. 298

LXXVII. Moscou. 3 oo

LXXVIII. Finlande, Suède et Norwège. 


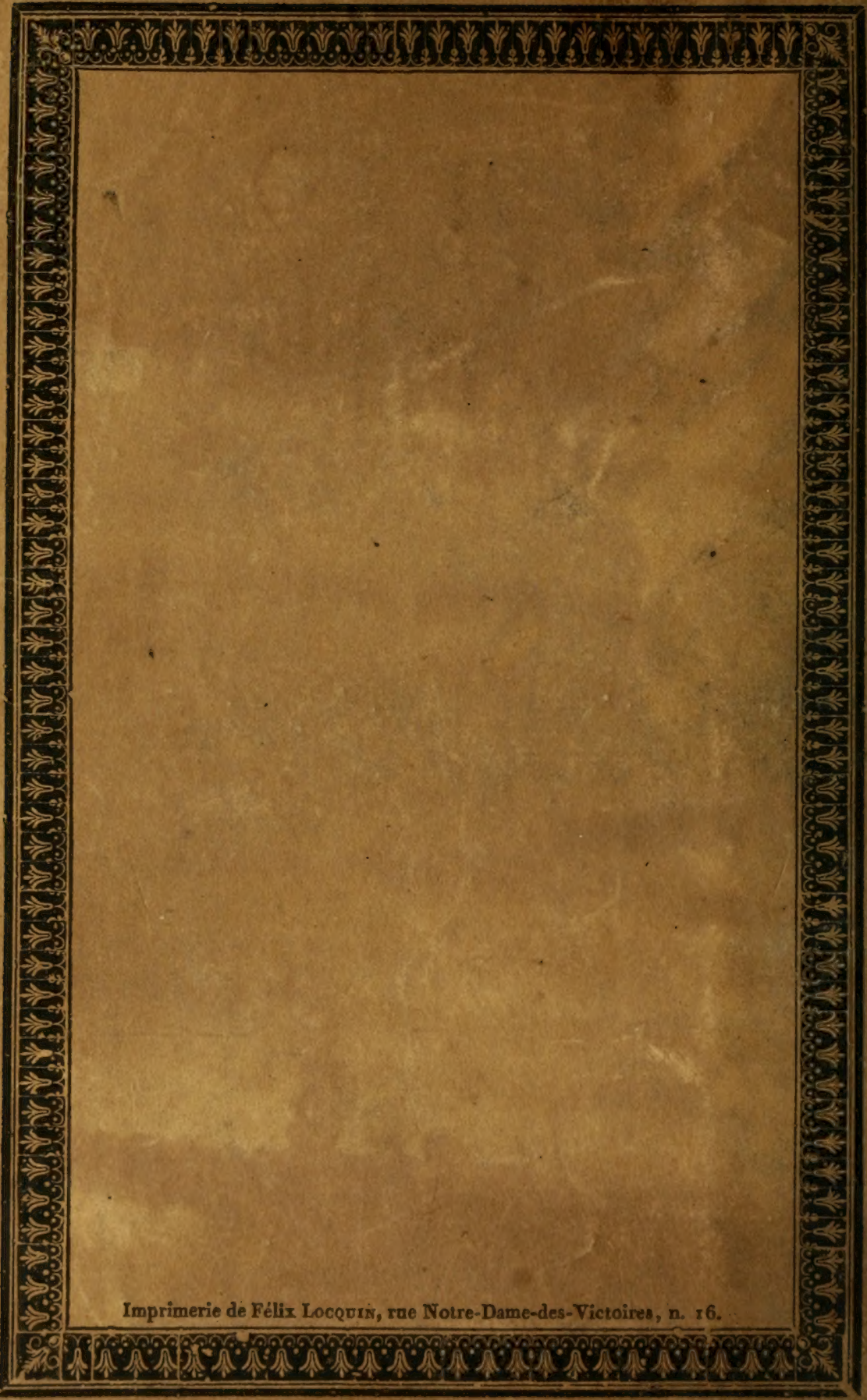

